RECEIVED
JAN 251996
OSTI

\title{
High Flux Isotope Reactor Cold Source Preconceptual Design Study Report
}

ORNLTM-13136

OAK RIDGE NATIONAL LABORATORY

MARTIN MARIETTA
MANAGED BY

MARTIN MARIETTA ENERGY SYSTEMS, INC. FOR THE UNITED STATES DEPARTMENT OF ENERGY
December 1995

DISTHBBUTON OF THIS DOCUAXNT IS UHLMTTED

Contributing Authors
S. E. Burnette
D. H. Cook
A. T. Lucas
M. B. Farrar
T. J. McManamy
J. C. Gehin
B. F. Siefken
M. A. Woody
J. B. Hayter

W. E. Hill
J. A. Bucholz

rincipal Author

D. L. Selby

Lead Designer

A. T. Lucas 
This report has been reproduced directly from the best available copy.

Available to DOE and DOE contractors from the Office of Scientific and Technical Information, P.O. Box 62, Oak Ridge. TN 37831; prices available from (615) 576-8401, FTS 626-8401.

Available to the public from the National Technical Information Service, U.S. Department of Commerce, 5285 Port Royal Rd., Springfield, VA 22161.

This report was prepared as an account of work sponsored by an agency of the United States Government. Neither the United States Government nor any agency thereof, nor any of their employees, makes any warranty, express or implied, or assumes any legal liability or responsibility for the accuracy, completeness, or usefulness of any information, apparatus, product, or process disclosed, or represents that its use would not infringe privately owned rights. Reference herein to any specific commercial product, process, or service by trade name, trademark, manufecturer, or otherwise, does not necessarily constitute or imply its endorsement, recommendation, or favoring by the United States Government or any agency thereof. The views and opinions of authors expressed herein do not necessarily state or reflect those of the United States Government or any agency thereof. 


\title{
HIGH FLUX ISOTOPE REACTOR COLD SOURCE PRECONCEPTUAL DESIGN STUDY REPORT
}

\author{
Principal Author \\ D. L. Selby \\ Lead Designer \\ A. T. Lucas
}

\section{Contributing Authors}
J. A. Bucholz
W. E. Hill
S. E. Burnette
A. T. Lucas
D. H. Cook
T. J. McManamy
M. B. Farrar
B. F. Siefken
J. C. Gehin
M. A. Woody
J. B. Hayter

December 1995

Prepared by

OAK RIDGE NATIONAL LABORATORY

Oak Ridge, Tennessee 37831-6285

managed by

LOCKHEED MARTIN ENERGY SYSTEMS, INC.

for the

U.S. DEPARTMENT OF ENERGY

under contract DE-AC05-84OR21400 



\section{CONTENTS}

FIGURES $\ldots \ldots \ldots \ldots \ldots \ldots \ldots \ldots \ldots \ldots \ldots \ldots \ldots \ldots \ldots \ldots \ldots \ldots \ldots \ldots$ vii

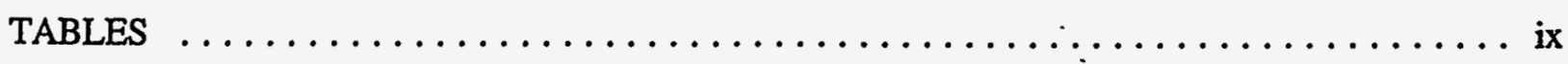

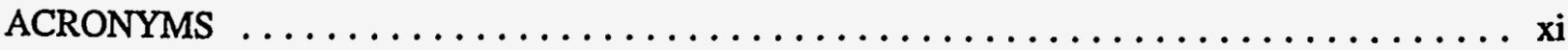

1. INTRODUCTION $\ldots \ldots \ldots \ldots \ldots \ldots \ldots \ldots \ldots \ldots \ldots \ldots \ldots \ldots \ldots \ldots \ldots \ldots$

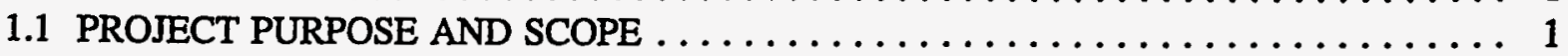

1.2 PROJECT GOALS AND REQUIREMENTS $\ldots \ldots \ldots \ldots \ldots \ldots \ldots \ldots \ldots \ldots \ldots \ldots$

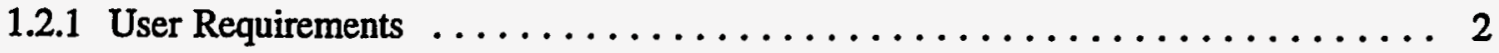

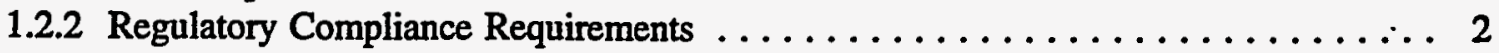

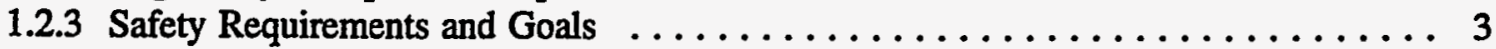

1.2.4 Operational Requirements $\ldots \ldots \ldots \ldots \ldots \ldots \ldots \ldots \ldots \ldots \ldots \ldots, \ldots \ldots \ldots$

1.2 .5 Maintenance Requirements $\ldots \ldots \ldots \ldots \ldots \ldots \ldots \ldots \ldots \ldots \ldots \ldots 6, \ldots \ldots \ldots$

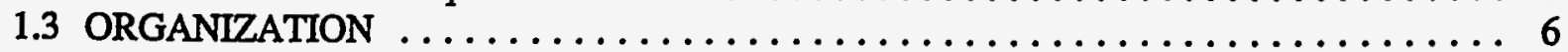

2. PRECONCEPTUAL DESIGN DESCRIPTION $\ldots \ldots \ldots \ldots \ldots \ldots \ldots \ldots \ldots \ldots \ldots \ldots$

2.1 PRECONCEPTUAL DESIGN OBJECTIVE $\ldots \ldots \ldots \ldots \ldots \ldots \ldots \ldots \ldots \ldots \ldots, 7$

2.2 DESIGN PHILOSOPHY $\ldots \ldots \ldots \ldots \ldots \ldots \ldots \ldots \ldots \ldots \ldots \ldots \ldots \ldots$

2.3 DESIGN DESCRIPTION $\ldots \ldots \ldots \ldots \ldots \ldots \ldots \ldots \ldots \ldots \ldots \ldots \ldots \ldots \ldots, 10$

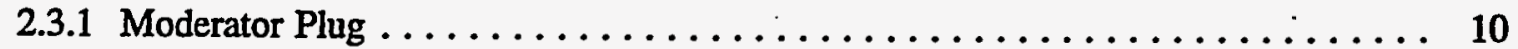

2.3.2 Pump Module $\ldots \ldots \ldots \ldots \ldots \ldots \ldots \ldots \ldots \ldots \ldots \ldots \ldots \ldots, 10$

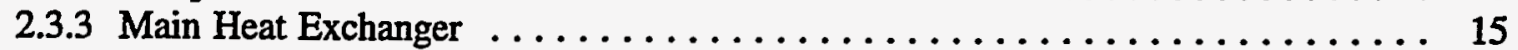

2.3.4 Transfer Lines $\ldots \ldots \ldots \ldots \ldots \ldots \ldots \ldots \ldots \ldots \ldots \ldots \ldots \ldots \ldots \ldots \ldots \ldots \ldots \ldots, 15$

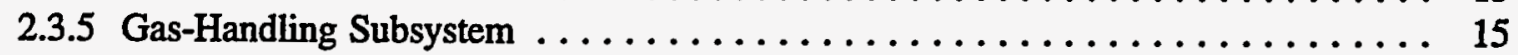

2.3.6 Refrigerator Subsystem $\ldots \ldots \ldots \ldots \ldots \ldots \ldots \ldots \ldots \ldots \ldots \ldots \ldots \ldots \ldots \ldots \ldots \ldots \ldots, 15$

2.3.7 Instrumentation and Control Subsystem $\ldots \ldots \ldots \ldots \ldots \ldots \ldots \ldots \ldots \ldots \ldots$

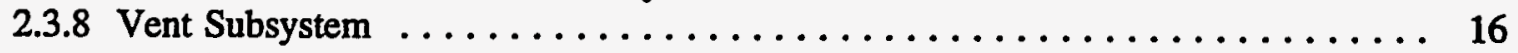

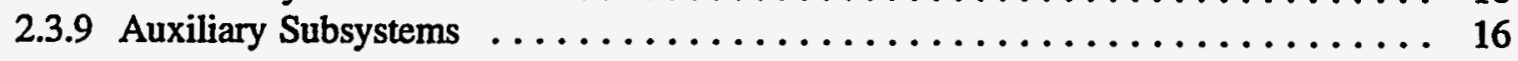

3. PRELIMINARY PHYSICS PERFORMANCE .................... 17

3.1 PHYSICS CODES, MODEL DESCRIPTION, AND CROSS SECTION DATA SETS . . 17

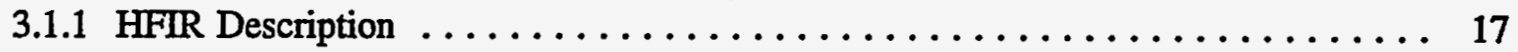

3.1 .2 Cold Source Model $\ldots \ldots \ldots \ldots \ldots \ldots \ldots \ldots \ldots \ldots \ldots \ldots \ldots \ldots$

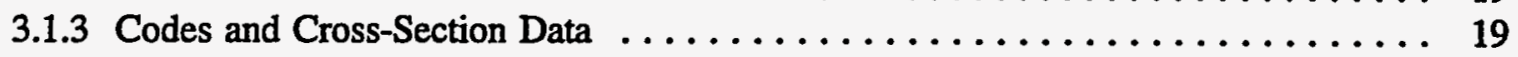

3.1.4 Source Terms Used in the Analyses $\ldots \ldots \ldots \ldots \ldots \ldots \ldots \ldots \ldots \ldots$

3.1.5 Method Used for Calculating the Brightness $\ldots \ldots \ldots \ldots \ldots \ldots \ldots \ldots \ldots 20$

3.1.6 Methods Used for Calculating Neutron and Gamma Heating ........... 21

3.2 BRIGHTNESS, GAIN FACTORS, AND COMPARISONS WITH EXISTING

FACILITIES $\ldots \ldots \ldots \ldots \ldots \ldots \ldots \ldots \ldots \ldots \ldots \ldots \ldots \ldots \ldots \ldots \ldots \ldots \ldots \ldots \ldots, 22$

3.3 NOMINAL HEAT LOAD CALCULATIONS $\ldots \ldots \ldots \ldots \ldots \ldots \ldots \ldots \ldots \ldots, 23$

3.4 PARAMETRIC OPTIMIZATION CALCULATIONS ................ 26

3.4.1 Studies to Determine the Optimal $\mathrm{LH}_{2}$ Thickness for the Moderator Section of the HFIR Cold Source $\ldots \ldots \ldots \ldots \ldots \ldots \ldots \ldots \ldots \ldots \ldots \ldots, 26$

3.4.2 The Search for an Optimal Ortho-H/Para-H Mixture $\ldots \ldots \ldots \ldots \ldots \ldots \ldots 27$ 
3.5 MISCELLANEOUS DESIGN QUESTIONS INVESTIGATED DURING THE

PRECONCEPTUAL DESIGN . . . . . . . . . . . . . . . . . . . . . . . . 29

3.5.1 Effect of the Cold Source in (HB-4) on Experiments that Use HB-1 . . . . . . . 30

3.5.2 Extent of Accelerated Silicon Production in the Through-Tube . . . . . . . . 31

3.5.3 Heat Load Reductions Afforded by Placing a Bi-209 Gamma Shield in the Reflector .............................. 31

3.5.4 Impact of Cold Source on the Rest of the Reactor $\ldots \ldots \ldots \ldots \ldots \ldots$

3.6 VALIDATION OF THE PHYSICS CALCULATIONS . . . . . . . . . . . 35

3.6 .1 MCNP Model Review . . . . . . . . . . . . . . . . . 35

3.6.2 Flux Comparisons with Experimental Measurements . . . . . . . . . . 35

3.6.3 Heat Load Experiment and Benchmark .................. 36

4. PROJECT PLANS $\ldots \ldots \ldots \ldots \ldots \ldots \ldots \ldots \ldots \ldots \ldots \ldots \ldots \ldots \ldots \ldots$

4.1 PRELIMINARY HFIR COLD SOURCE ACCIDENT ANALYSIS PLAN . . . . . . 37

4.2 PRELIMINARY CONSTRUCTION AND INSTALLATION PLAN $\ldots \ldots \ldots \ldots \ldots$

4.3 PRELIMINARY OPERATIONS PLAN $\ldots \ldots \ldots \ldots \ldots \ldots \ldots \ldots \ldots \ldots \ldots \ldots \ldots \ldots$

4.4 PRELIMINARY PROCUREMENT PLAN $\ldots \ldots \ldots \ldots \ldots \ldots \ldots \ldots \ldots \ldots \ldots \ldots$

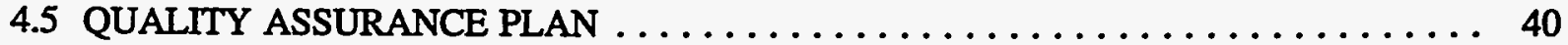

4.6 PRELIMINARY R\&D TESTING AND EVALUATION PLAN $\ldots \ldots \ldots \ldots \ldots \ldots \ldots .41$

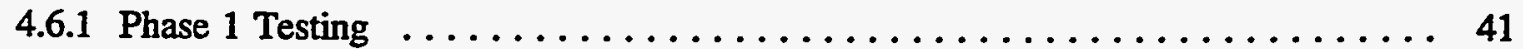

4.6.1.1 Circulator (Pump) Tests $\ldots \ldots \ldots \ldots \ldots \ldots \ldots \ldots \ldots \ldots \ldots \ldots \ldots \ldots \ldots$

4.6.1.2 Moderator Plug Flow Tests $\ldots \ldots \ldots \ldots \ldots \ldots \ldots \ldots \ldots \ldots \ldots \ldots \ldots$

4.6 .1 .3 Heat Load Measurements . . . . . . . . . . . . . . . . . . 42

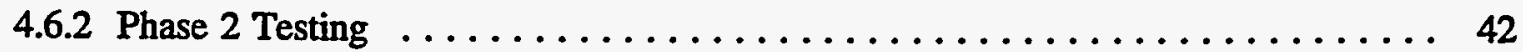

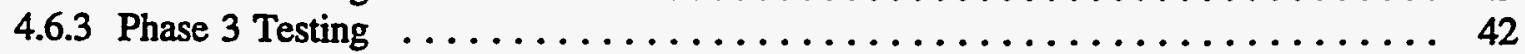

4.7 PRELIMINARY START-UP TESTING PLAN $\ldots \ldots \ldots \ldots \ldots \ldots \ldots \ldots \ldots \ldots \ldots \ldots$

4.8 PRELIMINARY HFIR COLD SOURCE CONFIGURATION MANAGEMENT

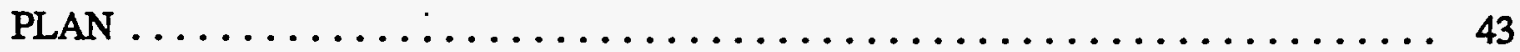

4.9 PRELIMINARY RELIABILITY, AVAILABILITY, AND MAINTAINABILITY

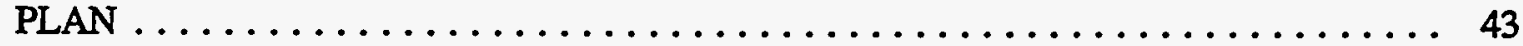

4.9 .1 Goals and Requirements $\ldots \ldots \ldots \ldots \ldots \ldots \ldots \ldots \ldots \ldots \ldots \ldots \ldots \ldots \ldots$

4.9 .2 Planned Activities $\ldots \ldots \ldots \ldots \ldots \ldots \ldots \ldots \ldots \ldots \ldots \ldots \ldots \ldots \ldots \ldots \ldots \ldots$

4.9.2.1 Preconceptual ........................... 44

4.9.2.2 Conceptual Phase $\ldots \ldots \ldots \ldots \ldots \ldots \ldots \ldots \ldots \ldots \ldots \ldots \ldots$

4.9.2.3 Detailed-Design Phase ....................... 44

4.9.2.4 Installation and Operation Phase $\ldots \ldots \ldots \ldots \ldots \ldots \ldots \ldots \ldots$

5. ASSESSMENTS $\ldots \ldots \ldots \ldots \ldots \ldots \ldots \ldots \ldots \ldots \ldots \ldots \ldots \ldots \ldots \ldots \ldots$

5.1 HFIR COLD SOURCE RISK MANAGEMENT ASSESSMENT . . . . . . . . . 45

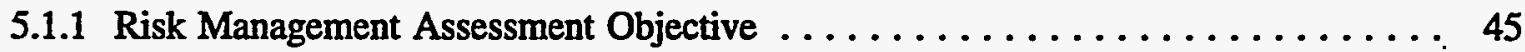

5.1 .2 Risk Management Activities ...................... 45

5.1 .3 Risk Management Responsibilities $\ldots \ldots \ldots \ldots \ldots \ldots \ldots \ldots \ldots \ldots \ldots \ldots \ldots$

5.1.4 Risk Management Status . . . . . . . . . . . . . . . . . . 49

5.2 ASSESSMENT OF CONSISTENCY WITH EXISTING LIQUID HYDROGEN

COLD SOURCES ................................. 49

5.2 .1 Physics $\ldots \ldots \ldots \ldots \ldots \ldots \ldots \ldots \ldots \ldots \ldots \ldots \ldots \ldots \ldots \ldots \ldots \ldots \ldots$ 


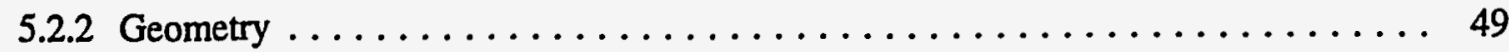

5.2 .3 Safety Philosophy $\ldots \ldots \ldots \ldots \ldots \ldots \ldots \ldots \ldots \ldots \ldots \ldots \ldots \ldots$

6. PRELIMINARY PROJECT SCHEDULE $\ldots \ldots \ldots \ldots \ldots \ldots \ldots \ldots \ldots \ldots \ldots$

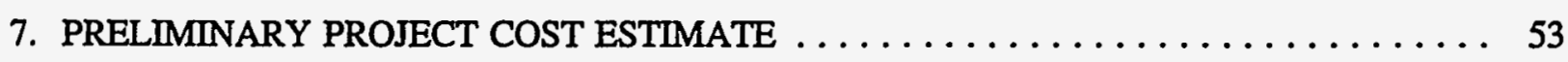

8. REFERENCES ............................... 59

APPENDIX A. WBS FOR THE HFIR COLD SOURCE PROJECT . . . . . . . . . . A-1

APPENDIX B. RISK MANAGEMENT ASSESSMENT FORMS $\ldots \ldots \ldots \ldots \ldots \ldots \ldots$. . . 



\section{FIGURES}

Figure

Page

2.1 Temperature/pressure operating envelope $\ldots \ldots \ldots \ldots \ldots \ldots \ldots \ldots \ldots \ldots \ldots$

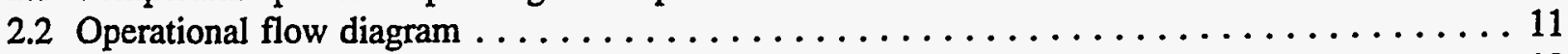

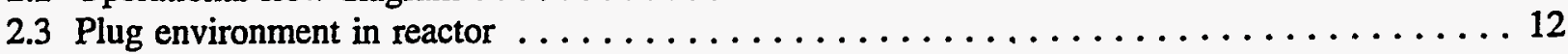

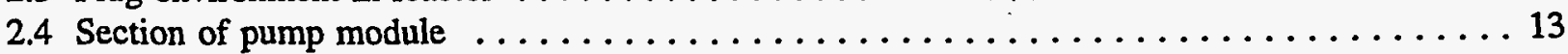

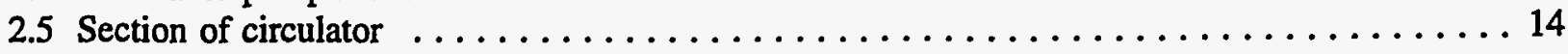

3.1 Cross sectional view of the 3-D MCNP HFIR model of the core and beryllium reflector

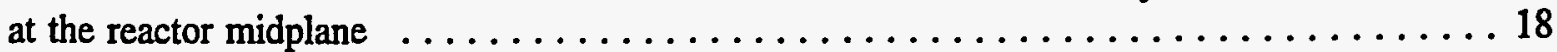

3.2 Plot of calculated HFIR cold source gain factors as a function of neutron wavelength, compared to measured and calculated gain factors at other reactor sites . . . . . . . . 24

3.3 Brightness of the HFIR cold source as a function of its thickness, based on 3-D

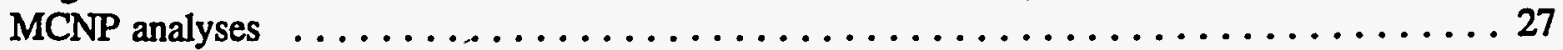

3.4 Relative brightness of cold neutrons emerging from an infinite slabe of parahydrogen, ortho-hydrogen, or a $50 / 50$ mixture, as the slab thickness is varied from 0 to $15 \mathrm{~cm} \ldots \ldots 28$

3.5 Brightness of the HFIR cold sources as a function of the ortho-H/papa-H ratio, based

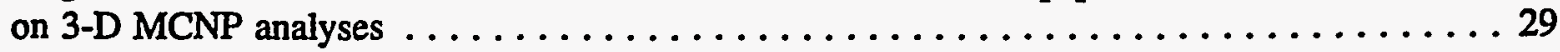

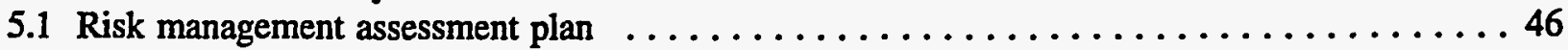

5.2 Table of possible causes $\ldots \ldots \ldots \ldots \ldots \ldots \ldots \ldots \ldots \ldots \ldots \ldots \ldots \ldots \ldots \ldots$

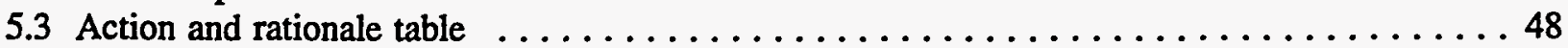

6.1 Preliminary schedule for HFIR cold source project $\ldots \ldots \ldots \ldots \ldots \ldots \ldots \ldots \ldots \ldots$ 



\section{TABLES}

Tables

Page

3.1 Key HFIR physics model parameters $\ldots \ldots \ldots \ldots \ldots \ldots \ldots \ldots \ldots \ldots \ldots \ldots$

3.2 Neutron brightness comparison between the HFIR cold source and the ILL horizontal

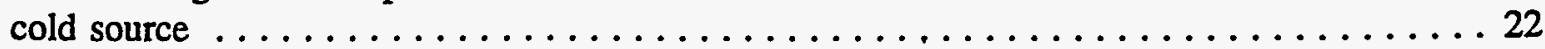

3.3 Gain factors as calculated for the proposed HFIR liquid hydrogen cold source . . . . . . 23

3.4 Origin and distribution of the nominal cryogenic heat loads for a HFIR cold source . . . . 25

3.5 Comparison of relative fluxes in HB-1 with and without the $\mathrm{HB}-4 \mathrm{LH}_{2}$ cold source . . . . 30

3.6 Impact of bismuth gamma shield on cold neutron beam brightness $\ldots \ldots \ldots \ldots \ldots \ldots$

3.7 Impact of bismuth gamma shield on cold neutron heat load $\ldots \ldots \ldots \ldots \ldots \ldots$

3.8 Compariosn of $\mathrm{RB}-7 \mathrm{~A}$ neutron fluxes with and without $\mathrm{HB}-4 \mathrm{LH}_{2}$ cold source $\ldots \ldots \ldots . \ldots 34$

3.9 Comparison of RB-8 neutron fluxes with and without $\mathrm{HB}-4 \mathrm{LH}_{2}$ cold source . . . . . . 34

3.10 Comparison of VXF-22 neutron fluxes with and without $\mathrm{HB}-4 \mathrm{LH}_{2}$ cold source . . . . . . 34

7.1 Summary of preliminary project cost estimate by WBS $\ldots \ldots \ldots \ldots \ldots \ldots$

7.2 Detailed breakdown of preliminary costs by WBS $\ldots \ldots \ldots \ldots \ldots \ldots \ldots \ldots \ldots$

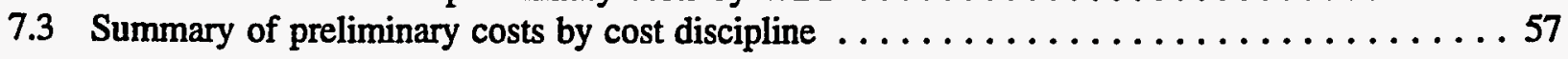


. 


\section{ACRONYMS}

1-D one-dimensional

3-D three-dimensional

ALARA as low as reasonably achievable

AOP abnormal operating procedures

ARIM accelerator reactor improvement modifications

ASME American Society of Mechanical Engineers

BOC beginning-of-cycle

CPU central processing unit

CR

EOC control rod access plug

EOP end-of-cycle

FEDC emergency operating procedure

FTE Fusion Energy Design Center

HFBR High Flux Breeder Reactor

HFIR

HOG

I\&C

ID High Flux Isotope Reactor hot off-gas

IKE

IILL

ISI

LANL Los Alamos National Laboratory

$\mathrm{LH}_{2} \quad$ liquid hydrogen

LMES Lockheed Martin Energy Systems

OD outside diameter

ORNL Oak Ridge National Laboratory

OSHP Occupational Health and Safety Plan

P\&E plant and equipment

PRA probabilistic risk assessment

PTP peripheral target position

QA quality assurance

RAM reliability/available/maintainability

$\mathrm{RB}$

R\&D

removable beryllium

RRD

SAR research and development

SBLOCA small-break loss-of-coolant accident

VXF

WBS vertical experiment facility work breakdown structure 



\section{INTRODUCTION}

\subsection{PROJECT PURPOSE AND SCOPE}

In February 1995, the deputy director of Oak Ridge National Laboratory (ORNL) formed a group to examine the need for upgrades to the High Flux Isotope Reactor (HFIR) system in light of the cancellation of the Advanced Neutron Source Project. One of the major findings of this study was that there was an immediate need for the installation of a cold neutron source facility in the HFIR complex. In May 1995, a team was formed to examine the feasibility of retrofitting a liquid hydrogen $\left(\mathrm{LH}_{2}\right)$ cold source facility into an existing HFIR beam tube. The results of this feasibility study indicated that the most practical location for such a cold source was the HB- 4 beam tube. This location provides a potential flux environment 2 to 3 times higher than the Institut Laue-Langevin (ILL) vertical cold source and maximizes the space available for a future cold neutron guide hall expansion. It was determined that this cold neutron beam would be comparable, in cold neutron flux, to the best facilities in the world, and a decision was made to complete a preconceptual design study with the intent to proceed with a 2-year activity to install a working $\mathrm{LH}_{2}$ cold source in the HFIR $\mathrm{HB}-4$ beam tube.

The anticipated cold source will consist of a cryogenic $\mathrm{LH}_{2}$ moderator plug (that will be inserted into the innermost part of the HB-4 beam tube), a cryogenic pump system, a refrigerator that uses helium gas as a refrigerant, a heat exchanger to interface the refrigerant with the hydrogen loop, liquid hydrogen transfer lines, a gas handling system that includes vacuum lines, and an instrumentation and control system to provide constant system status monitoring and to maintain system stability. All aspects of the cold source design will be based on demonstrated technology adapted to the HFIR design and operating conditions.

The scope of this project includes the development, design, safety analysis, procurement/fabrication, testing, and installation of all of the components necessary to produce a working cold source within an existing HFIR beam tube. This project will also include those activities necessary to transport the cold neutron beam to the front face of the present HFIR beam room. The development of operation and maintenance procedures will also be covered by this project. The project will be considered complete when the facility is declared ready for normal operation.

The cold source project has been divided into four phases: (1) preconceptual, (2) conceptual design and research and development (R\&D), (3) detailed design and procurement, and (4) installation and operation. Although there is some time overlap between the phases, in general, they are sequential. This report marks the conclusion of the preconceptual phase and establishes the concept feasibility. In addition, the documentation provided establishes the background necessary to proceed with a more formal design process. The information presented includes the project scope, the preliminary design requirements, the preliminary cost and schedule, the preliminary performance data, and an outline of the various plans for completing the project.

\subsection{PROJECT GOALS AND REQUIREMENTS}

In order to proceed with an efficient design process, the project requirements and goals must be well understood. As a result, user community, regulatory compliance, safety, HFIR operational, and HFIR maintenance requirements and goals have been established for this project. The remainder of this section provides a compilation of these preliminary requirements and goals that will be reviewed and finalized in the design concept report. 


\subsubsection{User Requirements}

Requirement 1: The purpose of the cold source is to increase the available neutron flux delivered to instruments at wavelengths from 4 to $12 \AA$. Optimization is to be done on the neutron brightness (/s/ $\mathrm{cm}^{2} /$ steradian/angstrom). The gain factor on brightness, as measured on HB-4, for these wavelengths should be comparable to existing cold sources of similar geometry (-10 to 20 at $7 \AA$ ).

Requirement 2: Because there is an established experiment station that uses the HB-1 beam tube that is close to the proposed cold source cryostat location, there should be no degradation of the thermal spectrum at HB-1 as measured after the cold source installation.

Requirement 3: The unobstructed viewing area on the surface of the cold source facing the instruments on $\mathrm{HB}-4$ is to be maximized. If a choice has to be made between viewed width and height for a given area, priority should be given to height, provided the viewed width is no less than $50 \mathrm{~mm}$.

Requirement 4: The beam shall interface to the instruments after passing through a primary shutter capable of stopping the beam and reducing radiation to acceptable levels in the beam room while the reactor is running at $100 \mathrm{MW}$. After the shutter, the beam shall pass through the existing HB-4/SANS graphite crystals, which at present should be assumed to be unchanged. The interface to other instruments will be at the reactor face, as it is currently for all instruments in the beam room. Delivery of the beam to this interface point shall not perturb the source spectrum by more than $10 \%$ and shall not restrict the available divergence.

Requirement 5: The design concept shall consider a future upgrade that would use one or more neutron guides within the beam-tube-plug assembly. The hardware initially fabricated does not have to be capable of accommodating guides; however, the design concept should not preclude the use of a guide system between external instruments and a point adjacent to the cold source where the guide could be fully illuminated. The shutter design should not preclude the later insertion of a guide section.

Requirement 6: Installation and testing of the cold source shall be designed and scheduled so as to cause minimum disruption to the beam-user program.

\subsubsection{Regulatory Compliance Requirements}

Requirement 1: Installation of the cold source cryostat shall be performed per procedures written to the requirements of ORNL/RRD/INT-89, The HFIR Operations Procedure Writer's Guide, and are approved per ADM-0100, Operations Procedures, ${ }^{2}$ prior to the installation of the cold source. All installation and operations activities shall also be subject to the requirements of the Lockheed Martin Energy Systems (LMES) Occupational Health and Safety Plan (OSHP) ${ }^{3}$ manual (or ORNL equivalent).

Requirement 2: Operating, abnormal, and emergency procedures written to the requirements of ORNL/RRD/INT- $89^{1}$ shall be approved per ADM $-0100^{2}$ prior to the installation of the cold source.

Requirement 3: Technical safety requirement modifications needed to support the operation of the cold source shall be approved and issued prior to installation. 
Requirement 4: Expected maximum releases of tritium from the cold source when added to routine HFIR gaseous releases shall not exceed the requirements of Technical Specification 3.19.

Requirement 5: The requirements of ORNL Procedure EPM-2.1, Environmental Protection and NEPA Compliance, ${ }^{5}$ shall be completed prior to the detailed design of the cold source.

Requirement 6: The HFIR Safety Analysis Report (SAR) ${ }^{6}$ shall be revised to reflect inclusion of the cold source in the SAR update following installation of the cold source.

Requirement 7: The HFIR Probabilistic Risk Assessment (PRA) ${ }^{7}$ shall be revised to reflect inclusion of the cold source at the PRA update following installation of the cold source.

\subsubsection{Safety Requirements and Goals}

The HFIR cold neutron source facility will be designed such that there is a low probability (less than $1 \times 10^{-6}$ per year best estimate frequency) that neither the reactor nor the public will be endangered by accidents that could occur within the cold source or as a result of the cold source facility interacting with the reactor or its safety systems. To achieve this overall safety goal, a number of requirements and goals are proposed, as described below.

Requirement 1: Under normal operating conditions, the hydrogen shall be contained by a combination of barriers so that no single failure would result in air or water contacting the hydrogen or being cryo-condensed on the outer surface of a cryogenic hydrogen vessel. For most of the system, this should be accomplished by a combination of a high-integrity liquid hydrogen circulating system surrounded by a vacuum, an interstitial barrier surrounded by inert gas, and the beam tube (separating the inert gas and the primary coolant system). Under abnormal operating conditions (including conditions of degraded liquid hydrogen system cooling, loss of vacuum barrier, loss of inert gas barrier, loss of offsite power, or hydrogen leakage), at least one containment barrier shall exist.

Requirement 2: Materials selected for use in the hydrogen system shall be compatible with the low temperature environment and shall be resistant to hydrogen embrittlement. Quality requirements for the hydrogen system materials shall be comparable to those currently in use for the reactor primary coolant pressure boundary material.

Requirement 3: Very high purity hydrogen and inert gas shall be used in the cold source to preclude oxygen contamination of either the primary liquid hydrogen system or the inert gas blanket system. The gases shall be rigorously tested prior to use in the facility. Administrative controls shall be in place during gas transfers to preclude oxygen intrusion.

Requirement 4: The vent system shall be designed to prevent the formation of an explosive cloud or the back-flow of air into the vent system. In the event of an ignition of the hydrogen in the vent system, no reactor safety system will be affected to the extent that its safety function is not performed.

Requirement 5: Vessels that comprise the primary hydrogen barrier shall be designed and fabricated in accordance with Section VIII of the ASME Boiler and Pressure Vessel Code. ${ }^{8}$ Piping that comprises the primary hydrogen barrier shall be designed and fabricated in accordance with ASME B31.3, Chemical and Petroleum Plant Piping. ${ }^{9}$ 
Requirement 6: Components that form the primary liquid hydrogen boundary shall be seismically qualified or shall be shown by analysis to maintain hydrogen containment integrity following a designbasis seismic event. Active components of the liquid hydrogen system shall not be required to function during and following a seismic event. Components of the hydrogen vent system located outside shall be designed to withstand seismic and wind/tornado events.

Requirement 7: The thimble vacuum tube (i.e., the tube that slides inside the beam tube and that contains the liquid hydrogen-bearing components) shall be designed to withstand the external pressure produced by a leaking beam tube. Technical Specification $3.8 .3(b)(1)^{10}$ currently specifies a value of $1000 \mathrm{psig}$ as the bounding external pressure. This specification should be changed to be consistent with the current maximum credible beam tube internal pressure that could be produced by the pressurizer pumps. During the HFIR hydrotest, special measures shall be taken to ensure the integrity of the thimble vacuum tube. These measures may include purging the system of hydrogen, pressurizing the beam tube, and post-hydrotest leak testing of the thimble.

Requirement 8: The consequences of beam tube failure shall be analyzed and shown to be less than the HFIR acceptance criteria for limiting events. Technical Specification $3.8 .3(b)(2)^{11}$ currently limits the consequences to a small-break loss-of-coolant accident (SBLOCA) of no more than $100 \mathrm{gpm}$ at 1000 psig (roughly equivalent to a 0.5 -in. line break). This specification should be changed to reflect consequences that are consistent with the limiting SBLOCA in the new HFIR SAR.

Requirement 9: The cold source facility shall be designed in conjunction with the beam tube to withstand the hydrogen-oxygen reaction that could occur in the event air were introduced into hydrogen-bearing components. For the thimble, the combination of the beam tube and vacuum tube shall be sufficient to withstand the reaction. A credible energy release is determined based on design basis failure modes. A detonation within the thimble will be considered beyond design basis.

In addition to the above safety requirements, a goal of this project is to minimize the operational interfaces between the cold source and the reactor. In particular, the classes of cold source system abnormal events that require a reactor scram should be limited. It is especially important to avoid a requirement to scram the reactor upon loss of cold source cooling (the perceived most frequent cold source system failure). Although a reactor scram is a controlled transient, it is still a transient and, therefore, places demands on system equipment. A significant increase in the number of reactor scrams per year would clearly have some safety implications. When appropriate, automatic reactor power setbacks should be considered as an alternative to a reactor scram.

\subsubsection{Operational Requirements}

The HFIR is a fully functional facility that has operated for more than 30 years. As a result, there are policies, procedures, and guidelines that have been long established for the day-to-day business activities. The following requirements and goals have been established to assure that the cold source facility is compatible with these practices.

Requirement 1: The cold source and its ancillary equipment shall be designed, procured, and installed per the requirements of RRAP-3.2, Configuration Control of Plant Design Modifications. ${ }^{12}$ Per RRAP-3.2, procurement requirements are specified in RRAP-1.9, Procurement of Items and Services, ${ }^{13}$ and fabrication requirements are specified in RRAP-3.3.1, Procedure for Fabrication Control Governing Modification of Reactor Systems and/or Replacement of Hardware. ${ }^{14}$ 
Requirement 2: The cold source shall be designed in accordance with ORNL ALARA design principles. The project goal is for radiological conditions in the beam room and experiment room to be maintained at current levels or improved.

Requirement 3: The cold source shall be designed assuming reactor operation at $100 \mathrm{MW}$.

Requirement 4: The cold source shall be designed to minimize administrative reactor shutdowns to protect cold source equipment (the goal shall be $<1$ shutdown per year).

Requirement 5: The use of the two hot off-gas (HOG) systems for venting hydrogen shall require RRD reactor technology review.

Requirement 6: The cold source shall be operated by RRD/HFIR operations personnel.

Requirement 7: Instrumentation shall be designed so that abnormal operating procedures (AOPs) and emergency operating procedures (EOPs) associated with the protection of the cold source that require immediate actions are limited to the HFIR control room. Follow-up operator actions may require activities at the location of cold source equipment.

Requirement 8: Instrumentation readouts and controls shall be calibrated in Imperial engineering units. Instrumentation and controls, valves, and switches shall be located for easy access by operators on routine shift checks and by operators manipulating the controls of the cold source as determined by the HFIR operations manager.

Requirement 9: The cold source support equipment layout shall be approved by the HFIR operations manager to assure that access to existing equipment required for operations is not blocked or impeded.

Requirement 10: All certified operators shall be trained on the operations of the cold source prior to its initial operation.

Requirement 11: The installation of the cold source cryostat shall be performed under an approved ALARA plan. Tools shall be designed and procedures shall be written to assure acceptable doses are not exceeded as a result of this job, based on our ALARA assessment.

Requirement 12: Operators and craftsmen involved in the installation of the cold source cryostat shall be trained on the installation procedures prior to installation.

Requirement 13: All installation and testing activities at HFIR shall be scheduled through the plan-of-the-day process and the outage planning process.

Requirement 14: The results of all preoperational testing shall be reviewed and approved by the HFIR operations manager and the HFIR section head prior to initial start-up with the cold source operational.

Requirement 15: Operational testing of the cold source, including initial reactor start-up and ascension to power, shall be performed per procedures written to the requirements of ORNL/RRD/INT- $89^{1}$ and approved per ADM-0100. ${ }^{2}$ Procedures shall be reviewed and approved prior to performance of activities requiring their use. 
Requirement 16: Cryostat removal procedures shall be developed, approved, and issued prior to the initial operation of the cold source equipment.

Requirement 17: The need for a backup power supply (e.g., diesel generator) for the cold source should be evaluated to assure reliable operation.

Requirement 18: The cold source refrigeration system design should consider the HFIR secondary coolant system as a heat sink, provided the tower is capable of handling the additional load. Secondary coolant is supplied at approximately $87^{\circ} \mathrm{F}$.

Requirement 19: The design of the cold source control and automated safety systems should be such as to minimize the personnel loads during off-shifts in such a manner that additional staff are not required.

\subsubsection{Maintenance Requirements}

Requirement 1: Installation of all ex-core cold source components shall be administered through the RRD work package system per RRD-M-1.6, Preparing and Processing a Maintenance Work Package, ${ }^{15}$ and RRD-M-1.14, Maintenance Work Control. ${ }^{16}$

Requirement 2: Breakdown maintenance procedures shall be developed, approved, and issued prior to initial reactor operation with the cold source cryostat installed.

Requirement 3: Maintenance personnel shall be trained on the routine and breakdown maintenance procedures prior to the initial reactor operation with the cold source cryostat installed.

Requirement 4: An appropriate spare parts inventory (part, maximum stock, reorder point, and storage requirements) of cold source equipment shall be developed and stocked to assure timely maintenance action in the event of equipment failure.

Requirement 5: The cold source shall be maintained by ORNL craftsmen under the direction of RRD.

Requirement 6: A preventive/reliability-centered maintenance program for cold source equipment shall be developed and implemented prior to initial operation.

\subsection{ORGANIZATION}

The preliminary elements of the HFIR cold source project are organized in a work breakdown structure (WBS) as depicted in Appendix A, Fig. A.1. Further breakdown of each of the level two WBS elements is provided in Figs. A.2-A.8 of the appendix. This WBS breakdown provides the lines of responsibility and represents the structure by which the project will be managed.

The separation of the design activity work into conceptual and detailed design WBS splits is somewhat unique but is considered necessary to reflect the characteristics of the project. The conceptual design requires practical development and testing activities that would best be performed outside of the existing Research Reactor Division organization. On the other hand, the detailed design must be controlled within the RRD organization framework to ensure compliance with all HFIR regulations and compatibility at all physical interfaces between the cold source and the existing HFIR systems. 


\section{PRECONCEPTUAL DESIGN DESCRIPTION}

\subsection{PRECONCEPTUAL DESIGN OBJECTIVE}

A preconceptual design activity has been completed to establish the basic cold source design philosophy that will be carried forward into a conceptual design phase. In addition, evaluations and analyses have been performed to define a baseline system to initiate the conceptual design process. This baseline system in general has been developed based on nine top-level system functional requirements that are consistent with the design requirements identified in Sect. 1.2. Although the design requirements imply more than nine system functional requirements, the nine listed below are the principal functional requirements that are the basis for the baseline system.

1. Provide a liquid hydrogen moderator within the HB-4 beam tube with a geometry that provides moderation and viewing areas consistent with user requirements.

2. Provide a system that satisfies the double barrier philosophy that isolates the hydrogen from atmospheric air, along with the monitoring systems required to assure the integrity of the double barrier.

3. Provide a system integrity that ensures that loads created under all normal or maximum credible accident conditions (including design basis seismic effects), do not result in fire, explosion, or a release of radioactive material that would present a hazard to ORNL staff or to the public in general.

4. Provide a system with temperature stability under all anticipated load conditions.

5. Provide the ability to replace vulnerable components such as the liquid hydrogen circulators, or vacuum pump stations without the need to shut down the reactor or the cold source.

6. Provide the ability to add or remove hydrogen gas from the system along with the ability to monitor the gas for impurities, particularly oxygen and nitrogen.

7. Provide the ability to transition the hydrogen from ambient temperature gas to a cryogenic liquid and back on a regular basis without harm to the cold source system.

8. Provide a means for removal and replacement of cold source components that adheres to ALARA principles with acceptable impacts to HFIR operations.

9. Provide an enclosed system able to contain the entire hydrogen inventory at temperatures between ambient and $20 \mathrm{~K}\left(-423^{\circ} \mathrm{F}\right)$ at constant pressure within the cold loop.

These functional requirements will be reviewed early in the conceptual design process and could be revised in part or in whole as needed to ensure that the design requirements are appropriate and are satisfied.

The remainder of this section provides a summary of the design philosophy and a description of the baseline system, along with perceived characteristics of the components that make up the system. 


\subsection{DESIGN PHILOSOPHY}

Early in the feasibility study, a decision was made to design a pressurized single-phase mechanically circulated system (with an operating envelope as shown in Fig. 2.1) rather than a twophase thermal-syphon arrangement. This decision was made for three principal reasons:

1. Subcooled liquid represents a cold moderator of higher density than a mixture of saturated liquid and gas, such as would be the case in a boiling type system; requiring less moderator space. This is particularly relevant to the HFIR design where the small beam tubes confine the cold source to a small moderator vessel.

2. The moderator plug is a long horizontal tube through which both the cold neutron beam and the hydrogen service lines pass. The long horizontal run would complicate the design of a natural convection system and would greatly complicate the design of a thermo-syphon circulation process. In addition, the larger diameter pipes required by such a system would be difficult to accommodate within the constraints of the small HB-4 beam tube.

3. It is easier to design a mechanically pumped system on a modular basis that allows major sections of the loop to be procured in parallel. This is an important factor, considering the short lead time for installation of the HFIR cold source.

Control of the liquid hydrogen pressure is of paramount importance to prevent boiling and consequential loss of prime in the circulator impeller. This control is achieved by a chamber containing liquid hydrogen with a controlled pressure of hydrogen buffer gas above it. Ambient temperature gas is added or vented from the top of this chamber by valves that operate in response to a pressure sensor in the loop. The gas inventory is held in a vessel [of up to 1500-L (396-gal.) capacity] when the system is not operating. The overall pressure, at ambient temperature, is 4-bar absolute (58 psia). When the system is cooling, gas is removed from the vessel by a transfer pump to maintain constant pressure in the loop. Eventually the pressure in the vessel falls to a minimum of about 0.3-bar absolute (4.4 psia). Under normal operating conditions, the liquid pressure is 4-bar absolute ( $58 \mathrm{psia}$ ) at the outlet of the circulator, and the loop pressure drop is anticipated to be of the order of 1 bar (14.5 psi). This arrangement limits the gas inventory to that strictly required for operation. The gas inventory of about $350 \mathrm{~g}$ (early estimate that will be revised as the design progresses) remains resident in the system until removal is required for servicing or until a rupture disk operates.

The liquid temperature is controlled by heaters in the refrigerant circuit. This allows the simplification of a constant refrigeration capacity even though the nuclear deposited heat load varies over the reactor cycle. Power to these heaters is controlled by one of three temperature sensors in the loop according to the prevailing operational state.

A decision was made early in the feasibility study to copy the ANS Project's philosophy of installing two circulators in the loop, one of which remains in standby. This is done to increase the availability of the cold source system. Double valving allows a circulator to be isolated, purged with inert gas, and replaced in a short time frame even when the reactor and cold source system are operating. Replacement is required before final failure, and the need to switch to the standby circulator will be established based on experience gained by performing circulator reliability tests early in the design program.

Other early philosophy decisions were that the design should contain vent capability and that all relief systems should be connected to a single outside vent system. It was further determined that vulnerable components such as the pump module and the main heat exchanger should be located in a frangible walled room. This room (sometimes referred to as a "hydrogen safe room") is ventilated to 


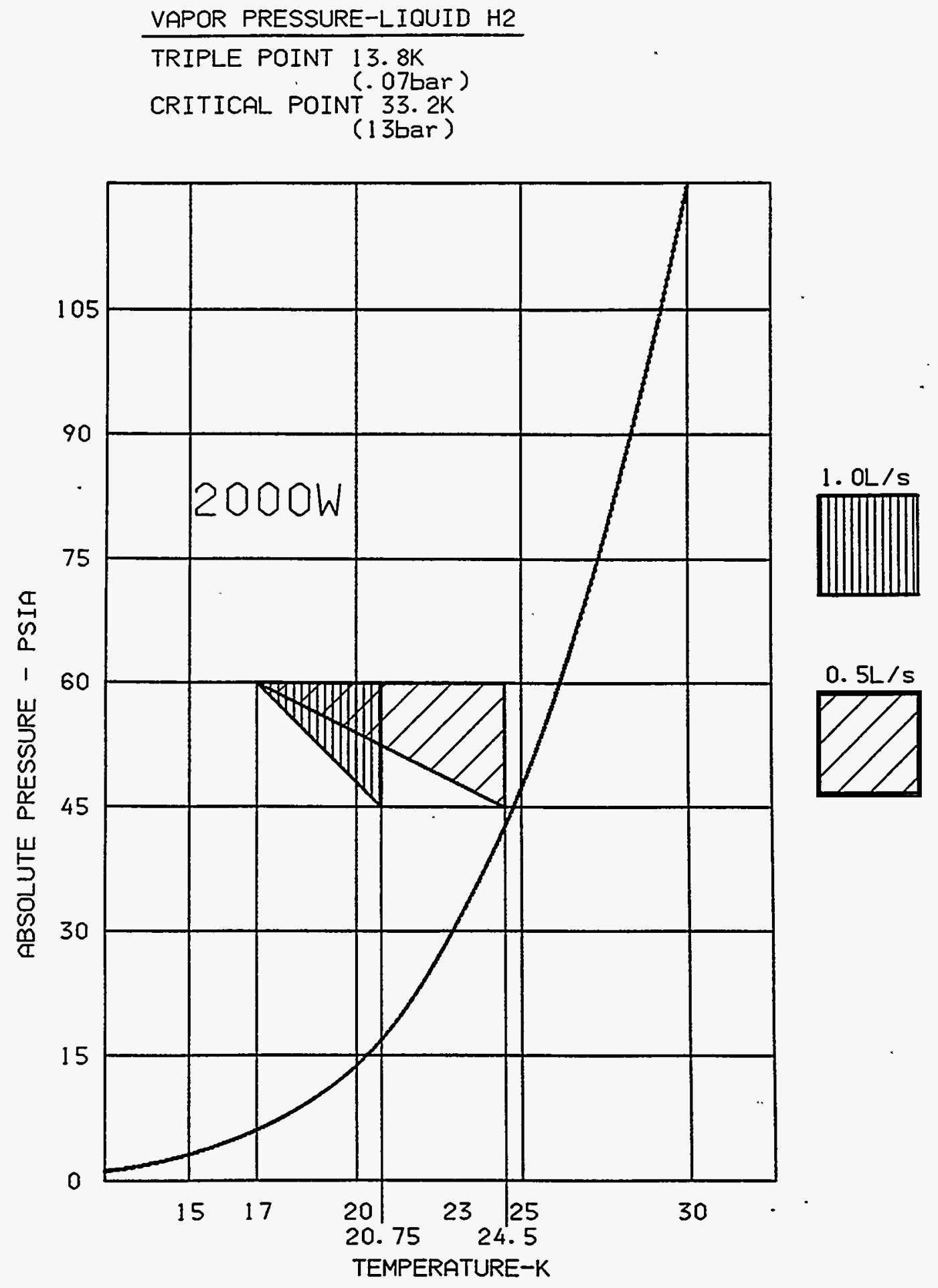

Fig. 2.1. Temperature/pressure operating envelope. 
the outside vent system, and the air removed is monitored for hydrogen. The definition of a safe room is: an enclosure in which uncontained hazardous gas is not normally present, but could be present under faulted conditions. Personnel access to the safe room is restricted, and precautions are taken to prevent electrical arcing or static discharge. Electronic barriers can protect normally intrinsically safe, very low-power components, such as parameter sensors, against higher than normal voltages in severe fault conditions. (Intrinsically safe is defined as a condition in which only an energy release of $0.019 \mathrm{~mJ}$ or less is allowed.) High-power devices such as electric motors and demountable connectors are normally blanketed with an inert gas. The room is ventilated by a hydrogen qualified fan, and its extraction rate is increased to the equivalent of one room air change per minute if installed monitors detect hydrogen.

\subsection{DESIGN DESCRIPTION}

A preliminary system flow diagram of the proposed HFIR cold source is shown in Fig. 2.2. The major components of the system are the moderator plug, the pumping module, the heat exchanger, the transfer lines, the gas-handling subsystem, the refrigerator subsystem, the instrumentation and control subsystem, and other auxiliary subsystems. The remainder of this section provides a preliminary description of these components and subsystems. It should be understood that in some cases, no actual component design work has been completed, and, in those cases, what is described is only a perception of the component design.

\subsubsection{Moderator Plug}

In general, the moderator plug, shown in more detail in Fig 2.3, is sufficiently long to pass from the cold source position, close to the reactor core, through the high-pressure light water vessel, the light water pool, and the biological shielding. The outer wall of the plug comprises the insulation vacuum chamber, and an inner composite tube forms the moderator vessel and facilitates beam transport and cryogenic service lines. The cold neutron line is evacuated, and a window at its outer end provides a structural boundary, while allowing the free passage of cold neutrons to the experiment systems beyond the biological shield. The moderator plug fits into the 4-in.-diam beam tube, and helium gas is circulated in the space between the plug and the beam tube to provide an early indication of any leaks. The liquid hydrogen reservoir at the end of the moderator plug provides the moderation effect necessary to produce the cold neutron spectrum desired by experimenters. This cryostat section has been sized to maximize the moderation effect, while minimizing the nuclear heat load deposited in the system. The moderator plug is coupled to the pump module by dual concentric cryogenic transfer lines.

\subsubsection{Pump Module}

The pump module (shown in Fig. 2.4) is situated in the hydrogen safe room on the second floor, requiring a transfer line $30-40 \mathrm{ft}$ long. The pumping module is a double-walled vessel containing both the active and the standby circulators (circulator sketch shown in Fig. 2.5), the isolation valves, and pressure and temperature sensors. The pumping module will be fitted with coupling units to accept the transfer lines that connect the pumping module with both the moderator plug and the main heat exchanger. 


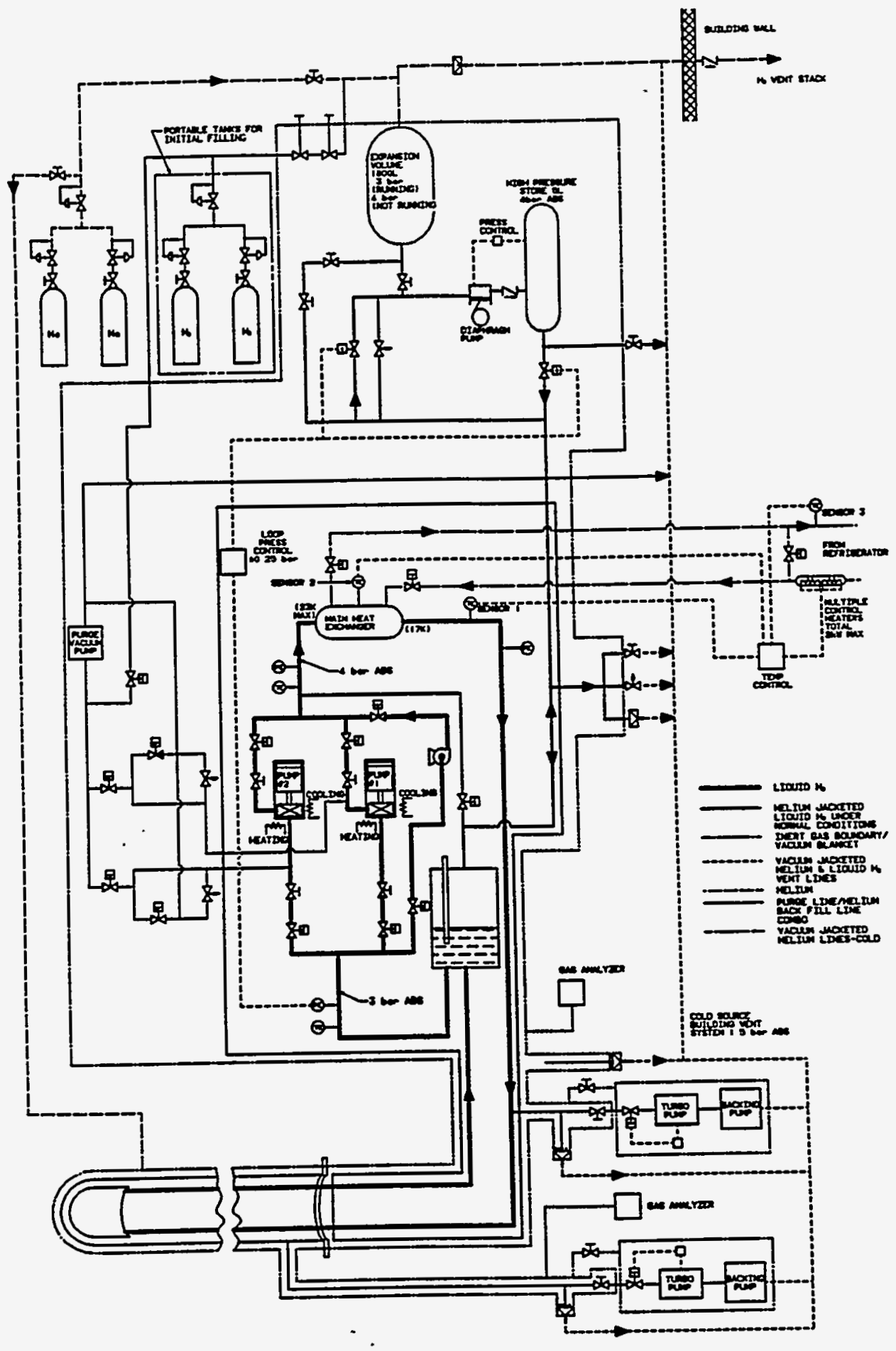

Fig. 2.2. Operational flow diagram. 


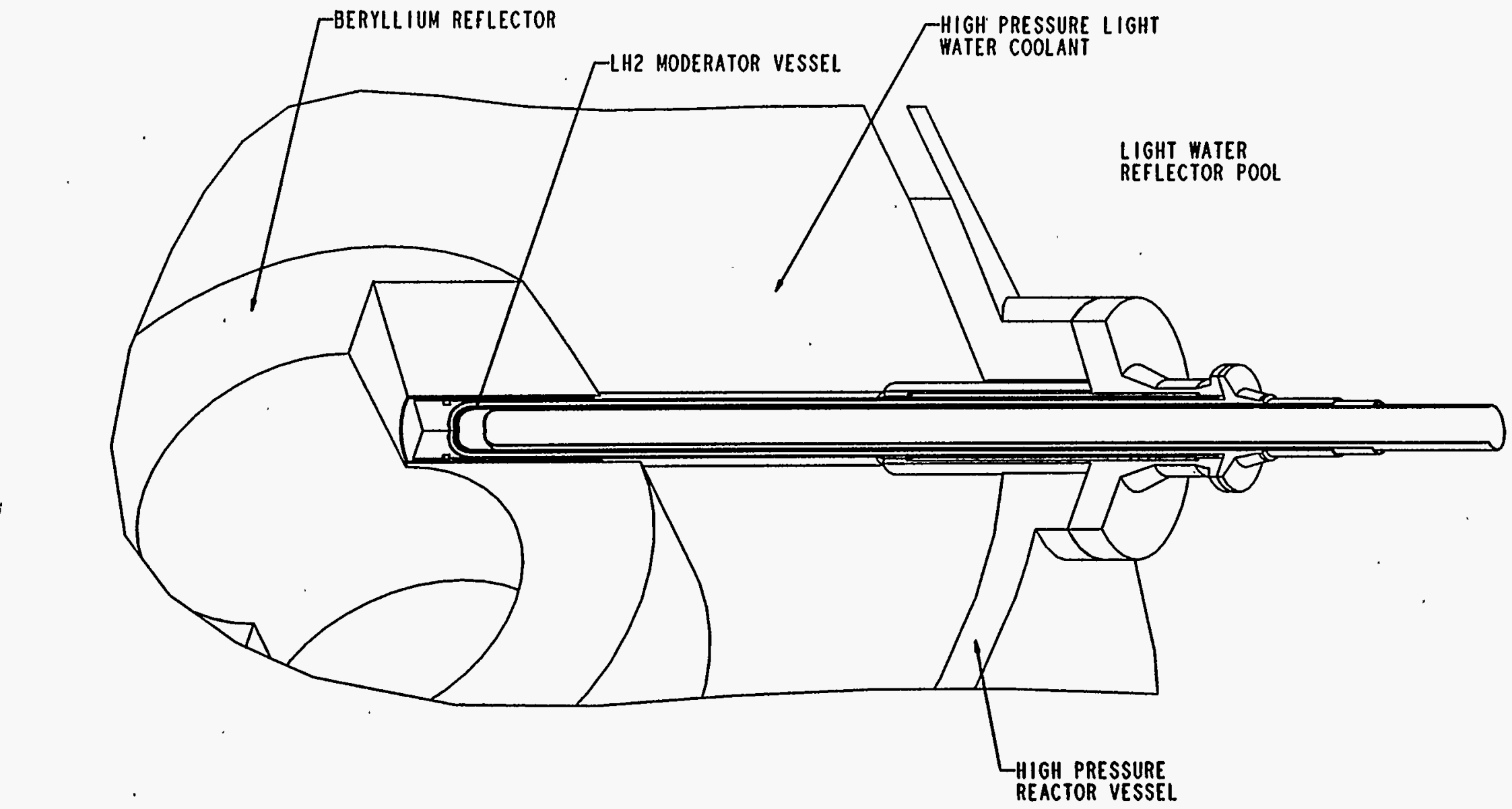

Fig. 2.3. Plug environment in reactor. 


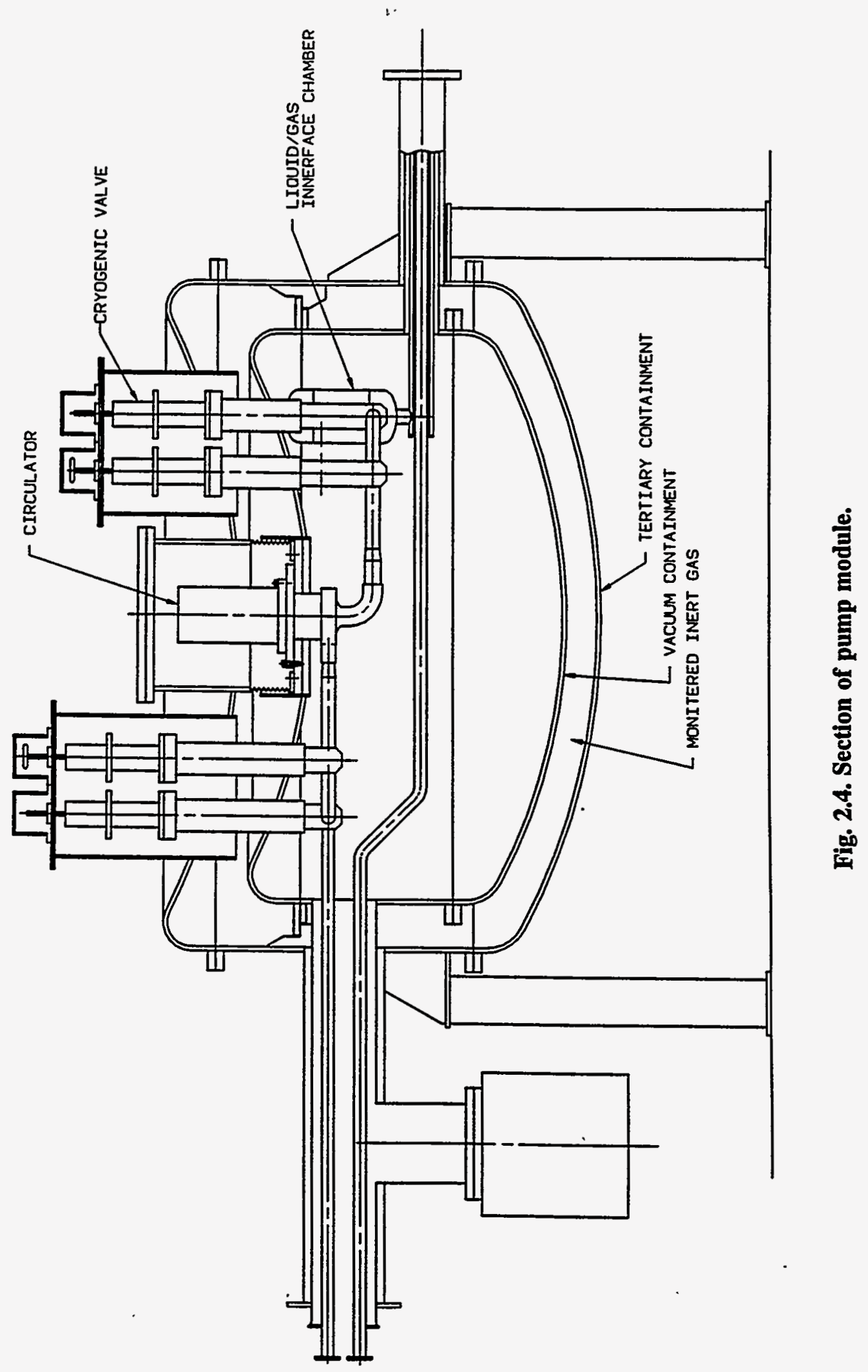




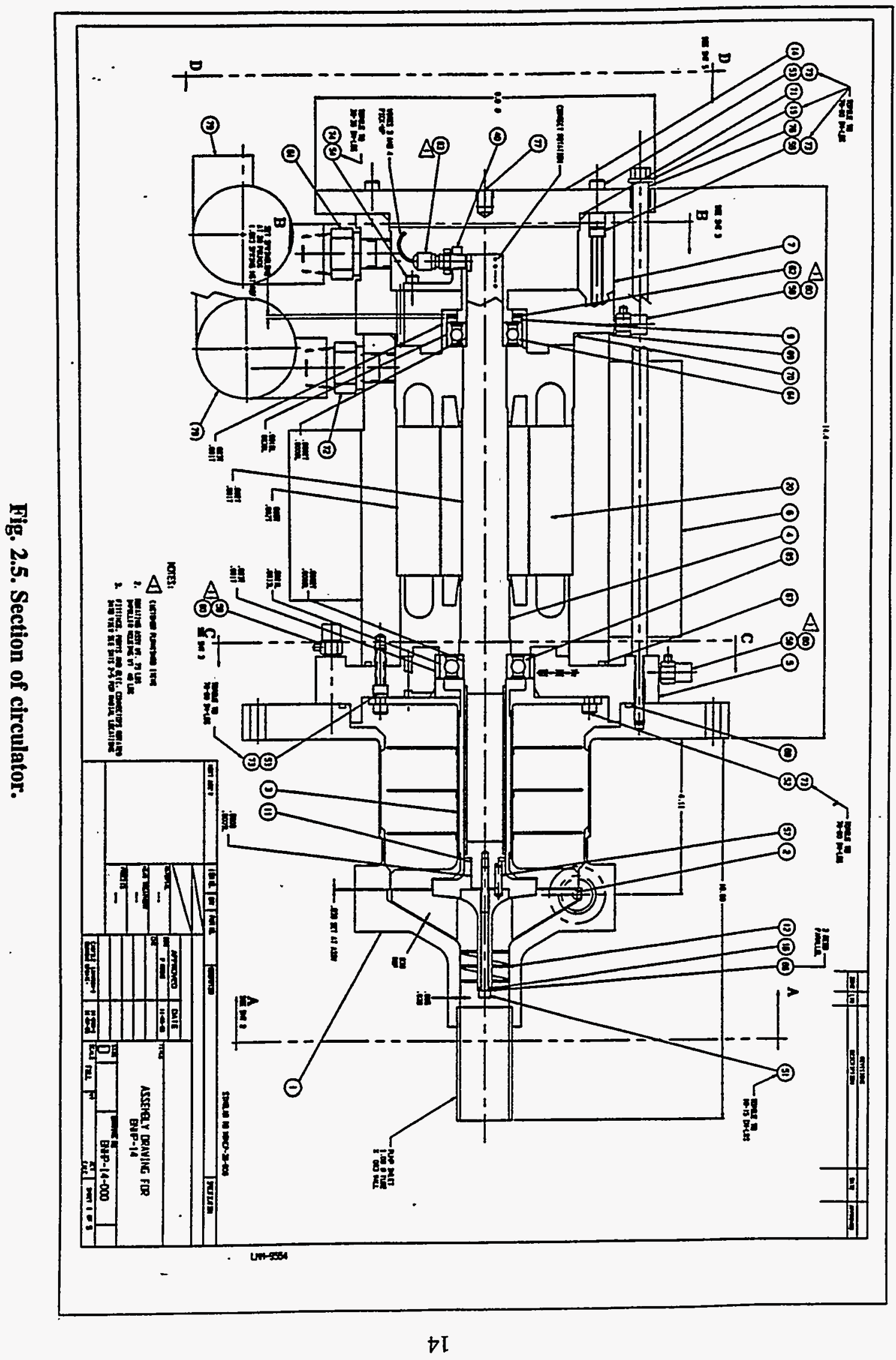




\subsubsection{Main Heat Exchanger}

The present perception of the heat exchanger is a separate module housed in a double-walled vessel alongside the pump module in the hydrogen safe room, but the development of high performance heat exchangers may allow the two to be combined. The heat exchanger will be specified to remove up to $2000 \mathrm{~W}$ of heat from liquid hydrogen flowing at $0.5-1.0 \mathrm{~L} / \mathrm{sec}$ at an entry temperature of up to $24 \mathrm{~K}$. The heat exchanger will also be required to liquefy and subcool the hydrogen inventory over a period of about $10 \mathrm{~h}$.

\subsubsection{Transfer Lines}

The transfer lines are the devices that provide the liquid hydrogen connection between the various components of the cold source system. These transfer lines are composed of an arrangement of multiconcentric tubes with the feed through the center. The center tube is vacuum insulated, and the surrounding annulus forms the return flow path, which is also vacuum insulated, and the whole is surrounded by an outer blanket chamber (total of five tubes). The main couplings combine gas insulation with a cold-actuated plug seal to allow a single ambient temperature seal to be used. Construction will be entirely of austenitic stainless steel with inorganic, radiation hard, internal insulation.

\subsubsection{Gas-Handling Subsystem}

The gas-handling system includes the double-walled hydrogen gas containment and fill vessels, the transfer pump, and the inlet and outlet control valves that respond to pressure sensors in the cold loop circuit. Most, if not all, of the gas-handling subsystem would be expected to be installed in the hydrogen safe room.

\subsubsection{Refrigerator Subsystem}

The refrigerator cold box and the compressors form the two main components of the refrigerator system. The cold box will be outside the safe room, but close by, to minimize the length of the cold helium lines. The refrigerator compressors can be a distance away outside of confinement to provide isolation from noise and vibration.

The refrigerant is helium gas compressed to pressures of up to 15 -bar absolute ( 218 psia) in a screw compressor. The pressurized gas is cooled to ambient temperature before it is piped to the cold box. Cooling is effected by expanding the helium in turbines that cause the gas to perform external work that is removed as heat. Interstage heat exchangers limit the proportion of gas passed through the turbines, since they are restricted to a rather narrow speed range. The refrigerator is operated at a constant output. Supplemental electrical heaters are utilized to suit the prevailing requirements of the system and to provide temperature control. The heaters are powered in response to one of three temperature sensors that are part of the control system.

\subsubsection{Instrumentation and Control Subsystem}

This subsystem will control the pressure and temperature of the liquid hydrogen loop under all conditions. It will also monitor main parameters throughout the loop and the condition of the on-line circulator. Both insulation vacuum systems, safety-related and interlock systems, and all relevant interlock logic will be monitored and operated from a central computer-based control module. This 
computer will also be responsible for data acquisition that will be fed ultimately to the main HFIR control facility.

Depending on the operating mode, the stability of the system is maintained by temperature sensors at one of three locations-two within the cold hydrogen loop and the third within the helium loop:

1. The sensors used during normal operation are positioned just downstream of the main heat exchanger. The liquid at this point is very close to that entering the moderator vessel but is still in a controlled location inside the pumping module.

2. A second set of temperature sensors is used during the initial cooldown of the hydrogen and is mounted on the cooling surface of the heat exchanger. This permits the cooling rate to match the heat capacity of the circulating hydrogen as its density and enthalpy increases and will also prevent freezing.

3. The third temperature sensor group is in the helium loop and allows the refrigerator to be operated while isolated from the cold source. This is used during certain time periods when it is considered desirable to keep the refrigerator operating even though other cold source systems are not functioning.

\subsubsection{Vent Subsystem}

All vents will be manifolded to a common vent line that will exit the building at a carefully chosen position and height. All system manifolds between the rupture discs and the stack closure valve (with the closure pressure as low as possible) are filled with an inert gas. The exit stack will consist of a dedicated line that is capped off with a nonreturn valve designed to lift at a minimum practical pressure. The size and location of this vent has not yet been determined, although the vent size will probably not exceed 6 in. The venting concept will be developed with HFIR staff involvement, so that the location is consistent with site safety and HFIR facility operation.

\subsubsection{Auxiliary Subsystems}

All cold parts of the loop require vacuum insulation, and although this is not considered a part of the safety barrier, it is constantly monitored to warn of gas leaking through either the inside or the outside wall.

The entire hydrogen-bearing system (and vacuum system where applicable) is further enclosed by a tertiary containment to create an inert barrier of either a gas or, where more convenient, a secondary vacuum. This barrier is constantly monitored to provide an early warning of leakage through either containment wall. 


\section{PRELIMINARY PHYSICS PERFORMANCE}

This section provides a description of the physics models that have been developed to perform preliminary analysis of the HFIR cold source geometry, along with the initial analytical results. It should be noted that some late changes in the preconceptual cold source geometry have not been incorporated yet in the physics models, and, therefore, some differences will be observed when comparing the geometry described here with the system as described in Sect. 2.3.1 of this report.

\subsection{PHYSICS CODES, MODEL DESCRIPTION, AND CROSS-SECTION DATA SETS}

\subsubsection{HIFIR Description}

The HFIR cold source physics analyses are, of course, greatly dependent on the model used to represent the HFIR reactor, which is the source of the neutrons reaching the cold source. The HFIR reactor core model used in these studies is believed to be the most detailed physics model of HFIR that has been developed. This model has been and will continue to be reviewed by HFIR staff to ensure an accurate representation of the HFIR system. Further validation of the model will be performed by comparisons with measured data. The key reactor parameters used in this study are provided in Table 3.1. It should be noted that although at present the HFIR operates at $85 \mathrm{MW}$, all calculations are based on a 100-MW operating condition (because an upgrade to this power level is being considered, the cold source should be designed to accommodate this higher power level).

Table 3.1. Key HFIR physics model parameters

\begin{tabular}{ll}
\hline \multicolumn{1}{c}{ Parameter } & Value \\
\hline Power level & $100 \mathrm{MW}$ \\
Maximum fuel cycle length & $23 \mathrm{~d}$ \\
Active fuel height & $20 \mathrm{in}$. \\
Active fuel region volume & $1.79 \mathrm{ft}^{3}(50.6 \mathrm{~L})$ \\
$\mathrm{U}^{235}$ loading & $9.4 \mathrm{~kg}$ \\
Total B ${ }^{10}$ burnable poison loading & $2.8 \mathrm{~g}$ \\
Fuel plate thickness & $0.050 \mathrm{in}$. \\
Coolant channel thickness & $0.050 \mathrm{in}$. \\
Cladding thickness & $0.010 \mathrm{in}$. \\
\hline
\end{tabular}

Figure 3.1 shows a cross section of the HFIR core and reflector at the reactor's midplane, as modeled in the present three-dimensional (3-D) Monte Carlo analysis. The proposed cold source will be placed adjacent to the beryllium block in HB-4. 


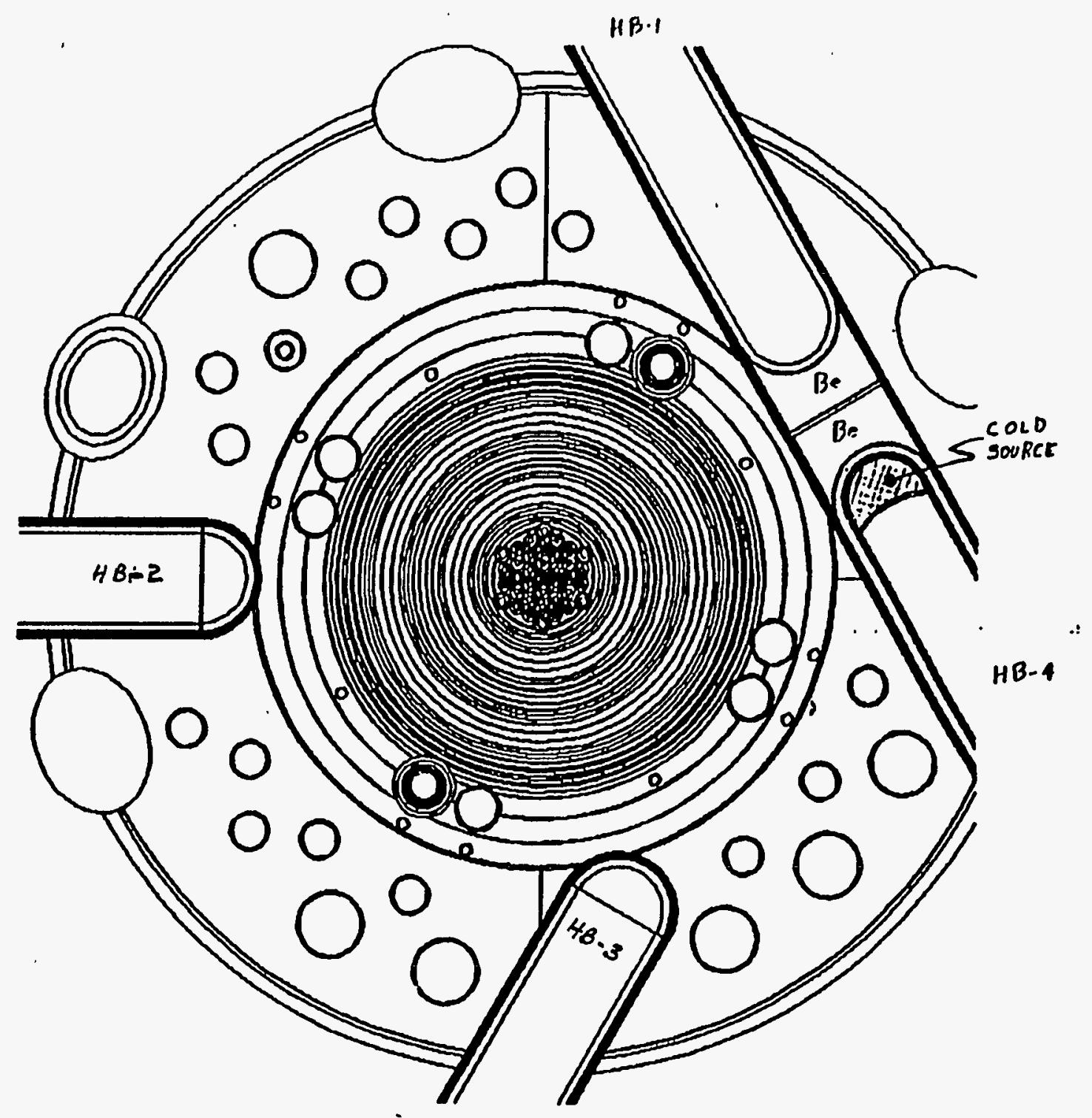

Fig. 3.1. Cross-sectional view of the 3-D MCNP HFIR model of the core and beryllium reflector at the reactor midplane. 


\subsubsection{Cold Source Model}

At this point, it is necessary to differentiate between two slightly different modeling efforts: (1) the final preconceptual cryogenic heat load calculations performed late in the study are based on a model that more closely resembles the final preconceptual design described in Sect. 2.3 of this report, and (2) all remaining calculations were performed using an earlier, but similar, model. In both cases, the moderator section of liquid hydrogen comprised a $5.0-\mathrm{cm}$-thick region with a liquid hydrogen density of $0.067 \mathrm{~g} / \mathrm{cc}$ at $20 \mathrm{~K}$. Although neither of these models is an exact representation of the final preconceptual design configuration, they are believed to be adequate for the trend and scoping analyses that have been performed. A representative model of the final preconceptual design will be built in the first phase of the conceptual design work, and that model will be placed under configuration management.

Lastly, while a fresh fuel composition was used in all the neutronic analyses to date, the physical configuration used in the calculational model assumed the control rods to be in their lifetime-averaged position, $22 \mathrm{~cm}$ above and below the core midplane. Short of performing beginning-of-cycle (BOC), mid-cycle, and end-of-cycle (EOC) calculations with progressively depleted fuel and with the control rods in their critical positions, this provides an "average estimate" of the cold source brightness. However, both the brightness and the local heating rates are expected to increase slightly near EOC when the fluxes near the midplane are higher and the control rods are further apart. The more detailed fuel cycle analyses will be performed as part of the conceptual design evaluation.

\subsubsection{Codes and Cross-Section Data}

Because of the inherent 3-D nature of the HFIR core, the various experimental and user facilities in the reflector, and the location of the proposed cold source in the HB-1/HB-4 through-tube, the 3-D MCNP Monte Carlo code (version $4 a)^{17}$ was used in virtually all of the analyses performed to date. In addition to being able to model all aspects of the 3-D geometry, it also has the advantage of being able to represent all of the cross-section data on a pointwise energy basis. Various pointwise crosssection libraries are typically supplied with the MCNP code. Each is the result of different historical evaluations of the cross-section data for the various nuclides. Except for parahydrogen and orthohydrogen, the data used here invariably corresponds to the Los Alamos National Laboratory (LANL)-recommended data set for each nuclide. In the case of parahydrogen and orthohydrogen at $20 \mathrm{~K}$, it was determined that the IKE data from Germany ${ }^{18}$ was superior to both the Young-Koppel data $^{19}$ and the MacFarlane data. ${ }^{20}$ These two data libraries were also obtained from LANL, although they were not supplied with the original release of the code.

\subsubsection{Source Terms Used in the Analyses}

Generally speaking, neutron-only k-effective calculations were used to determine the neutron source distribution in the core under the conditions described above (fresh fuel, control rods at their lifetime-averaged positions, $22 \mathrm{~cm}$ above and below the core midplane). Acceptable statistical uncertainties (within 2-3\%) at the various point detectors of interest generally required 160 batches of 15,000 source neutrons, for a total of $2,400,000$ histories, although the results from the first 20 batches ( 300,000 histories) were typically discarded as the source distribution within the core was being converged. Reportable results were based therefore on the remaining 2,100,000 histories after the source was deemed converged. Such calculations typically required $2 \mathrm{~h}$ of central processing unit (CPU) time on eight IBM Model $590 \mathrm{RS} / 6000$ workstations working in parallel for a total of $16 \mathrm{CPU} h$ in each case. These calculations were typically performed on the IBM SP-2 multinode 
cluster of workstations. For cases where neutron and gamma heating rates were both required, the memory requirements were too large and would not allow such calculations to be performed on the present ORNL SP-2 cluster. Thus, these coupled neutron-gamma k-effective calculations were typically performed on other (separate) Model 580 workstations in a stand-alone mode. While we again used 160 batches of 15,000 histories per batch (for a total of $2,400,000$ histories), such calculations typically required several days each. In each case, however, the source distribution in the core was determined statistically by the individual Monte Carlo calculations as they progressed. In some cases, the prompt fission gammas from the fuel were turned on, and, in some cases, they were turned off, so that the heating rates from prompt fission gammas from the fuel and secondary gammas from the other materials could be determined separately.

Because MCNP does not automatically track delayed fission-product gammas, at least one fixedsource calculation was performed to determine this component of the gamma heating in the various materials. In prior neutron-only k-effective calculations, the fission density had been tallied in each of 119 fuel zones. Using this prior data, the delayed fission-product decay gamma sources were placed in the MCNP model with the appropriate decay gamma spectrum. Moreover, while there are typically 2.43 neutrons per fission, there are approximately 16.042 effective fission-product decay gammas per fission. Since MCNP normalizes the calculational results "per source particle," this difference had to be accounted for properly when determining the respective gamma heating rates.

\subsubsection{Method Used for Calculating the Brightness}

The cold neutron beam magnitude is typically expressed in terms of its "brightness," which is defined as the number of neutrons per second, per square centimeter, per angstrom, per steradian. Throughout this study, the calculated brightness is tabulated in four energy bands, with the last two being the energy bands of most interest:

1. $0.010 \mathrm{eV}$ to $0.104 \mathrm{eV}$, (neutron wavelengths between 0.887 and $2.86 \AA$ ),

2. $0.00325 \mathrm{eV}$ to $0.010 \mathrm{eV}$, (neutron wavelengths between 2.86 and $5.02 \AA$ ),

3. $0.00145 \mathrm{eV}$ to $0.00325 \mathrm{eV}$, (neutron wavelengths between 5.02 and $7.51 \AA$ ),

4. $0.00085 \mathrm{eV}$ to $0.00145 \mathrm{eV}$, (neutron wavelengths between 7.51 and $9.81 \AA$ ).

To determine the brightness in the direction of interest (down the HB- 4 beam tube), the scalar flux was tabulated at a point $254.654 \mathrm{~cm}$ away from midpoint of the HB-1/HB-4 through-tube, along its centerline. More specifically, the model only tabulated a select portion of the scalar flux at that point detector. Looking back from that point, the liquid hydrogen portion of the cold source (having a diameter of $3.5 \mathrm{in}$.) would subtend an angle of $\pm 1.056^{\circ}$ about the beam tube centerline, or a solid angle of $1.068 \mathrm{E}-3$ steradians. To ensure that the MCNP tally counter associated with that point detector counted only neutrons traveling within that solid angle, next event estimates of the flux at that point were made only from collision sites in the cold source and from those material regions directly behind the cold source. Specifically, this included only the following regions: the liquid hydrogen itself, the aluminum membrane holding the $\mathrm{LH}_{2}$ inside the cold source guide tube, the hemispherical tip and cylindrical wall of the cold source guide tube immediately adjacent to the $\mathrm{LH}_{2}$, the hemispherical end of the HB-4 beam tube and the water between the hemispherical tip of the HB-4 beam tube and the cold source guide tube, the beryllium blocks next to the HB- 4 and HB-1 beam tubes, and the water-filled region between these two beryllium blocks. Next event estimates from all other collision sites were ignored by setting the probability of a contribution from these other cells to zero. This not only had the desired effect of tallying selectively only those neutrons traveling within the desired range of solid angular directions, but it also allowed the calculations to proceed about five 
times faster than they would have if next event estimates were made from all collision sites in the problem.

\subsubsection{Methods Used for Calculating Neutron and Gamma Heating}

Estimates of the neutron and gamma heating in the liquid hydrogen and in the various aluminum components around the cold source were generally obtained by two independent methods. Both methods rely on region-averaged estimates of the total neutron or gamma track length in the various cells comprising the system. In the first method, the average energy-dependent neutron or photon heating number (MeV/collision) available in the MCNP cross section libraries is folded with the total (pointwise energy-dependent) neutron or gamma cross-section, which is then folded with the (pointwise energy-dependent) neutron or gamma track length each time a neutron or photon passes through a cell of interest. These values are then integrated over all energy and spatially averaged over the volume of the respective cells to obtain the specific neutron and gamma heating rates in terms of watts/gram. In the case of the second method, the cell-averaged neutron and gamma fluxes in the aluminum-filled cells were first tallied in multigroup energy bins corresponding to the $39 \mathrm{n} / 44 \mathrm{~g}$ group structures used in the analysis of the ANS reactor. These multigroup neutron and gamma fluxes were then folded with the multigroup neutron and gamma kerma factors described in Appendix D of ORNL/TM-12672 ${ }^{21}$ to obtain the average specific heating rate (watts/gram) for the various cells. (These multigroup kerma factors were based on the KAOS-V kerma factor data library available from Argonne and/or the Radiation Shielding Information Center in Oak Ridge.) $)^{22}$ After several such calculations showed the directly calculated MCNP heating rates to be in good agreement with those calculated indirectly using the multigroup data, the latter procedure was dropped.

Lastly, nuclear heating in the aluminum due directly or indirectly to neutron radiation has three separate components: that directly because of the kinetic interactions between the neutrons and the aluminum, that because of the subsequent gamma decay of Al-28 atoms that became activated by thermal neutron absorption in the Al-27, and that because of the subsequent beta decay of Al-28 atoms that become activated by thermal neutron absorption in the Al-27. The cell-averaged neutron heating rate tallies used here for cells containing aluminum account for all three processes. Basically, the pointwise energy-dependent flux is folded with the pointwise total cross section and the energy-dependent neutron heating number (MeV/collision) to obtain the direct component. In addition, the pointwise flux is also folded with the pointwise Al-27 absorption cross section to obtain the Al-28 production rate, which is then folded with the average beta decay energy $(1.2423 \mathrm{MeV})$ and the average gamma decay energy $(1.7789 \mathrm{MeV})$ to obtain the total energy production rate because of thermal neutron absorption in the aluminum. The MCNP tally counters used in these analyses then sum all three components (direct energy deposition + the decay beta energy + the decay gamma energy) to obtain the total neutron heating rate in the aluminum. The argument for including the direct neutron heating is clear and straightforward. Likewise, including the beta decay energy from the Al-28 is appropriate because the stopping distance for a beta particle of this energy is on the order of only $1.9 \mathrm{~mm}$ in aluminum. The assumption that the decay gamma energy is deposited locally in the aluminum is generally conservative. In reality, much of this energy will be transported (via gamma ray transport) and deposited in nearby materials. For a single aluminum component in a vacuum, depositing this energy locally in the aluminum would certainly be a very conservative assumption; however, when one has a thin aluminum component (such as the 1.5-mm-thick cold source capsule) close to a thicker aluminum component (such as the cold source guide tube or the 3/4-in.-thick HB-4 beam tube), the amount of decay gamma energy actually "deposited" in each aluminum component is not clear. Short of performing a separate decay gamma transport analysis for all of the aluminum components in the system, however, there is no good way to a priori determine exactly where this 
energy will be deposited. This analysis was considered prohibitively complex for the preconceptual analysis, but methods to account for the transport of the decay gammas will be incorporated early in the conceptual design evaluations.

\subsection{BRIGHTNESS, GAIN FACTORS, AND COMPARISONS WITH EXISTING FACILITIES}

Table 3.2 shows the brightness of the 5-cm-thick HFIR cold source in the four energy ranges of interest, as well as the comparable values for the horizontal cold source in the ILL reactor.

Results for HFIR (operating at $100 \mathrm{MW}$ ) are based on MCNP calculations with 2.4 million neutron histories having 116,000 collisions in the cold source. Fractional standard deviations were between 1.5-2.9\% for all four energy ranges. Group-averaged brightness data for the ILL reactor were taken from a log-log plot in Fig. 1 of a paper by Paul Ageron. ${ }^{23}$ These comparisons suggest that the proposed HFIR cold source will be comparable to (or brighter than) the ILL cold source, depending on the energy range of interest.

Although a full validation of the HFIR calculations has not been undertaken yet, some evaluations were performed to determine if they were consistent with existing data. Two questions were addressed: (1) are the calculated thermal neutron fluxes at the cold source location (without cold source in place) consistent with expected values? and (2) are the gains in longer wave neutron fluxes consistent with gains measured at existing hydrogen cold source facilities? The first question addresses the ability of the model to calculate the physics of the reactor core and to transport the neutrons to the cold source location. To answer this question, a comparison was made with previously reported HFIR fluxes. Although comparisons with identical geometry could not be made, the fluxes were roughly comparable and the differences can be explained in general by the geometry differences. The gain factor issue was addressed by comparing the calculated gain factors associated with a HFIR cold source (as shown in

Table 3.2. Neutron brightness comparison between the HFIR cold source and the ILL horizontal cold source

\begin{tabular}{ccccc}
\hline $\begin{array}{c}\text { Wavelength } \\
(\AA)\end{array}$ & $\begin{array}{c}\text { Neutron energy } \\
\text { bounds } \\
(\mathrm{eV})\end{array}$ & $\begin{array}{c}\text { HFIR cold source } \\
\text { brightness } \\
\left(\mathrm{s}^{-1} \cdot \mathrm{cm}^{-2} \cdot \AA^{-1}\right. \\
\left.\text { steradian }^{-1}\right)\end{array}$ & $\begin{array}{c}\text { ILL cold source } \\
\text { brightness } \\
\left(\mathrm{s}^{-1} \cdot \mathrm{cm}^{-2} \cdot \AA^{-1}\right. \\
\left.\cdot \text { steradian }^{-1}\right)\end{array}$ & $\begin{array}{c}\text { Ratio } \\
\text { HFIR/LL }\end{array}$ \\
\hline $0.887-2.86$ & $0.104-0.010$ & $1.69 \times 10^{13}$ & $7.72 \times 10^{12}$ & 2.19 \\
$2.86-5.02$ & $0.010-.00325$ & $7.17 \times 10^{12}$ & $4.05 \times 10^{12}$ & 1.77 \\
$5.02-7.51$ & $0.00325-.00145$ & $1.46 \times 10^{12}$ & $1.39 \times 10^{12}$ & 1.05 \\
$7.51-9.81$ & $0.00145-.00085$ & $5.39 \times 10^{11}$ & $4.00 \times 10^{11}$ & 1.35 \\
\hline
\end{tabular}

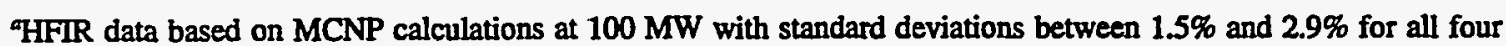
energy ranges.

Average values over energy range as estimated from ref. 23. 
Table 3.3) with gain factors measured at other hydrogen cold source facilities as reported in ref. 23. This comparison is summarized by Fig. 3.2 where the calculated HFIR gain factors are plotted as a function of neutron wavelength along with the maximum and minimum measured values from existing hydrogen cold source facilities. It is interesting to note that the calculated gain factors for the HFIR cold source start at the low end of the range of hydrogen cold sources but finishes at the high end for the $9 \AA$ neutrons. This effect is believed to be a characteristic of the HFIR beryllium reflected system, which is different from any of the other systems used in this evaluation.

\subsection{NOMINAL HEAT LOAD CALCULATIONS}

Accurate determination of the overall heat load associated with the cold source is quite important since this will define the cooling requirements for the cryogenic cooling system. Especially important are the heat loads associated with the liquid hydrogen, the aluminum capsule containing the liquid hydrogen, and the inlet and outlet tubes carrying the liquid to and from the cold source. In addition, one must also consider the intrinsic heat load associated with pumping the liquid hydrogen through the system. This aggregate heat load must all be removed by the cryogenic cooling system. In addition, one also is concerned with the heat loads associated with the cold source guide tube and the HB-4 beam tube because, even though these heat loads will not have to be removed cryogenically, the design must still supply adequate cooling to these components.

As previously stated, one must consider energy deposited by prompt fission gammas from the core, delayed fission gammas from the core, and secondary gammas produced in these and other components, as well as energy deposited directly by neutrons from the core, energy deposited by Al-28 decay gammas, and Al-28 decay betas to estimate the total nuclear heat load on the various components. Nonnuclear intrinsic heat loads such as frictional heating and conventional thermal radiation must also be considered, although the latter can be shown to be negligible. Once these specific heat loads.(watts/gram) were determined using the standard neutronic model, the volumes and masses of the corresponding cells in the design were used to estimate the actual heat loads. Table 3.4 shows the origin and distribution of the nominal cryogenic heat loads (in watts) associated with the cold source at a HFIR operating power of $100 \mathrm{MW}$. As indicated in this table, the preliminary estimate

Table 3.3. Gain factors as calculated for the proposed HFIR liquid hydrogen cold source

\begin{tabular}{ccccc}
\hline $\begin{array}{c}\text { Wavelength } \\
(\AA)\end{array}$ & $\begin{array}{c}\text { Neutron energy } \\
\text { bounds } \\
(\mathrm{eV})\end{array}$ & $\begin{array}{c}\text { HFIR brightness } \\
\text { with } \mathrm{LH}_{2} \text { cold source } \\
\left(\mathrm{s}^{-1} \cdot \mathrm{cm}^{-2} \cdot \AA^{-1}\right. \\
\left.\text { steradian }^{-1}\right)\end{array}$ & $\begin{array}{c}\text { HFIR brightness } \\
\text { without } \mathrm{LH}_{2} \text { cold source } \\
\left(\mathrm{s}^{-1} \cdot \mathrm{cm}^{-2} \cdot \AA^{-1}\right. \\
\text { steradian }\end{array}$ & $\begin{array}{c}\text { Gain } \\
\text { ratio }\end{array}$ \\
\hline $0.887-2.86$ & $0.010-0.104$ & $1.69 \times 10^{13}$ & $3.79 \times 10^{13}$ & 0.45 \\
$2.86-5.02$ & $0.00325-0.010$ & $7.17 \times 10^{12}$ & $1.61 \times 10^{12}$ & 4.45 \\
$5.02-7.51$ & $0.00145-0.00325$ & $1.46 \times 10^{12}$ & $1.16 \times 10^{11}$ & 12.59 \\
$7.51-9.81$ & $0.00085-0.00145$ & $5.39 \times 10^{11}$ & $1.95 \times 10^{10}$ & 27.64 \\
\hline
\end{tabular}




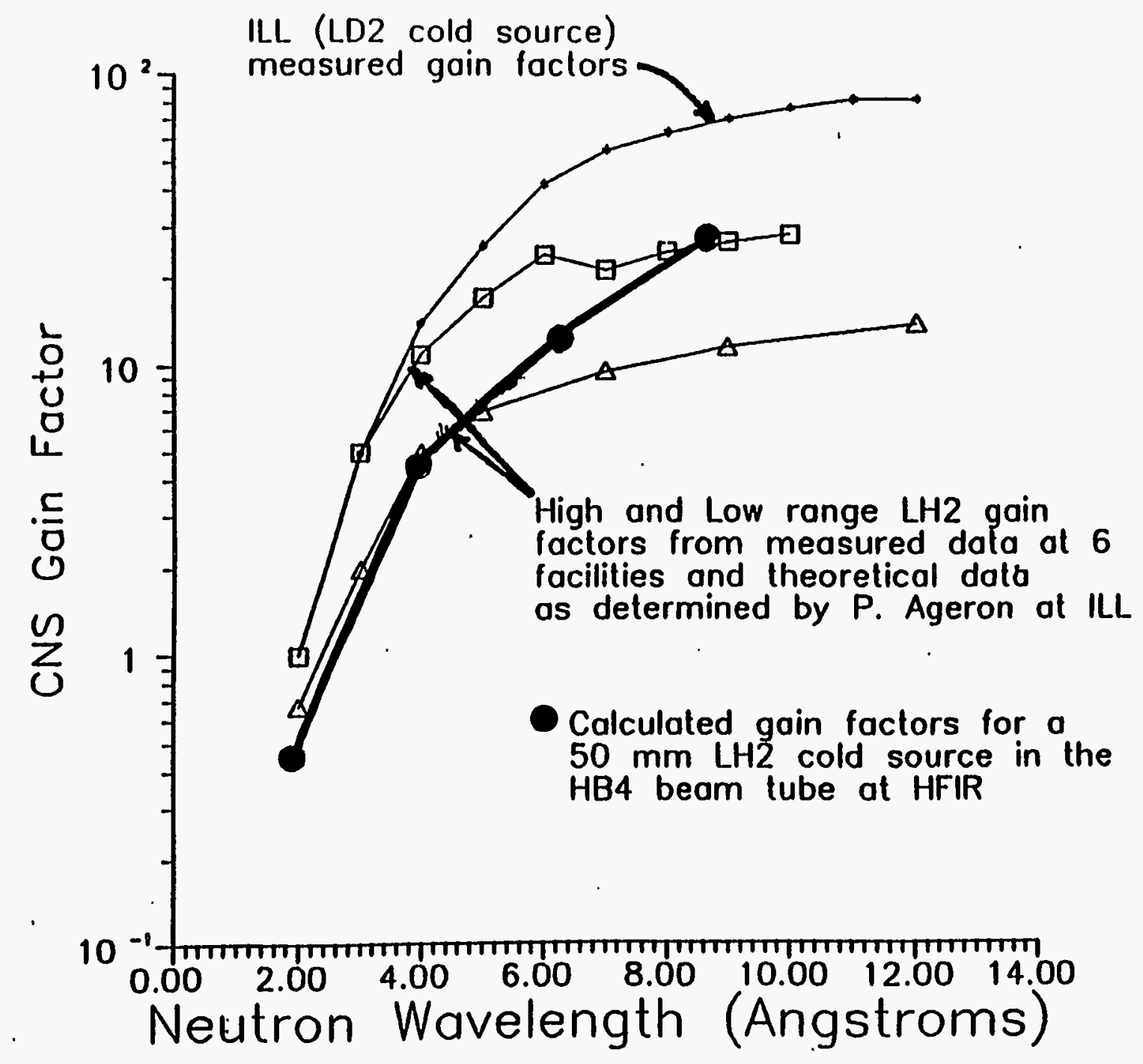

Fig. 3.2. Plot of calculated HFIR cold source gain factors as a function of neutron wavelength, compared to measured and calculated gain factors at other reactor sites. 
Table 3.4. Origin and distribution of the nominal cryogenic heat loads for a HFIR cold source

\begin{tabular}{lcccc}
\hline \multicolumn{1}{c}{$\begin{array}{c}\text { Source of } \\
\text { heating }\end{array}$} & $\begin{array}{c}\text { Liquid } \\
\text { hydrogen } \\
(\mathrm{W})\end{array}$ & $\begin{array}{c}\text { Aluminum } \\
\text { structure } \\
(\mathrm{W})\end{array}$ & $\begin{array}{c}\text { Total } \\
\text { (W) }\end{array}$ & $\begin{array}{c}\text { Percent } \\
\text { of system } \\
\text { total }\end{array}$ \\
\hline Prompt fission gamma & 53.1 & 173.6 & 226.7 & 14.0 \\
Secondary (n, $\gamma$ ) & 69.2 & 243.5 & 312.7 & 19.3 \\
Delayed fission gamma & 22.9 & 83.8 & 106.7 & 6.6 \\
Aluminum decay gamma & 0.0 & 166.3 & 166.3 & 10.2 \\
Aluminum decay beta & 0.0 & 116.1 & 116.1 & 7.1 \\
Direct neutron & 206.1 & 5.1 & 211.1 & 13.0 \\
Nuclear heating of inlet/outlet tubes ${ }^{a}$ & 43.6 & 240.6 & 284.2 & 17.5 \\
\hline \multicolumn{1}{c}{ Total nuclear heating } & 394.9 & 1029.0 & 1423.9 & 87.7 \\
Intrinsic system heating & & & 200.0 & 12.3 \\
\hline \multicolumn{1}{c}{ Total cryogenic heat load } & & & 1623.9 & 100.0 \\
\hline
\end{tabular}

aalue is based on a 0.375 -in. inside diameter (ID) inlet tube and a 0.5 -in. ID outlet tube, both with a 0.039 -in. thick aluminum wall.

of the heat load is approximately $1.6 \mathrm{~kW}$. However, it should be noted that there are several caveats associated with this nominal value.

1. The aluminum decay gammas are presently assumed to deposit their heat at the point where they are created. This is believed to be conservative because most of the gammas will escape and deposit their heat elsewhere. However, aluminum decay gammas created outside of the cold source system may deposit energy in the cold source system, and these have not been accounted for. Efforts are underway to incorporate a means of transporting the aluminum decay gammas as part of the calculation.

2. The present calculations have been performed at a mid-cycle control rod position, but with BOC core compositions. The k-effective is around 1.1 for this geometry and this is believed to introduce a normalization issue. It is believed that the normalization used may result in a 10 to $15 \%$ overprediction of the heat loads. A more detailed cycle analysis is underway that will track appropriate control rod and core compositions over the cycle so that $k$-effective is approximately 1.0 in all instances. This should resolve any normalization issues.

3. The heat load is expected to peak at or near the end of the cycle. Therefore, a heat load rise over the cycle of as much as $15 \%$ is not accounted for. The cycle analysis discussed above will also address this issue.

When these three factors are considered, the nominal heat load value of $1.6 \mathrm{~kW}$ could be high for the specific geometry evaluated, but a more accurate value cannot be obtained at this time. Therefore, 
the $1.6-\mathrm{kW}$ value will be used as the nominal heat load until the early conceptual design heat load analysis is performed. It should be noted, however, that this heat load is based on a particular configuration; and as such items as wall thicknesses and moderator volumes are better defined during the conceptual design phase, the cryogenic heat load is expected to change. A defendable heat load will not be available until after a more detailed mechanical design and cycle analysis has been completed.

The uncertainty to be applied to the nominal heat load calculation is a separate issue. In the past large uncertainty factors ( $40 \%$ and higher) have been applied to the calculated heat loads. It is believed that today the calculational techniques and models are better than this, and, thus, this represents an overly conservative approach that translates to additional costs. Therefore, a heat load measurement will be conducted in HFIR close to the proposed cryostat location and will be used to develop a defendable uncertainty factor. A $40 \%$ uncertainty factor will be used in the short-term until the results of this measurement are available.

\subsection{PARAMETRIC OPTIMIZATION CALCULATIONS}

Several parametric evaluations were performed as part of the preconceptual design effort. Two of these evaluations are particularly important for the development of the design concept and are reported here. The first of these was to examine the optimal thickness of the proposed HFIR liquid hydrogen cold source, assuming it was all $100 \%$ parahydrogen. The second parametric study focused on the evaluation of the impact of the orthohydrogen and parahydrogen mixture on the source brightness.

\subsubsection{Studies to Determine the Optimal $\mathrm{LH}_{2}$ Thickness for the Moderator Section of the HFIR Cold Source}

Initially, a series of one-dimensional (1-D) scoping calculations were performed to estimate the optimal thickness of the $\mathrm{LH}_{2}$ cold source moderator section. In these calculations, an isotropic source of thermal neutrons (at $300 \mathrm{~K}$ ) was assumed to be impingent on an infinite slab of liquid parahydrogen (at $20 \mathrm{~K}$ ) whose thickness was varied between 0.5 and $15 \mathrm{~cm}$ in increments of $0.5 \mathrm{~cm}$. The results of this analysis indicate a very clear but broad optimal thickness at $5.0 \mathrm{~cm}$, as found by others at Julich and elsewhere.

As useful as these results were, there was some question as to how applicable these 1-D slab results might be to the finite HFIR cold source, where the impingent spectrum may be somewhat different. Moreover, the geometry of the HFIR cold source relative to neutrons coming from the core is entirely different. In the HFIR cold source, for example, the diameter of the cold source is restricted by the diameter of the HB-4 beam tube and the cold source thimble. Increasing the thickness of the cold source means increasing the length of the cold source along the centerline of the guide tube, which is more-or-less tangent to the core, so that many of the neutrons coming from the core would enter the cold source from the side rather than on one end. For that reason, a 3-D MCNP optimization

study was undertaken. In this case, the thickness of the $\mathrm{LH}_{2}$ inside the cold source was varied from 3.0 to $10.0 \mathrm{~cm}$ in increments of $1.0 \mathrm{~cm}$ simply by moving the location of the concave aluminum - membrane holding the $\mathrm{LH}_{2}$ inside the guide tube.

Results of this 3-D optimization study are presented in Fig. 3.3. The analysis indicated that by increasing the length of the cold source from 5 to $10 \mathrm{~cm}$, the brightness of the two lowest energy groups could be increased by about $27 \%$. Moreover, if the thickness of the aluminum membrane holding the $\mathrm{LH}_{2}$ in place is reduced from 3.2 to $1.5 \mathrm{~mm}$, and made slightly more concave than assumed in the original neutronics model, the neutron brightness of the $10-\mathrm{cm}$ cold source in the two 


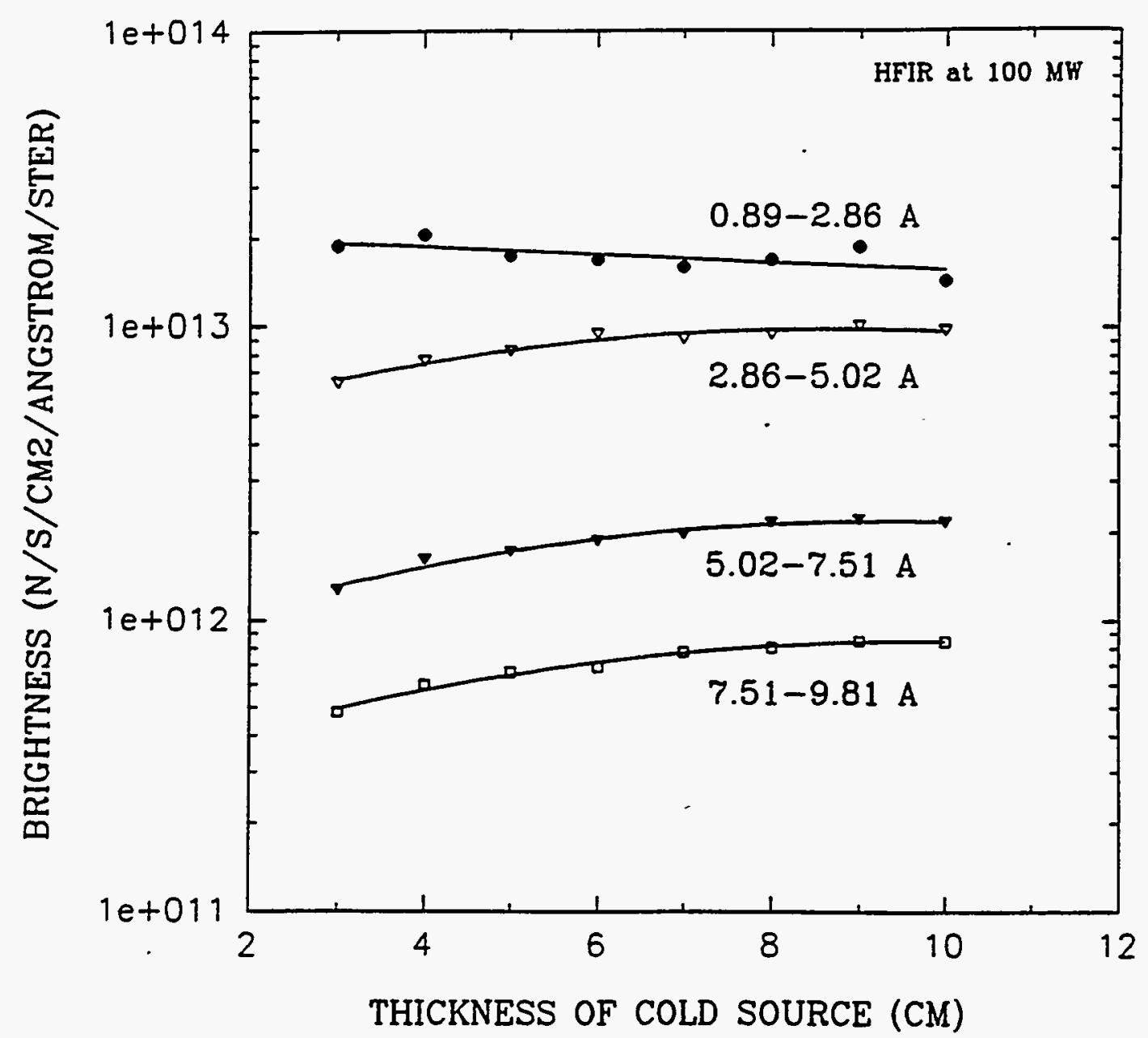

Fig. 3.3. Brightness of the HFIR cold source as a function of its thickness, based on 3-D MCNP analyses.

lowest energy groups would actually be 1.49 to 1.58 times higher than for the base reference case in Table 3.2. Unfortunately, the heat load associated with the additional $\mathrm{LH}_{2}$ and the additional aluminum in the cold source capsule would also be significantly larger.

\subsubsection{The Search for an Optimal Orthohydrogen/Parahydrogen Mixture}

Parahydrogen is a form of hydrogen in which the spin states of all or most of the atoms in the cryogenic liquid hydrogen are aligned in the same direction. For an unperturbed system at rest, this is the natural state for liquid hydrogen at $20 \mathrm{~K}$. Orthohydrogen is a form of hydrogen in which the spin states of the atoms are more-or-less randomly oriented with respect to each other. At $20 \mathrm{~K}$, the presence of intense radiation fields will cause some of the parahydrogen to convert to orthohydrogen. Nevertheless, the amount of each species present can be controlled. Because cold neutrons have longer wavelengths and tend to interact with whole arrays of hydrogen atoms simultaneously as a wavefront, the spin states affect the manner and extent to which energy is exchanged in these interactions. Below $0.01 \mathrm{eV}$, for example, the low-energy scattering cross sections for orthohydrogen at $20 \mathrm{~K}$ are an order of magnitude higher than for parahydrogen at $20 \mathrm{~K}$. This effect is illustrated in Fig. 3.4, which shows 


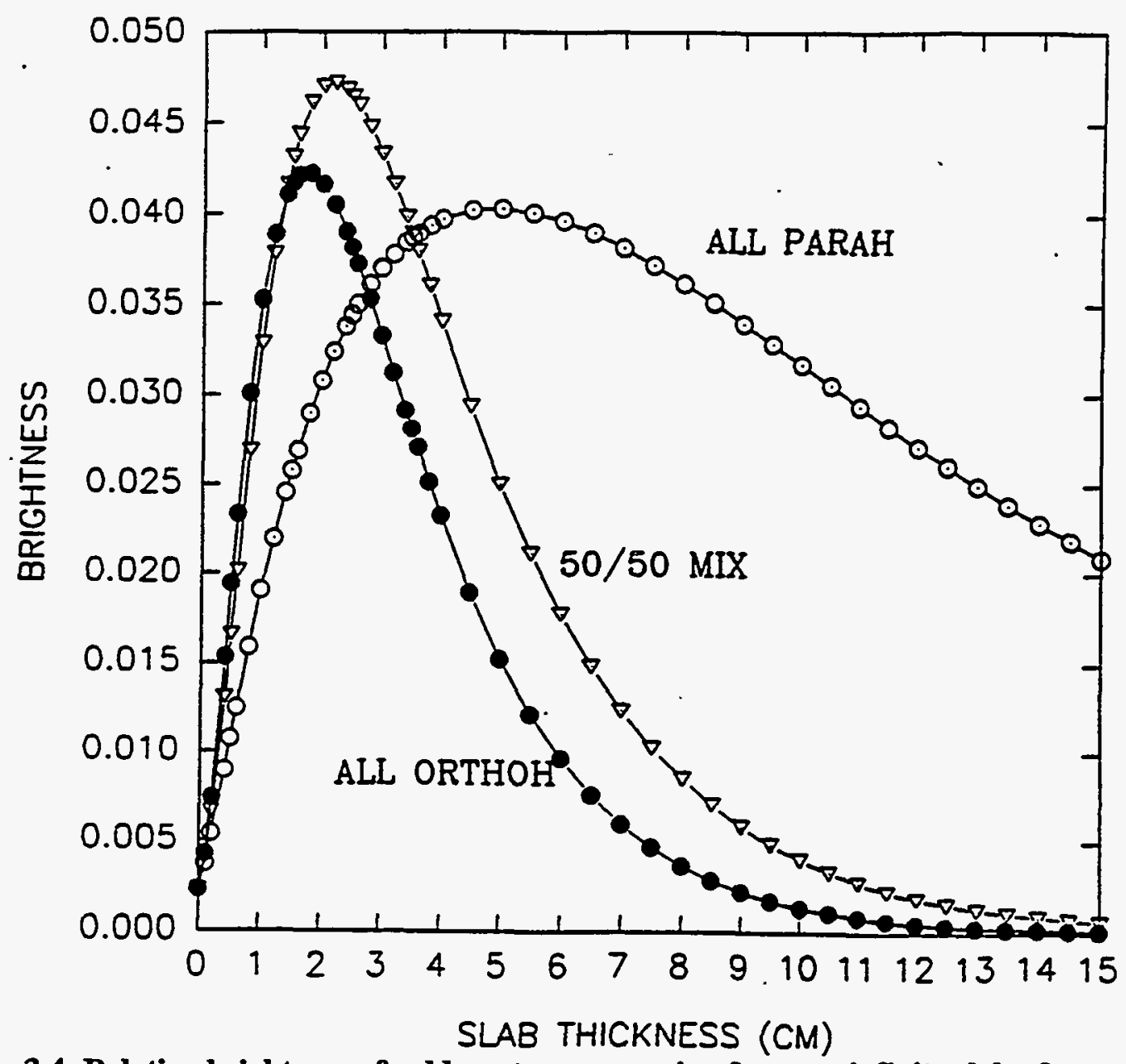

Fig. 3.4. Relative brightness of cold neutrons emerging from an infinite slab of parahydrogen, ortho-hydrogen, or a 50/50 mixture, as the slab thickness is varied from 0 to $15 \mathrm{~cm}$.

the relative brightness of cold neutrons emerging from an infinite slab of orthohydrogen, parahydrogen, and a 50/50 mixture of the two when the isotropic thermal neutron source impingent on the other side of the slab is at $300 \mathrm{~K}$.

Ageron has reported that a 5-cm-thick $\mathrm{LH}_{2}$ cold source comprised of $50 \%$ orthohydrogen and $50 \%$ parahydrogen could increase the brightness of the cold source by 30 to $70 \%$ over what it would be for an all-parahydrogen system based on ILL reflector conditions. ${ }^{23}$ In practice, however, it must be remembered that the potential increase in the gain with some orthohydrogen is dependent on the spectrum of the neutrons entering the cold moderator. With a beryllium reflector, the spectrum is . somewhat different and the potential for increased gain because of the presence of the orthohydrogen is believed to be more limited.

In this study, a number of 3-D MCNP calculations were performed to determine how the brightness of the 5-cm-thick HFIR cold source would be affected by varying the percentage of orthohydrogen. Results for the four energy ranges of interest are shown in Fig. 3.5. Despite relatively poor statistics in some cases, some conclusions may still be drawn: it is clear, for example, that there is some modest increase in the brightness in the primary energy range of interest (5.02 to $9.81 \AA$ ) with 20 to $40 \%$ orthohydrogen in the cold source. Unfortunately, these particular results have larger 


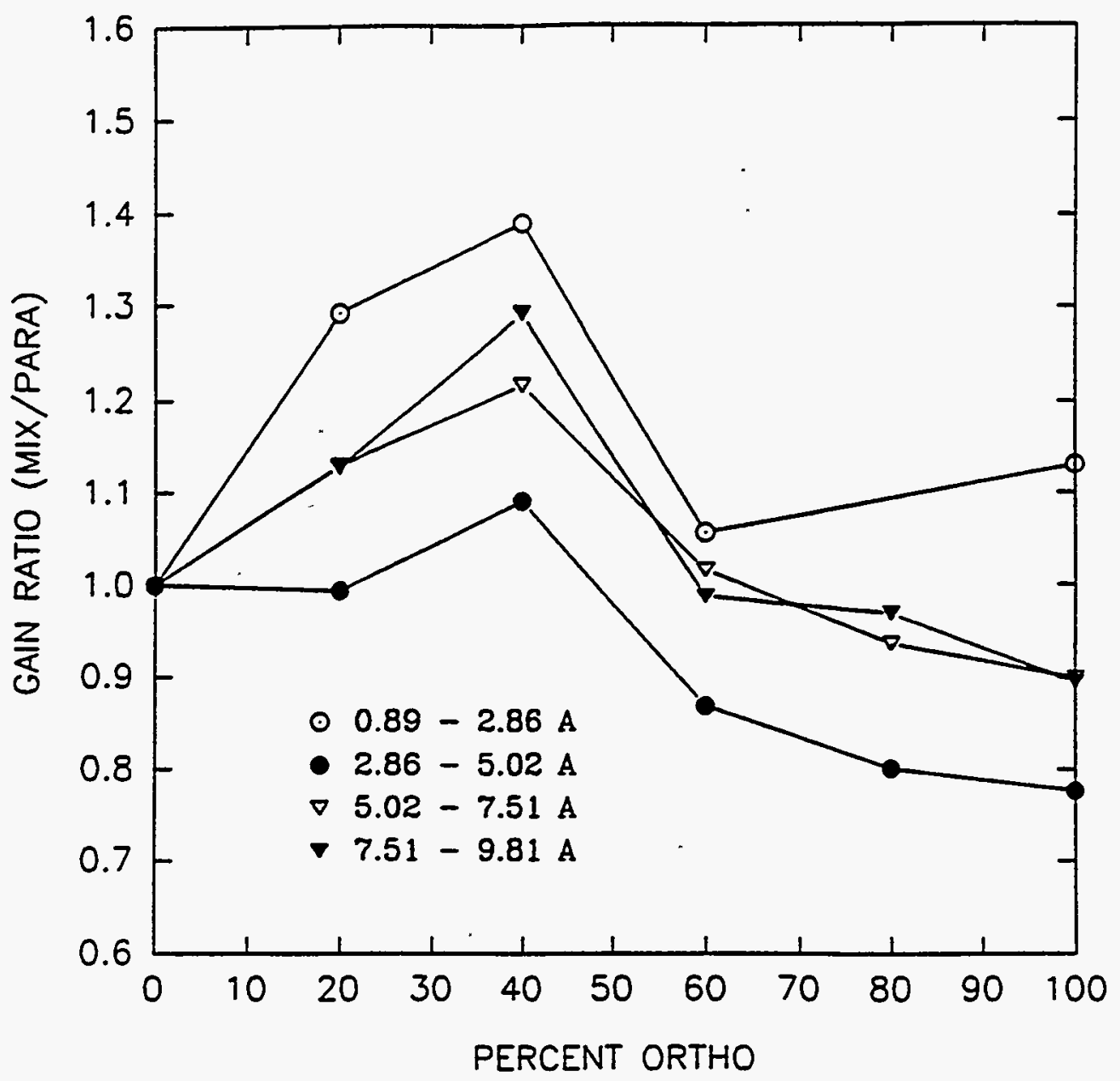

Fig. 3.5. Brightness of the HFIR cold source as a function of the orthohydrogen/ parahydrogen ratio, based on 3-D MCNP analyses. Here, one very questionable data point in the 0.89 to $2.86 \AA$ range for the $80 \%$ orthohydrogen case has been intentionally ignored.

fractional standard deviations of $9 \%$ and $19 \%$, respectively, and, therefore, it would not be prudent to put too much credibility in these particular results. Nevertheless, some modest increase in the brightness is clearly expected in the $40 \%$ orthohydrogen case. Lastly, it is clear that, as the orthohydrogen content is advanced from 60 to 80 to $100 \%$, the brightness of the cold source in the 2.86 to $9.81 \AA$ range is consistently less than in the all-para case. Furthermore, the brightness in this energy range continued to decrease as the orthohydrogen content was increased. For these particular results, all of the statistics were quite good and quite credible.

\subsection{MISCELLANEOUS DESIGN QUESTIONS INVESTIGATED DURING THE PRECONCEPTUAL DESIGN}

In addition to the topics described above, a host of other design-oriented questions, each requiring one or two individual stand-alone calculations, were raised as part of the preconceptual design effort. 
Some of these issues were examined thoroughly, while others were given only cursory attention and may be revisited during the conceptual design phase. Four of these studies are discussed below.

\subsubsection{Effect of the Cold Source (in HB-4) on Experiments that Use HB-1}

Initially, some members of the present HFIR user community had expressed some concern as to whether or not the presence of the cold source in the HB-4 beam tube might cause some undesirable perturbations for the user station located at the end of the HB-1 beam tube. While it is true that the presence of the liquid hydrogen in the cold source will greatly enhance the number of very slow neutrons in and around the HB-4 beam tube, it was noted that very little material is required to stop or absorb such neutrons. Moreover, because of the thermal neutron absorption in the aluminum at the end of the cold source guide tube and at the end of the HB-4 beam tube, and because of the thermal neutron absorption in the two beryllium blocks and the interstitial water between them, it was believed that the presence of the cold source should have very little (if any) effect on flux levels at the end of the HB-1 beam tube. Based on the results shown in Table 3.5, we can now estimate that the fluxes in the lowest energy groups of interest may be (at most) 9 to $13 \%$ higher than they would be if the cold source were not present. Such small changes are of no apparent consequence to the experimenters involved.

Table 3.5 shows the resulting (partial) scalar fluxes $2.5 \mathrm{~m}$ down the HB-1 beam tube, with and without the $\mathrm{LH}_{2}$ present in the cold source. It also shows the percent change in the (partial) scalar flux in the various energy groups because of the presence of the $\mathrm{LH}_{2}$. Note that the "percent change" in scalar flux in the various energy groups is (1) generally quite small in an absolute sense (i.e., usually within 1 to 4\%), and (2) always negligible in the statistical sense (i.e., within 1 to 1.3 standard deviations) and generally positive (i.e., slightly higher with the $\mathrm{LH}_{2}$ present, as one would physically

Table 3.5. Comparison of relative fluxes in $\mathrm{HB}-1$ with and without the $\mathrm{HB}-4 \mathrm{LH}_{2}$ cold source

\begin{tabular}{cccc}
\hline $\begin{array}{c}\text { Energy range } \\
(\mathrm{eV})\end{array}$ & $\begin{array}{c}\text { With } \mathrm{LH}_{2} \\
\text { cold source }\end{array}$ & $\begin{array}{c}\text { Without } \mathrm{LH}_{2} \\
\text { cold source }\end{array}$ & Ratio \\
\hline $1 \times 10^{5}-2 \times 10^{6}$ & $0.050 \pm .002$ & $0.052 \pm .002$ & 0.96 \\
$1 \times 10^{2}-1 \times 10^{5}$ & $0.111 \pm .003$ & $0.107 \pm .003$ & 1.04 \\
$0.625-1 \times 10^{2}$ & $0.099 \pm .003$ & $0.097 \pm .003$ & 1.02 \\
$0.104-0.625$ & $0.115 \pm .003$ & $0.114 \pm .003$ & 1.01 \\
$0.01-0.104$ & $0.597 \pm .010$ & $0.596 \pm .009$ & 1.00 \\
$.00325-.01$ & $0.031 \pm .001$ & $0.029 \pm .001$ & 1.05 \\
$.00145-.00325$ & $0.0034 \pm .0002$ & $0.0034 \pm .0002$ & 0.99 \\
$8.5 \times 10^{-4}-.00145$ & $0.0006 \pm .00007$ & $0.0005 \pm .00006$ & 1.13 \\
$<8.5 \times 10^{-4}$ & $0.00020 \pm .00003$ & $0.00019 \pm .00003$ & 1.09 \\
Total & $1.01 \pm .01$ & $1.00 \pm .01$ & 1.01 \\
\hline
\end{tabular}

aAll fluxes are normalized relative to the total neutron flux in HB-1 without the $\mathrm{HB}-4 \mathrm{LH}_{2}$ cold source. The ratio represents the expected nominal change in the HB-1 neutron flux when the $\mathrm{LH}_{2}$ cold source is added to the system. 
expect). Only in the very low energy range (i.e., the $0.00085 \mathrm{eV}$ to $0.00145 \mathrm{eV}$ energy range

corresponding to 7 to $9 \AA$ ) does one see any noticeable change $\left(+13 \%\right.$ with the $\mathrm{LH}_{2}$ present). Even that, however, is statistically insignificant when one realizes that the fluxes in this particular group, with and without the $\mathrm{LH}_{2}$, both have fractional standard deviations of about $11 \%$.

Based on these findings, the fluxes at the instrumented end of HB-1 will not be significantly affected by the presence or absence of $\mathrm{LH}_{2}$ in the cold source capsule located in $\mathrm{HB}-4$; If anything, the fluxes in HB-1 will be a few percent higher when the $\mathrm{LH}_{2}$ is present.

\subsubsection{Extent of Accelerated Silicon Production in the Through-Tube}

With a much more intense source of very cold neutrons now located in the HB- 4 beam tube, there was some concern over the extent to which this might accelerate silicon production in the aluminum beam tube and the aluminum through-tube. This process of transmuting the structural aluminum into silicon occurs when Al-27 absorbs a thermal neutron, becomes Al-28, and very quickly decays via beta emission to become silicon. With many more neutrons present at very low energies, this transmutation process will become more accelerated, but to what extent? The question is worth investigating, since the through-tube and the through-tube liner are permanent components, and since the HB- 4 beam tube is both a semipermanent component and a pressure boundary.

First, it must be recognized that cold neutrons are readily absorbed and cannot travel very far in most materials. The cold neutron flux levels in the through-tube and the through-tube liner, for example, will be less than in the HB-4 beam tube. The cold neutron flux levels in the HB-4 beam tube, in tum, will be less than at the tip of the cold source guide tube. At most, the cold neutron flux levels in the hemispherical tip of the HB-4 beam tube will be comparable to those in the hemispherical tip of the aluminum cold source guide tube immediately adjacent to the liquid hydrogen in the present neutronic model.

Estimates of the silicon production rate there can be readily and reliably estimated from the Al-28 decay-beta heating rates, which were based on the actual steady-state Al-27 absorption rate and on an average beta-decay energy of $1.2423 \mathrm{MeV}$. Using this approach, it was estimated that $0.7 \%$ of all the aluminum atoms in the cold source capsule (and at the end of the cold source guide tube) will be converted to silicon every "full power year" (assuming HFIR is operating at $100 \mathrm{MW}, 365.25$ full power days per year). The amount of silicon produced in the wall of the HB-4 beam tube close to the cold source guide tube will be less, but not significantly less. This rate of transmutation is believed to be slightly higher than the present transmutation rate and is consistent with increases observed for a similar analysis performed for the ANS reactor cold source. The implication of this increase will need to be examined.

\subsubsection{Heat Load Reductions Afforded by Placing a Bi-209 Gamma Shield in the Reflector}

Subsequent to the nominal heat load calculations reported in Sect. 3.3, it became clear that prompt fission gammas, delayed fission gammas, and other secondary gammas from various components accounted for $39.9 \%$ of the entire cryogenic heat load. The HFIR staff suggested that much of this heat load could perhaps be eliminated if a suitable gamma shield could be found and inserted in place of a removable $66^{\circ}$ segment of the semipermanent beryllium reflector ring facing the cold source. After due consideration, bismuth (Bi-209) was suggested as a potentially good candidate because of its unusually small thermal neutron capture cross section and its high mass, which makes it nearly as good as lead as a gamma shield. Allowing for some cladding material, the bismuth itself could nominally be up to $2.699 \mathrm{~cm}$ thick in the existing model. Unfortunately, as shown in Fig. 3.1, the through-tube partially penetrates the side of the semipermanent reflector in a near tangential fashion 
such that, at the midplane, the proposed bismuth shield would only be about a half-inch thick $(1.272 \mathrm{~cm})$. To determine if this scalloped shadow shield would provide adequate gamma attenuation while simultaneously not impacting the outward flow of neutrons toward the cold source required a separate 3-D MCNP calculation. Surprisingly, the Bi-209 shield was remarkably efficient in both respects.

Because the additional calculations (for the heat load) had to be run in a fixed-source, coupled neutron/photon mode, a surrogate reference case was also run in that mode and compared to the original base reference case, which was a neutron-only k-effective calculation run with many more histories.

Table 3.6 shows the relative neutron brightness in the four energy ranges of interest. Note that, within the limits of the rather small standard deviations ( 3 to $5 \%$ ), the original reference k-calculation and the surrogate fixed-source reference calculation gave virtually identical results, as expected.. More importantly, however, the two fixed-source calculations, with and without the Bi-209 gamma shield, also gave virtually identical results. In the 0.86 to $2.86 \AA$ range, they differed by only $6 \%$ (well within the uncertainty band), while in the primary range of interest ( 2.86 to $9.81 \AA$ ), they only differed by $2 \%$. This clearly indicates that the brightness of the cold source would not be adversely affected by the presence of this particular Bi-209 gamma shield.

To parallel the nominal heat load calculation reported in Sect. 3.3, Table 3.7 shows the origin and distribution of the cryogenic heat loads (in watts) associated with the cold source when HFIR is operating at $100 \mathrm{MW}$ and when a segment of the semipermanent reflector is replaced with the Bi-209 gamma shield described above. Comparisons with the nominal heat loads in Table 3.4 show that, as intended, the cryogenic heat load because of the prompt fission gammas from the core and the delayed fission gammas from the core have been eliminated almost, while the heat load because of secondary gammas has been reduced by a third. Altogether, the total neutron + gamma + beta heat load on the liquid hydrogen and aluminum in the cold source capsule has been reduced from $1139.7 \mathrm{~W}$ to 804.5 W, which represents a $29.4 \%$ reduction. More importantly, the total cryogenic load has been reduced by $25.8 \%$, from $1623.9 \mathrm{~W}$ in the nominal case without the gamma shield, to $1204.7 \mathrm{~W}$ with the Bi-209 gamma shield. The structural design of such a shield, and the ability to cool it, will be examined as part of the conceptual design.

Table 3.6. Impact of bismuth gamma shield on cold neutron beam brightness

\begin{tabular}{|c|c|c|c|}
\hline $\begin{array}{l}\text { Neutron } \\
\text { wavelength } \\
(\AA)\end{array}$ & $\begin{array}{c}\text { Neutron energy } \\
\text { bounds } \\
(\mathrm{eV})\end{array}$ & $\begin{array}{c}\text { Brightness from } \\
\text { fixed-source calculation }^{a} \\
\text { brightness from }^{\text {k-calculation }}{ }^{a}\end{array}$ & $\begin{array}{c}\text { Brightness }^{b} \\
\text { with bi shield } \\
\text { brightness }{ }^{b} \text { without } \\
\text { bi shield }\end{array}$ \\
\hline $0.89-2.86$ & $.104-0.010$ & 1.054 & 1.063 \\
\hline $2.86-5.02$ & $.010-0.00325$ & 1.026 & 0.980 \\
\hline $5.02-7.51$ & $.00325-0.00145$ & 1.014 & 1.001 \\
\hline $7.51-9.81$ & $.00145-0.00085$ & 1.033 & 0.993 \\
\hline
\end{tabular}

"Brightness calculated without bismuth shield.

'Brightness was determined using a fixed source calculation. 
Table 3.7. Impact of bismuth gamma shield on cold neutron heat load

\begin{tabular}{|c|c|c|c|c|}
\hline $\begin{array}{c}\text { Source of } \\
\text { heating }\end{array}$ & $\begin{array}{l}\text { Liquid } \\
\text { hydrogen } \\
\text { (W) }\end{array}$ & $\begin{array}{l}\text { Aluminum } \\
\text { structure } \\
\text { (W) }\end{array}$ & $\begin{array}{c}\text { Total } \\
(W)\end{array}$ & $\begin{array}{c}\text { Percent } \\
\text { of system } \\
\text { total }\end{array}$ \\
\hline Prompt fission gamma & 9.1 & 37.2 & 46.3 & 3.8 \\
\hline Secondary $(n, \gamma)$ & 50.9 & 171.7 & 222.6 & 18.5 \\
\hline Delayed fission gamma & 4.7 & 16.6 & 21.3 & 1.8 \\
\hline Aluminum decay gamma & 0.0 & 148.9 & 148.9 & 12.4 . \\
\hline Aluminum decay beta & 0.0 & 104.0 & 104.0 & 8.6 \\
\hline Direct neutron & 255.8 & 5.6 & 261.4 & 21.7 \\
\hline Nuclear heating of inlet/outlet tubes ${ }^{a}$ & 30.7 & 169.5 & 200.2 & 16.6 \\
\hline Total nuclear heating & 351.2 & 653.5 & 1004.7 & 83.4 \\
\hline Intrinsic system heating & & & 200.0 & 16.6 \\
\hline Total cyogenic heat load & & & 1204.7 & 100.0 \\
\hline
\end{tabular}

${ }^{\sigma}$ Value is based on a 0.375 -in. ID inlet tube and a 0.5 -in. ID outlet tube, both with a 0.039 in.-thick-aluminum wall.

\subsubsection{Impact of Cold Source on the Rest of the Reactor}

The HFIR is a multifunction research reactor that has facilities for isotope production, materials irradiation, and beam experiments. In its current configuration, HFIR has 12 irradiation positions in the removable beryllium (RB) reflector, 8 irradiation positions in the control rod access plugs (CRs), 22 vertical experiment facilities (VXFs) in the permanent reflector, and 4 beam tubes. There are also many irradiation and production positions located in the central hole of the annular fuel element. The proposed cold source represents a change in the configuration of the reflector system, and, therefore, may have an impact on the neutron fluxes at these facilities. Calculations were performed with and without the cold source to determine its impact on the reactor in terms of the neutron fluxes at these experimental facilities as well as on the core reactivity.

The MCNP calculations for the base case (no cold source) and the perturbed case (with cold source) were performed with 5 million neutron histories. The effective multiplication factor for the base case is $1.10235 \pm 0.00049$, and for the perturbed case is $1.10150 \pm 0.00044$. This results in a reactivity worth of the cold source of $-70 \pm 60 \mathrm{pcm}$, which indicates essentially no reactivity impact on the core. In addition to the multiplication factors, the neutron fluxes in the RB and VXF positions were also calculated. The results of the calculations for the nearest large RB position (RB-7A), the nearest small RB position (RB-8), and the nearest VXF position (VXF-22) are given in Tables 3.8, 3.9 , and 3.10, respectively. The results indicate that the changes in the neutron fluxes in these regions are small and are generally within the MCNP calculational statistics. 
Table 3.8. Comparison of RB-7A neutron fluxes with and without $\mathrm{HB}-4 \mathrm{LH}_{2}$ cold source

\begin{tabular}{cccc}
\hline $\begin{array}{c}\text { Energy range } \\
(\mathrm{eV})\end{array}$ & $\begin{array}{c}\text { RB-7A neutron } \\
\text { fluxes without } \\
\mathrm{HB}-4 \text { cold source } \\
\left(\mathrm{s}^{-1}-\mathrm{cm}^{-2}\right)\end{array}$ & $\begin{array}{c}\text { RB-7A neutron } \\
\text { fluxes with } \\
\mathrm{HB}-4 \text { cold source } \\
\left(\mathrm{s}^{-1}-\mathrm{cm}^{-2}\right)\end{array}$ & $\begin{array}{c}\text { Nominal ratio } \\
\text { with/without }\end{array}$ \\
\hline$>1.83 \times 10^{5}$ & $4.85 \pm 0.09 \times 10^{14}$ & $4.78 \pm 0.09 \times 10^{14}$ & 0.99 \\
$101-1.83 \times 10^{5}$ & $6.85 \pm 0.12 \times 10^{14}$ & $6.90 \pm 0.12 \times 10^{14}$ & 1.01 \\
$0.414-101$ & $4.10 \pm 0.07 \times 10^{14}$ & $4.11 \pm 0.07 \times 10^{14}$ & 1.00 \\
$<0.414$ & $1.35 \pm 0.02 \times 10^{15}$ & $1.35 \pm 0.02 \times 10^{15}$ & 1.00 \\
\hline
\end{tabular}

Table 3.9. Comparison of RB-8 neutron fluxes with and without $\mathrm{HB}-4 \mathrm{LH}_{2}$ cold source

\begin{tabular}{cccc}
\hline $\begin{array}{c}\text { Energy range } \\
(\mathrm{eV})\end{array}$ & $\begin{array}{c}\text { RB-8 neutron } \\
\text { fluxes without } \\
\mathrm{HB}-4 \text { cold source } \\
\left(\mathrm{s}^{-1}-\mathrm{cm}^{-2}\right)\end{array}$ & $\begin{array}{c}\text { RB-8 neutron } \\
\text { fluxes with } \\
\mathrm{HB}-4 \text { cold source } \\
\left(\mathrm{s}^{-1}-\mathrm{cm}^{-2}\right)\end{array}$ & $\begin{array}{c}\text { Nominal ratio } \\
\text { with/without }\end{array}$ \\
\hline$>1.83 \times 10^{5}$ & $5.17 \pm 0.21 \times 10^{14}$ & $5.08 \pm 0.21 \times 10^{14}$ & 0.98 \\
$101-1.83 \times 10^{5}$ & $6.20 \pm 0.26 \times 10^{14}$ & $6.04 \pm 0.25 \times 10^{14}$ & 0.97 \\
$0.414-101$ & $4.32 \pm 0.19 \times 10^{14}$ & $4.06 \pm 0.19 \times 10^{14}$ & 0.94 \\
$<0.414$ & $1.11 \pm 0.03 \times 10^{15}$ & $1.11 \pm 0.03 \times 10^{15}$ & 0.99 \\
\hline
\end{tabular}

Table 3.10. Comparison of VXF-22 neutron fluxes with and without $\mathrm{HB}-4 \mathrm{LH}_{2}$ cold source

\begin{tabular}{cccc}
\hline $\begin{array}{c}\text { Energy range } \\
(\mathrm{eV})\end{array}$ & $\begin{array}{c}\text { VXF-22 neutron } \\
\text { fluxes without } \\
\mathrm{HB}-4 \text { cold source } \\
\left(\mathrm{s}^{-1}-\mathrm{cm}^{-2}\right)\end{array}$ & $\begin{array}{c}\text { VXF-22 neutron } \\
\text { fluxes with } \\
\mathrm{HB}-4 \text { cold source } \\
\left(\mathrm{s}^{-1}-\mathrm{cm}^{-2}\right)\end{array}$ & $\begin{array}{c}\text { Nominal ratio } \\
\text { with/without }\end{array}$ \\
\hline$>1.83 \times 10^{5}$ & $4.22 \pm 0.27 \times 10^{13}$ & $4.34 \pm 0.28 \times 10^{13}$ & 1.03 \\
$101-1.83 \times 10^{5}$ & $1.03 \pm 0.05 \times 10^{14}$ & $1.12 \pm 0.05 \times 10^{14}$ & 1.09 \\
$0.414-101$ & $9.92 \pm 0.41 \times 10^{13}$ & $1.11 \pm 0.04 \times 10^{14}$ & 1.12 \\
$<0.414$ & $8.39 \pm 0.15 \times 10^{14}$ & $8.50 \pm 0.15 \times 10^{14}$ & 1.01 \\
\hline
\end{tabular}




\subsection{VALIDATION OF THE PHYSICS CALCULATIONS}

\subsubsection{MCNP Model Review}

On August 22, 1995, a meeting was held with the Research Reactor Division staff to review the HFIR physics model that has been developed for the design analysis of the cold source. Two objectives were identified for this review meeting: (1) to assure that the 3-D model is the best representation of the HFIR system that is practically possible and (2) to identify potential HFIR experiment loadings so that the effect of system perturbations on the cold source can be evaluated.

The following findings were made:

1. The fuel grading used in the model, as taken from ref. 24 , is the correct and the only HFIR grading.

2. The model does not contain the small gaps in the europium sections of the control plates.

3. The beryllium/water volume fractions for the VXF plugs were determined to be a good representation, but it was decided that the water should be treated explicitly as a ring around the beryllium rather than homogenized with the beryllium.

4. It was determined that it was appropriate to have four water-filled VXFs as indicated in the present model, but the water should be replaced with a stainless steel liner filled with water.

5. A more detailed model of VXF-7 is needed.

6. Except as discussed in items 4 and 5, all VXFs should be filled with beryllium plugs for the base model.

7. Iridium, hafnium, graphite/inconel, cobalt-60, and neptunium were identified as potential loadings for VXF perturbation analyses.

8. It was determined that the two hafnium-lined RB experiments (that have been in HFIR for several cycles) should be removed from the base model and be examined as part of the perturbation analysis.

9. The cross-sectional model of the peripheral target positions (PTPs), which are located in the central hole, was questioned. The model will be verified and modified if necessary.

10. Typical loadings in the central hole positions from previous cycles should be considered.

11. The gray region of the control rods should contain the equilibrium concentration of tantalum- 182 .

Many of these findings represent details that do not significantly affect the cold source, but that should be implemented to make the model more useful for general analyses. Furthermore, the findings indicate that the present model is adequate for the preliminary analysis of the cold source design. All of the findings listed above will be addressed in the model used for the conceptual design analysis.

\subsubsection{Flux Comparisons with Experimental Measurements}

To date, no extensive comparisons have been made against experimental measurements, although, as noted in Sect. 3.2, some limited comparisons have been made against previously published (calculated) flux levels in the permanent beryllium reflector. During the conceptual design phase, however, this will be one of the major activities within the physics task. 


\subsubsection{Heat Load Experiment and Benchmark}

One of the primary results of the MCNP analysis was the determination of the neutron and gamma heating rates within the cold source capsule, since these largely determine the cryogenic cooling requirements. The lack of measured heating rates in the HFIR reflector requires the assignment of large uncertainties to the calculated results and leads to a large amount of conservatism in the specifications for the refrigeration equipment. A heat load experiment to be used for benchmarking the MCNP heating calculations has been proposed to provide a better basis for the assignment of the calculational uncertainties.

The proposed experiment involves the placement of melt wire filings in capsules that will be placed in VXF-22 for one cycle. A postirradiation analysis of the capsules will indicate which of the alloys melted during the irradiation and, therefore, will provide data on heat loads deposited. 


\section{PROJECT PLANS}

At present, nine project plans have been identified:

1. accident analysis plan,

2. construction and installation plan,

3. operations plan,

4. procurement plan,

5. quality assurance plan,

6. R\&D testing and evaluation plan,

7. start-up testing plan,

8. configuration management plan, and

9. reliability/available/maintainability (RAM) plan.

Detailed versions of these plans will be developed as part of the conceptual design activities and will be documented in the design concept report. When these plans are completed, they will provide a structured format by which major aspects of the project will be completed. The remainder of this section provides a summary status report of each of these plans.

\subsection{PRELIMINARY HFIR COLD SOURCE ACCIDENT ANALYSIS PLAN}

The accident analysis plan for the HFIR cold neutron source facility involves using PRA methods to identify accident scenarios and then performing detailed analyses for bounding accident sequences in appropriate frequency groups for each category. First, a failure modes and effects analysis and screening will be performed to develop the scenarios. Then, frequency estimates will be prepared for the various accident sequences. For each category of events, a bounding moderate, infrequent, and limiting frequency event will be chosen for mechanistic analysis. The PRA work that has been performed for the ANS reactor cold source ${ }^{25}$ will be a starting point for the HFIR PRA analysis, because the HFIR cold source is patterned after the ANS design.

Because the liquid hydrogen loop relies on active components for liquid hydrogen flow, for heat removal to the refrigeration system, and for steady-state pressure control, a systems analysis model will be prepared to facilitate transient analysis of scenarios involving failure or malfunction of the various active components. Based on a review of the cold source literature and on ref. 25 , the following is a preliminary list of initiating events for which detailed accident analyses will be required:

1. loss of adequate ability to remove heat from the moderator vessel walls,

2. loss of liquid hydrogen flow,

3. loss of helium refrigeration,

4. loss of vacuum,

5. loss of adequate pressure,

6. loss of tertiary containment,

7. hydrogen leaks/transfer line breaks,

8. loss of off-site power,

9. control system failure, and

10. gas transport/handling event. 
Although not part of the accident analysis, a number of design support analyses will be necessary to establish the final design. These analyses will form part of the overall safety analysis, and it is expected that they will be performed in part by safety analysis personnel. Some examples of the types of analyses included in this category are listed below:

1. heat removal from the thimble under steady-state conditions,

2. stress analysis of thimble components,

3. analysis of liquid hydrogen vaporization and flow into the expansion vessel, and

4. heat transfer analysis of gas/liquid interface vessel.

A very aggressive schedule is proposed for the design, approval, fabrication, testing, and installation of the HFIR cold source. Installation is planned for the fall of 1997 when HFIR enters a detailed in-service inspection outage. Toward that end, the schedule currently calls for production of an accident analysis report to be finished in November 1996. To produce this major deliverable, preparation of a cold source system model and the PRA work must begin as soon as possible.

The accident analysis report and a functional description of the cold source will be the key references for a Design Change Memorandum and an associated Unreviewed Safety Question Determination,-which will form the regulatory basis for approval for installation of the cold source into HFIR. To prepare these documents, the accident analysis methodology will need to be established and documented early. The planned milestone for issuance of an accident analysis methodology report is April 1996. In addition, a model description/validation report should be issued as soon as possible and is currently planned for July 1996.

\subsection{PRELIMINARY CONSTRUCTION AND INSTALLATION PLAN}

The end result of this project will be to have a cold source installed and operational in HFIR's HB-4 beam tube by the end of the first quarter of FY 1998. Installation of the cold source cryostat will be scheduled to correspond with the upcoming 10-year in-service inspection (ISI). The ISI is required to be completed prior to the end of calendar year 1997. It is currently projected to begin in September 1997 at the end of cycle 358 and is projected to last approximately 6 weeks. The construction and installation plan will be consistent with the proposed cryostat installation date.

An initial construction and installation plan will be issued as part of the project's design concept report scheduled for April 1996. This initial plan will be used to establish FY 1997 budget requirements. The detailed construction and installation plan will provide the guidelines and procedures by which all construction and installation activities will be performed. This document will be finalized after the final design description report, with estimated completion on or before December 1996. The philosophy of the plan will be to integrate and coordinate all construction and installation activities associated with the HFIR cold source. Emphasis will be placed on minimizing the effect of cold source installation activities on HFIR availability.

\subsection{PRELIMINARY OPERATIONS PLAN}

The cold source is expected to be operated $24 \mathrm{~h}$ a day during reactor operation to provide cold neutrons for experimentalists. As currently envisioned, the proposed cold source operational support organization will consist of up to four full-time employees (FTEs): a cold source manager, a cold source supervisor, and two technicians. Because of the special and unique operations the cold source 
will undergo, it will be more effective to have a dedicated crew who are experienced in the intricacies of the machine versus a 20-man crew of reactor operators who will be removed, by necessity, from daily contact with it. The Cold Neutron Facility at Brookhaven National Laboratory has this arrangement and has found it to work very satisfactorily. The proposed organizational structure will continue to evolve as additional information is obtained from other cold-source-operating organizations and unique operational requirements associated with the HFIR cold source design are finalized. All maintenance is expected to be performed by plant and equipment (P\&E) craftsmen. Procedures and maintenance work packages will be written and approved using the existing $R R D$ procedure approval process and work control process, respectively.

Daily rounds for the cold source will be performed by one of the technicians during normal working hours. This role may be filled by a reactor operator during weekends and holidays to minimize overtime costs. Rounds should require approximately $45 \mathrm{~min}$ to complete. The reactor operators will be trained to recognize problems and to perform very simple proceduralized adjustments. Problems beyond the scope of their training will require the call-in of a dedicated cold source technician or supervisor. A call-in person will be available within $2 \mathrm{~h}$ of notification.

A detailed operations plan, along with the basic outline of a training program, will be developed during the conceptual design phase and will be documented as part of the design concept report. As part of this conceptual design activity, a human factors evaluation will be performed to provide timely input to the cold source design. Operations and maintenance activities will be analyzed to match personnel to their environment safely and effectively in terms of machine/computer control and communication, accessibility, work space, lighting, atmosphere, and noise.

\subsection{PRELIMINARY PROCUREMENT PLAN}

Procurement of items and fabrication services from sources outside of ORNL will be processed utilizing the RRD procedure RRAP 1.9, Procurement of Items and Services. ${ }^{13}$ A graded approach will be used to evaluate all purchased items. All items determined to be nuclear-related will either be procured though NQA-1 qualified vendors or through the dedication process. Dedication is a process whereby design engineering determines the critical characteristics for each item, and methods are established to verify that the procured item meets these characteristics. These dedication methods include activities such as reviews of supplier performance history, commercial-grade supplier surveys, source inspection, and special tests and inspections.

Nonnuclear safety-related items will be evaluated against the requirements of ORNL Standard Practice Procedure X-GP-16, Procurement of Critical Applications/Safety Class Items and Services at $O R N L .{ }^{26}$ Critical applications and safety-class items include commercial safety-class hardware; personnel safety items; and items with critical environmental, safety, and health applications. The procurement specification for these items requires additional reviews by appropriate groups such as health physics, industrial safety, engineering, and quality assurance. This additional review assures that proper inspection and testing will be specified in the procurement and receiving process. Dedication methods as described above will be used on critical items where appropriate.

Procurement records, including purchase specifications, dedication packages, vendor surveys, and test and inspection reports, will be stored.at $\mathrm{RRD}$ as quality records.

Items fabricated inside LMES will be processed through RRD procedure RRAP 3.3.1, Fabrication Control Governing Modifications to Reactor Systems and/or Replacement Hardware. ${ }^{14}$ This procedure provides for collection, review, and audit of all required fabrication records such as dimensional reports, weld reports, material test reports, cleaning reports, and nonconformances before 
the item can be put into reactor service. This collection of information is kept in the RRD document control center as official quality records and serves as the as-built documentation for fabricated parts.

\subsection{QUALITY ASSURANCE PLAN}

QA encompasses all those planned and systematic actions and controls necessary to provide adequate confidence that a structure, system, or component will perform satisfactorily in service. The HFIR cold source QA program will provide this function by being responsive to applicable DOE Orders, ORNL Standard Practice Procedures, RRD Quality Assurance Procedures, and RRD Administrative Policies and Procedures. All quality-related project activities shall be evaluated against these requirements to determine those procedures/processes that shall be implemented for project activities.

Control mechanisms shall be established to ensure that:

1. design inputs are correctly translated into design documents in a timely manner;

2. organizational and physical interfaces are identified and controlled;

3. changes to the design and/or procurement activities are controlled in a manner commensurate with the original requirements; and

4. documentation and records of the design, design verification process, procurement process, and construction activities are maintained in accordance with the QA program established for the project.

The QA function also provides quality control, which includes actions needed to ensure that the physical characteristics of a material, structure, component, or system meet predetermined

requirements. The HFIR cold source QA program shall include quality control functions to assure that:

1. the design satisfies functional requirements as determined by the customer/user;

2. the prepared drawings and construction specifications adequately incorporate QA requirements, design requirements, and applicable codes, standards, and rules and are available in a timely manner;

3. construction can be performed in accordance with the approved design, and any changes made during the construction phase shall be documented and approved;

4. tests, reviews, or inspections to confirm the adequacy of the design and quality of the construction and manufactured components are performed where deemed necessary by the project team and responsible designers; and

5. a quality status tagging system is provided for turnover acceptance, maintenance, and system outages related to project activities.

As part of the QA program, the design shall be closely coordinated and functionally analyzed to avoid conflicts that could result in costly changes during the construction phase of the project. Prior to initiating detailed design, QA requirements for that phase of the project shall be established and the means by which they will be implemented shall be defined. Essentially, QA evaluations will be performed prior to each major phase of the project (i.e., conceptual, design, and construction phases) to determine what QA requirements shall be implemented. The evaluation will take into consideration the following:

1. the project phase; 
2. the functional requirements of the facility;

3. the range of operating conditions and the associated risks;

4. the required degree of reliability;

5. the proposed life span of the facility/equipment; and

6. how it can be maintained, repaired, and/or replaced.

Deviations from specified standards shall be identified and procedures established to ensure their control.

To the extent practical, particularly in the case of innovative design, the design should be independently reviewed by competent consultants in construction or manufacturing techniques to confirm the practicality of construction or manufacture. Provisions shall also be made for review and checking of design calculations, drawings, and construction specifications by qualified personnel other than those responsible for the original design. Whenever possible, the design shall reflect experience gained on similar types of construction.

A QA requirements document shall be prepared for the conceptual design phase of the project. Separate QA plans shall be prepared for the design and construction activities.

\subsection{PRELIMINARY R\&D TESTING AND EVALUATION PLAN}

The R\&D testing for the HFIR cold source will be performed in three phases: separate effects tests, integral system tests, and prototype tests. The first phase will provide important information to the conceptual design team. The second phase will provide performance testing of the conceptual design. The final phase will provide testing of the as-built system prior to installation in the HFIR beam tube. A more detailed discussion of each phase is provided below.

\subsubsection{Phase 1 Testing}

Three critical items will be tested as part of this testing phase. These tests will be performed during the first year of the project so that test data can be factored into the conceptual and early detailed-design phases of the project.

\subsubsection{Circulator (Pump) Tests}

The proposed HFIR cold source system is totally dependent on the liquid hydrogen circulator during operation. A test program, during which a circulator will be operated in a liquid nitrogen loop (flowing at the same mass flow rate), will provide data such as normal winding temperatures, motor current, and vibration levels. Pump reliability tests will also be performed with the intention of characterizing any performance degradation with time. If the pump fails during the test period, test data will be evaluated for early indications of failure that could be used to determine conditions under which circulators should be switched.

\subsubsection{Moderator Plug Flow Tests}

A thorough understanding of the flow patterns of liquid hydrogen through the moderator plug, especially the cold source:moderator vessel at the end, is essential in order to maintain adequate heat transfer coefficients between the liquid hydrogen and the vessel walls. If velocity is not maintained, or if local boiling occurs, the vessel could overheat. Computer modeling will provide the main study, but 
as a precursor to this, a study using water will be used as an aid to providing suitable flow baffling. A temperature-sensitive crystal film may be used to indicate hot spots. Data from these tests will be used to benchmark the analytical model.

\subsubsection{Heat Load Measurements}

One of the most important parameters is the quantity of nuclear-deposited heat that must be removed at cryogenic temperatures. This parameter will be used to set the capacity requirements for the refrigeration system, to perform the steady-state thermal-hydraulics analysis, and to set initial conditions for transient analysis. The cryogenic heat load includes the heat deposited directly in the $\mathrm{LH}_{2}$ as well as the heat deposited in the structural components that ends up being removed by the $\mathrm{LH}_{2}$ system. The actual heat loads will be calculated using state-of-the-art techniques, but the uncertainty in this calculation is unknown. Independent heat load measurements will be performed in HFIR at a location very close to the proposed cold source location (see Sect. 3.6.3). These measured values will then be compared with calculated values for the test geometry and will be used to establish uncertainty bounds.

\subsubsection{Phase 2 Testing}

Testing will be carried out in a vacuum chamber using a realistic system loop to examine operational characteristics during normal and fault conditions. A realistic heat load will be provided to the vessel, and the liquid hydrogen will be circulated at the design speed. As part of the exercise, the heat load will be removed to confirm the ability of the system to respond accordingly. The ability to fill the system with liquid will also be examined as completely as possible within the limited geometric constraints of the test configuration. Reactor scrams as well as other anticipated transients or off-normal conditions will be simulated during this test phase. These tests are expected to be performed at the Amold Engineering Design Center* using their large vacuum chambers.

\subsubsection{Phase 3 Testing}

Before final installation of the plug, a complete system test run will be carried out in the reactor building in as realistic a configuration as possible. This test plan differs from the previous two in that its purpose is purely one of validation. However, it will also serve to check out instrumentation and will offer a final opportunity to change measurement points if necessary.

\subsection{PRELIMINARY START-UP TESTING PLAN}

The installed cold source system will be started initially before the reactor is operational to confirm its functionality. The reactor will then be started and the power increased gradually as the cold source parameters are observed. The reactor might be scrammed at this point, possibly from full power, to check the response of the cold source control systems. The full scope of initial operation of the reactor with the cold source installed has not been evaluated yet. A detailed start-up testing plan

\footnotetext{
Anold Air Force Base, Tullahoma, Tennessee.
} 
will be developed, documented, and approved by RRD prior to the installation of the cold source facility.

\subsection{PRELIMINARY HFIR COLD SOURCE CONFIGURATION MANAGEMENT PLAN}

Configuration management is a management process that identifies the system baseline functional and physical characteristics of an operating system throughout its life cycle. In addition, it controls changes to those baselines, reports change implementation status, and maintains records. Configuration management maintains the integrity and continuity of the technical, schedule, and cost baselines as trade-off decisions are made with respect to proposed changes.

Configuration control will begin following the issuance of the preconceptual design study report. The preconceptual design as presented in this report will serve as an initial baseline. During the conceptual design phase, the principal method of recording and communicating changes shall be through biweekly cold source meetings. Task leaders or designated representatives will be required to attend these meetings and to provide impact evaluations of any proposed design changes in their task area. The project manager shall issue the minutes of the meetings, and a copy is to be kept in the project working file. An electronic copy of the minutes is to be kept on the FEDC server. Task leaders have the responsibility to ensure that the minutes covering their areas of responsibility are correct and include accurate descriptions of any significant design changes.

Following the issuance of the design concept report, detailed design, construction, and installation configuration management shall be in accordance with the requirements of RRAP-3.2, Configuration Control of Plant Design Modifications. ${ }^{12}$ The conceptual design and associated plans, the estimated costs, and the schedule will serve as the baseline.

\subsection{PRELIMINARY RELIABILITY, AVAILABILITY, AND MAINTAINABILITY PLAN}

This section describes the RAM analysis activities initially planned for the HFIR cold source project. The objective of this analysis is to ensure that the cold source meets its availability design requirements. This objective will be achieved through evaluations of potential equipment systems failures (reliability) and the time it takes to return to normal operation (maintainability).

\subsubsection{Goals and Requirements}

The basic goals are to have the maximum availability of the cold source for neutron scattering experiments and to minimize the impact of any cold source system problems on other reactor operations. Specific goals and requirements are given in Sect. 1.2, Project Goals and Requirements, of this report.

\subsubsection{Planned Activities}

The RAM analysis has been divided into four phases (preconceptual, conceptual, detailed design, and installation and operation) covering the duration of the project. A description of the planned RAM activities for each of the four phases is provided below. 


\subsubsection{Preconceptual}

This phase of the RAM work has been completed. It consisted of identification of components or systems with unknown or possibly low reliability. A test program will be developed in the next phase to obtain required reliability data as deemed necessary. An additional activity of this phase was the development of design concepts that allow, whenever possible, maintenance to be performed on key components without requiring a system shutdown. This is expected to have a major impact on system availability and maintainability.

\subsubsection{Conceptual Phase}

A key activity during this phase will be the initiation of testing of key components and the development and documentation of a reliability data base. Possible failure modes for critical items will be identified, and, where possible, designs will be modified as necessary to minimize the probability of failure. In addition, maintenance requirements will be identified and general approaches to maintenance will be developed during this phase.

\subsubsection{Detailed-Design Phase}

Testing will be completed during this phase, and the test data will be a major factor in establishing availability predictions for the cold source systems. Design reviews held during this phase shall include evaluation of RAM issues.

\subsubsection{Installation and Operation Phase}

A preventive/reliability-centered maintenance program for cold source equipment will be developed and implemented prior to initial operation. 


\section{ASSESSMENTS}

Two assessments were performed during the preconceptual design study period: a project risk management assessment and an assessment of the comparison of the preconceptual HFIR cold source with other existing liquid hydrogen facilities. The intention of both of these assessments is to define the technical risks associated with the project.

\subsection{HFIR COLD SOURCE RISK MANAGEMENT ASSESSMENT}

This document provides a plan for performing risk assessments for the HFIR cold source project and for formulating management activities to control project risks. Risk can be defined as the potential for an occurrence that would be detrimental to the program or project. Risk is a measure of the likelihood of the occurrence combined with its level of consequence. Risk management involves . (1) identifying potential failures, (2) determining their probable or potential causes and likely consequences, (3) determining activities that would reduce the resulting risk, and (4) executing a plan to accomplish these risk-reducing activities.

\subsubsection{Risk Management Assessment Objective}

The objective of this plan is to define (1) the work that will be performed to assess and control project risk, (2) how this management function will be performed, (3) what responsibilities are assigned to various project staff, and (4) when various activities will occur. It is important to note that this effort is focused on project-oriented risks rather than safety risk. A PRA will be performed as part of the safety analysis under WBS 1.3.4 and is not part of this risk management assessment.

\subsubsection{Risk Management Activities}

The project risk management assessment has been initiated as part of the preconceptual project phase, but the full risk management assessment will not be completed until the end of the conceptual design phase. However, the functions to be performed by all phases of the project, including installation and operation phases, will be addressed by the assessment, along with project management functions for cost and schedule control.

The Central Engineering EP-E-09 forms employed in the Advanced Neutron Source Project risk management assessment have been used to form the structure for the HFIR cold source risk management assessment. These forms, shown in Figs. 5.1-5.3, were chosen because they were successfully implemented in the ANS Project and because several of the HFIR cold source project staff are already familiar with their use. All assessments that have been completed and all assessments that will be produced additionally during the conceptual design phase will be performed within the WBS structure. Within each assessment, potential project-oriented problems or failures are identified along with their perceived potential causes. The risk associated with each problem or failure identified is then evaluated and determined to be acceptable or unacceptable. When a risk is considered acceptable, the rationale for the decision is documented. When a risk is deemed unacceptable, actions are identified to mitigate the risk or at least greatly reduce the probability to the extent that the risk would be considered acceptable. Actions to address unacceptable risks are documented, and they then become part of the planning base for the particular WBS. 
RISK MANAGEMENT ASSESSMENT/PLAN

PROJECT TITLE

DATE OF THIS ASSESSMENT

PAGE 1 OF -

MO_DAY_YR -

WBSSSYSTEM NUMBER

RESPONSIBLE PERSON

WBSSYSTEM TITLE

ELEMENT DESCRIPTION

SIGNATURE

POTENTIAL PROBLEM OR FAIIURE MODE

EFFECTS (MARK AN "X" FOR ALL EFFECTS OF FAILURE

\begin{tabular}{|l|l|l|l|}
\hline \multicolumn{1}{|c|}{ EFFECT } & KNOWN & PROBABLE & NO EFFECT \\
\hline & & & \\
\hline SAFETY & & & \\
\hline ENVIRONMENTAL INSULT & & & \\
\hline COST IMPACT & & & \\
\hline FUNCTIONAL PERFORMANCE & & & \\
\hline PROJECT SCHEDULE & & & \\
\hline OPERATIONAL IMPACT & & & \\
\hline
\end{tabular}

RANKING OF CONSEQUENCE OF PROBLEM OR FAILURE: SIGNIFICANT() OR INSIGNIFICANT()

Fig. 5.1. Risk management assessment plan. 


\section{TABLE OF POSSIBLE CAUSES}

\begin{tabular}{|c|c|l|l|}
\hline \multicolumn{2}{|c|}{ POSSIBLE CAUSES } & $\begin{array}{l}\text { PROBABIIITY } \\
\text { Low (L) } \\
\text { Unknown (U) } \\
\text { High (H) }\end{array}$ & $\begin{array}{l}\text { RISK } \\
\text { Acceptable (A) } \\
\text { Unacceptable (U) }\end{array}$ \\
\hline & DESCRIPTION & & \\
\hline & & & \\
\hline & & & \\
\hline & & & \\
\hline & & & \\
\hline & & & \\
\hline & & & \\
\hline & & & \\
\hline & & & \\
\hline & & & \\
\hline & & & \\
\hline
\end{tabular}

Fig. 5.2. Table of possible causes. 
ACTION (A) AND RATIONALE (R) TABLE

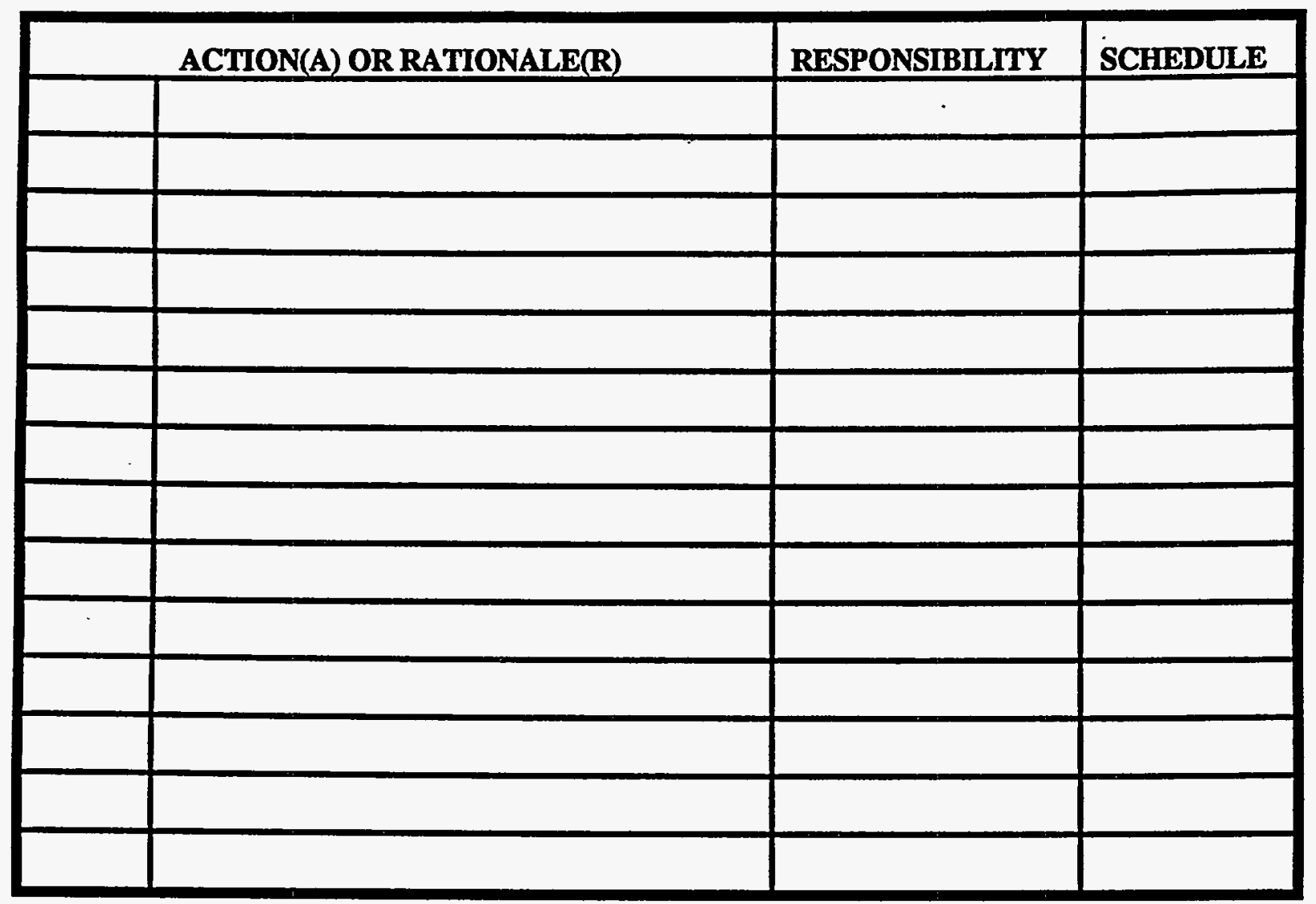

Fig. 5.3. Action and rationale table. 


\subsubsection{Risk Management Responsibilities}

Although the project risk management ašsessment will be integrated under the systems engineering activity (WBS 1.1.1), the WBS level-two task leaders will be accountable for making sure that appropriate assessments are performed for their areas of responsibility. Team members participating in the assessments will include the project manager, the lead designers, the quality assurance specialist, and others as required. All project staff members are required to review the risk assessments when made available and to report risks that are not covered by the assessments.

\subsubsection{Risk Management Status}

A set of initial assessments have been performed as part of the preconceptual design activities and are provided in Appendix B of this report. An electronic data base form of these assessments has been produced and will be maintained on the local FEDC server. Action items that have been identified are being implemented into task plans. If new issues are identified during the design, they are to be added to the data base with the approval of the responsible level-two task leader and the project manager. As new action items are identified, they will be tracked and reported at the regular cold source task leader meetings.

\subsection{ASSESSMENT OF CONSISTENCY WITH EXISTING LIQUD HYDROGEN COLD SOURCES}

In the early stages of the preconceptual design, it was important to evaluate the consistency of the HFIR cold source analysis with those observed at other liquid hydrogen cold sources. Comparisons were made in three areas: physics, geometry, and safety philosophy. The main findings from each comparison are provided below:

\subsubsection{Physics}

As stated in Sect. 3.2, the calculated gain factors for the HFIR cold source were compared with those reported for other liquid hydrogen facilities. Comparisons were made with RISO (Denmark), Julich (Germany), Orphee (France), and HFBR. The results of these comparisons indicated that physics calculations were, in general, consistent.

\subsubsection{Geometry}

The 50-mm liquid hydrogen thickness (in the axis of the cold neutron beam) chosen for the HFIR cold source is also consistent with other facilities (RISO - $70 \mathrm{~mm}$, Julich - $55 \mathrm{~mm}$, Orphee - $50 \mathrm{~mm}$, and HFBR - $71 \mathrm{~mm}$ ).

\subsubsection{Safety Philosophy}

In general, although accomplished in different manners, the basic safety philosophy for all facilities examined is to avoid conditions in which hydrogen and oxygen can come into contact.

These comparisons have provided some assurance that the approaches taken in the preconceptual design of the HFIR cold source are reasonable and are of low risk. There is certainly enough confidence in the proposed design approach to proceed with a concept design at a more detailed level. 



\section{PRELIMINARY PROJECT SCHEDULE}

A preliminary project schedule has been developed as presented in Fig. 6.1. This schedule is considered aggressive, but it is consistent with two major assumptions considered in the development of the schedule:

1. Costs will be minimized if the project is completed in the shortest possible time frame, and

2. The impact on existing user programs will be minimized if the in-reactor portion of the cold source system can be installed during the planned HFIR ISI (scheduled to be initiated in September 1997).

A number of factors will affect the ability to meet this schedule: the timing of the funding, the number of problems encountered in the testing program, the efficiency of the procurement activities, and the quality and timing of the review process. Special emphasis will be made in the planning of these activities during the conceptual design phase to minimize the risk in the schedule. 


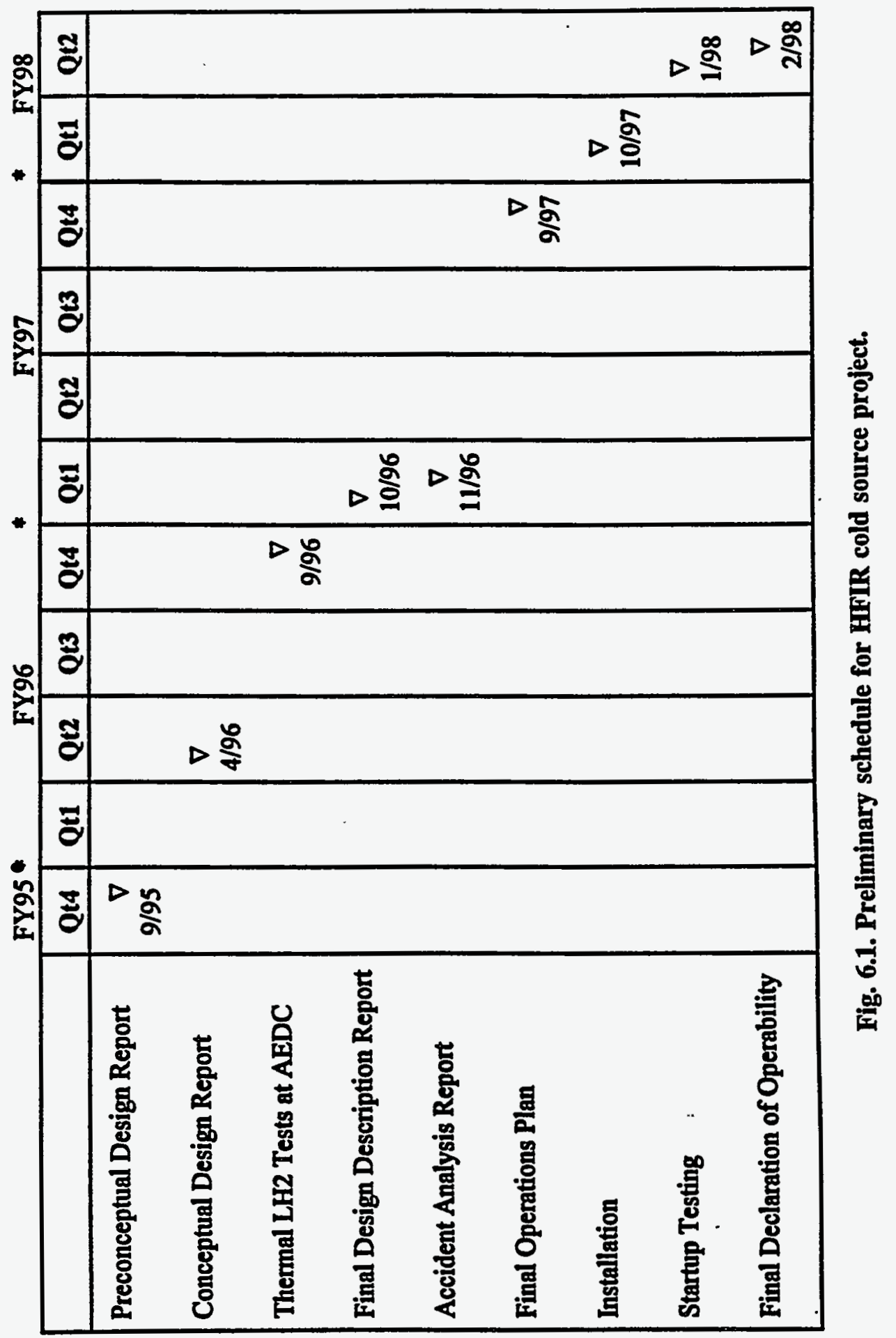




\section{PRELIMINARY PROJECT COST ESTIMATE}

A summary preliminary cost estimate by WBS is presented in Table 7.1. A more detailed breakdown of the costs is presented in Table 7.2, and a summary of the costs by discipline is presented in Table 7.3. The additional cost of the project, beyond existing or expected operating funds, is estimated to be approximately $\$ 2.5 \mathrm{M}$ for FY 1996 and $\$ 2.5 \mathrm{M}$ for FY 1997 (this difference is being provided by DOE's ARIM program) and $\$ 300 \mathrm{~K}$ for start-up activities in 1998 (source of funding for this $\$ 300 \mathrm{~K}$ has not been identified yet).

There is still considerable uncertainty in the costs presented because at present the design is not fully defined. In addition, meaningful component cost discussions with vendors could not be performed without detailed drawings, which are not available at the preconceptual design phase. Therefore, the component and material costs presented in the tables of this section are clearly only estimates and are not defendable in detail at this time. The ability to control costs will depend on the success in maintaining the schedule and avoiding unexpected costs. A task-based management system will be used to monitor project progress on a monthly basis in conjunction with project spending to identify potential problems. Increases in project costs beyond those presented here will be minimized by considering decreases in task scope before any increases in spending are approved.

Table 7.1. Summary of preliminary project cost estimate by WBS

\begin{tabular}{|c|c|c|c|c|}
\hline WBS & $\begin{array}{c}\text { FY } 1996 \\
\text { budget } \\
\text { (\$K) }\end{array}$ & $\begin{array}{c}\text { FY } 1997 \\
\text { budget } \\
\text { (\$K) }\end{array}$ & $\begin{array}{c}\text { FY } 1998 \\
\text { budget } \\
(\$ K)\end{array}$ & $\begin{array}{c}\text { Total estimate } \\
\text { costs } \\
(\$ \mathrm{~K})\end{array}$ \\
\hline 1.0 Project management & 90 & 90 & 30 & 210 \\
\hline 1.1 Project support & 274 & 274 & 40 & 588 \\
\hline 1.2 Conceptual design & 1062 & 0 & 0 & 1062 \\
\hline 1.3 Safety & 411 & 289 & 82 & 782 \\
\hline 1.4 Detailed design & 1878 & 1840 & 0 & 3718 \\
\hline 1.5 Installation & 39 & 1218 & 123 & 1380 \\
\hline 1.6 Start-up testing & 0 & 85 & 135 & 220 \\
\hline 1.7 Operations & 39 & 207 & 310 & 556 \\
\hline Total projects costs & $3793^{*}$ & $4003^{*}$ & $720^{*}$ & 8516 \\
\hline
\end{tabular}

Includes \$2.5M in FY 1996 and \$2.5M in FY 1997 of DOE's ARIM' program funding. The balance of approximately \$1.3M in FY 1996 and \$1.5M in FY 1997 is to be covered by existing or expected operating funds. The complete funding source for the FY 1998 work has not been established.

'ARIM - accelerator reactor improvement modifications. 
Table 7.2. Detailed breakdown of preliminary costs by WBS

\begin{tabular}{|c|c|c|c|c|c|}
\hline WBS & $\begin{array}{l}\text { Expense } \\
\text { type }\end{array}$ & $\begin{array}{c}\text { FY } 1996 \\
\text { budget } \\
\text { \$K (FTEs) }\end{array}$ & $\begin{array}{c}\text { FY } 1997 \\
\text { budget } \\
\text { \$K (FTEs) }\end{array}$ & $\begin{array}{c}\text { FY } 1998 \\
\text { budget } \\
\text { \$K (FTEs) }\end{array}$ & $\begin{array}{c}\text { Total estimate } \\
\text { costs } \\
(\$ \mathrm{~K})\end{array}$ \\
\hline 1.0 & Project management & $90(0.5)$ & $90(0.5)$ & $30(0.2)$ & 210 \\
\hline \multirow[t]{5}{*}{1.1} & Project support & & & & \\
\hline & $\begin{array}{l}\text { Systems engineering } \\
\text { support }\end{array}$ & $74(0.5)$ & $74(0.5)$ & & 148 \\
\hline & $\begin{array}{l}\text { RRD support for } \\
\text { QA and regulatory } \\
\text { compliance }\end{array}$ & $75(0.5)$ & $75(0.5)$ & $10(0.1)$ & 160 \\
\hline & Physics analysis & $95(0.5)$ & $95(0.5)$ & $30(0.2)$ & 220 \\
\hline & External reviews & 30 & 30 & & 60 \\
\hline \multirow[t]{9}{*}{1.2} & Conceptual design & & & & \\
\hline & Lead designer & $151(0.8)$ & & & 151 \\
\hline & Engineering support & $147(1.0)$ & & & 147 \\
\hline & $\begin{array}{l}\text { RRD support for } \\
\text { design }\end{array}$ & $164(1.0)$ & & & 164 \\
\hline & Materials evaluation & $30(0.1)$ & & & 30 \\
\hline & $\begin{array}{l}\text { ORNL support to } \\
\text { testing }\end{array}$ & $148(0.8)$ & & & 148 \\
\hline & $\begin{array}{l}\text { Equipment for } \\
\text { testing }\end{array}$ & 102 & & & 102 \\
\hline & $\begin{array}{l}\text { Subcontract for } \\
\text { testing }\end{array}$ & 310 & & & 310 \\
\hline & Other subcontracts & 10 & & & 10 \\
\hline \multirow[t]{2}{*}{1.3} & Safety & & & & \\
\hline & $\begin{array}{l}\text { RRD support for } \\
\text { safety Analysis }\end{array}$ & $411(2.5)$ & $289(1.7)$ & $82(0.5)$ & 782 \\
\hline \multirow[t]{3}{*}{1.4} & Detailed design & & & & \\
\hline & $\begin{array}{l}\text { RRD support for } \\
\text { detailed design }\end{array}$ & $178(1.1)$ & $680(4.0)$ & & 858 \\
\hline & Lead designer & & $150(0.8)$ & & 150 \\
\hline
\end{tabular}


Table 7.2. (cont.)

\begin{tabular}{|c|c|c|c|c|c|}
\hline WBS & $\begin{array}{l}\text { Expense } \\
\text { type }\end{array}$ & $\begin{array}{c}\text { FY } 1996 \\
\text { budget } \\
\text { \$K (FTEs) }\end{array}$ & $\begin{array}{c}\text { FY } 1997 \\
\text { budget } \\
\text { \$K (FTEs) }\end{array}$ & $\begin{array}{c}\text { FY } 1998 \\
\text { budget } \\
\text { \$K (FTEs) }\end{array}$ & $\begin{array}{c}\text { Total estimate } \\
\text { costs } \\
(\$ \mathrm{~K})\end{array}$ \\
\hline \multirow[t]{8}{*}{$\begin{array}{c}1.4 \\
\text { (cont.) }\end{array}$} & $\begin{array}{l}\text { Engineering support } \\
\text { outside of RRD }\end{array}$ & & $75(0.5)$ & & 75 \\
\hline & $\begin{array}{l}\text { Refrigeration } \\
\text { equipment }\end{array}$ & 1500 & 375 & & $1875^{*}$ \\
\hline & Additional pump & & 50 & & 50 \\
\hline & I\&C system & & 200 & & 200 \\
\hline & $\begin{array}{l}\text { Heat exchanger } \\
\text { equipment }\end{array}$ & & 40 & & 40 \\
\hline & Transfer lines & & 150 & & 150 \\
\hline & Moderator vessel & & 120 & & 120 \\
\hline & Pump module & 200 & & & 200 \\
\hline \multirow[t]{6}{*}{1.5} & Installation & & & & \\
\hline & $\begin{array}{l}\text { RRD support for } \\
\text { installation }\end{array}$ & $39(0.3)$ & $306(2.3)$ & $51(0.3)$ & 396 \\
\hline & Craft support & & $296(6020 \mathrm{~h})$ & $42(180 \mathrm{~h})$ & 338 \\
\hline & Engineering support & & $316(2.1)$ & & 316 \\
\hline & Materials & & 240 & 30 & 270 \\
\hline & Tooling & & 60 & & \\
\hline \multirow[t]{3}{*}{1.6} & Start-up testing & & & & \\
\hline & Lead designer & & & $50(0.3)$ & 50 \\
\hline & $\begin{array}{l}\text { RRD support for } \\
\text { start-up testing }\end{array}$ & & $85(0.5)$ & $85(0.5)$ & 170 \\
\hline \multirow[t]{4}{*}{1.7} & Operations & & & & \\
\hline & $\begin{array}{l}\text { RRD support for } \\
\text { operation }\end{array}$ & $39(0.3)$ & $64(0.5)$ & $164(1.0)$ & 267 \\
\hline & Maintenance support & & $13(200 \mathrm{~h})$ & $26(400 \mathrm{~h})$ & 39 \\
\hline & Training & & 45 & 35 & 80 \\
\hline
\end{tabular}


Table 7.2. (cont.)

\begin{tabular}{clcccc}
\hline WBS & \multicolumn{1}{c}{$\begin{array}{c}\text { Expense } \\
\text { type }\end{array}$} & $\begin{array}{c}\text { FY 1996 } \\
\text { budget } \\
\text { \$K (FTEs) }\end{array}$ & $\begin{array}{c}\text { FY 1997 } \\
\text { budget } \\
\text { \$K (FTEs) }\end{array}$ & $\begin{array}{c}\text { FY 1998 } \\
\text { budget } \\
\text { \$K (FTEs) }\end{array}$ & $\begin{array}{c}\text { Total estimate } \\
\text { costs } \\
\text { (\$K) }\end{array}$ \\
\hline $\begin{array}{c}1.7 \\
\text { (cont.) }\end{array}$ & $\begin{array}{l}\text { Equipment } \\
\text { purchases } \\
\end{array}$ & & 10 & 10 & 20 \\
& $\begin{array}{l}\text { Spare parts } \\
\text { Readiness } \\
\text { assessment }\end{array}$ & 25 & 25 & 50 \\
& & 50 & 50 & 100 \\
& & & & & \\
Total project costs & $3793^{* *}$ & $4003^{* *}$ & $720^{* *}$ & 8516 \\
\hline
\end{tabular}

An informal estimate as low as $\$ 1.5 \mathrm{M}$ for the refrigeration system has been discussed, but the legitimacy of this estimate has not been established. A $25 \%$ contingency $(\$ 375 \mathrm{~K}$ ) has been included for our present estimate. The real cost of the refrigeration system can not be defined and defended until its functional requirements are frozen, and, therefore, even with the contingency included there is still much uncertainty in the cost value for this item.

"Includes \$2.5M in FY 1996 and \$2.5M in FY 1997 of DOE's ARIM program funding. The balance of approximately \$1.3M in FY 1996 and \$1.5M in FY 1997 is covered by existing or expected operating funds. The complete funding source for the FY 1998 work has not been established. 
Table 7.3. Summary of preliminary costs by cost discipline

\begin{tabular}{lcccc}
\hline \multicolumn{1}{c}{$\begin{array}{c}\text { Work } \\
\text { discipline }\end{array}$} & $\begin{array}{c}\text { FY 1996 } \\
\text { budget } \\
\text { \$K (FTEs) }\end{array}$ & $\begin{array}{c}\text { FY 1997 } \\
\text { budget } \\
\text { \$K (FTEs) }\end{array}$ & $\begin{array}{c}\text { FY 1998 } \\
\text { budget } \\
\text { \$K (FTEs) }\end{array}$ & $\begin{array}{c}\text { Total } \\
\text { estimate } \\
\text { costs } \\
\text { (\$K) }\end{array}$ \\
\hline Research Reactor Division & 906 & 1499 & 392 & 2797 \\
Other ORNL research divisions & 148 & 430 & 195 & 773 \\
ANS technology transfer & 440 & 0 & 0 & 440 \\
Engineering support & 147 & 465 & 0 & 612 \\
Equipment for testing & 102 & & & 102 \\
Subcontract for testing & 310 & & & 310 \\
Other subcontracts & 40 & 30 & 10 & 70 \\
Cold source equipment & 1700 & 1005 & 55 & 320 \\
Installation materials & & 265 & 68 & 377 \\
Crafts & & 309 & $720^{* *}$ & 8516 \\
\hline \multicolumn{1}{c}{ Total } & $3793^{* *}$ & $4003^{* *}$ & & \\
\hline
\end{tabular}

"Existing FY 1995 carryover for transfer to other DOE programs of new technology, R\&D results, and designs created by the ANS Project.

“Includes \$2.5M in FY 1996 and \$2.5M in FY 1997 of DOE's ARIM program funding. The balance of approximately \$1.3M in FY 1996 and \$1.5M in FY 1997 is covered by existing or expected operating funds. The complete funding source for the FY 1998 work has not been established. 



\section{REFERENCES}

1. R. A. Crone, comp., The High Flux Isotope Reactor Operations Procedure Writer's Guide, ORNL/RRD/INT-89, Martin Marietta Energy Systems, Inc., Oak Ridge Natl. Lab., March 1993.

2. Research Reactors Division HFIR Operations Procedures, ADM-0100, Operations Procedures, ORNL/RRD/INT-99, Martin Marietta Energy Systems, Inc., Oak Ridge Natl. Lab., October 1995.

3. ORNL Office of Safety and Health Protection Procedures, OSHP Manual, Rev. 12, Oak Ridge Natl. Lab., December 1995.

4. High Flux Isotope Reactor Technical Specifications, 3.19, Gaseous Effluent Releases, ORNL/TM-5711/R2, August 1988.

5. ORNL Environmental Protection Manual, EPM-2.1, Rev. 0, Environmental Protection and NEPA Compliance, May 1993.

6. High Flux Isotope Reactor Safety Analysis Report, ORNL/M-2344, Vols. 1-5, Martin Marietta Energy Systems, Inc., Oak Ridge Natl. Lab.

7. D. H. Johnson et al., The High Flux Isotope Reactor Probabilistic Risk Assessment, ORNL/RRD/INT-36/R1, Martin Marietta Energy Systems, Inc., Oak Ridge Natl. Lab., August 1991.

8. "Pressure Vessels, Alternative Rules," American Society of Mechanical Engineers (ASME) Boiler and Pressure Vessel Code, Section VIII, Division 2, 1989.

9. Chemical Plant and Petroleum Refinery Piping, ASME b31.3, American Society of Mechanical Engineers, 1993.

10. Ref. 4, 3.8, Limitations on Experiments, 3. Specifications, part b, paragraph (1)..

11. Ref. 4, 3.8, Limitations on Experiments, 3. Specifications, part b, paragraph (2).

12. Research Reactors Division Administrative Policies and Procedures Manual, RRAP-3.4, Configuration Control System, ORNL/RRD/INT-12, September 28, 1987.

13. Ref. 12, RRAP-1.9, Procurement of Items and Services

14. Ref. 12, RRAP-3.1.1, Procedure for Fabrication Control Governing Modification of Reactor Systems and/or Replacement of Hardware

15. RRD Maintenance Manual, Volume 1, Maintenance Program, RRD-M-1.6, Preparing and Processing a Maintenance Work Package, ORNL/RRD/INT-42, April 24, 1995.

16. Ref. 15, RRD-M-1.14, Maintenance Work Control. 
17. J. F. Breismeister, MCNP-A General Monte Carlo N-Particle Transport, version 4a, LA-12625-M, Los Alamos National Laboratory, Los Alamos, New Mexico, November 1993.

18. D. L. Selby, R. M. Harrington, and P. B. Thompson, Advanced Neutron Source Progress Report, FY 1991, ORNL-6696, p. 22, Martin Marietta Energy Systems, Inc., Oak Ridge Natl. Lab., January 1992.

19. J. L. Young and J. U. Koppel, "Slow Neutron Scattering by Molecular Hydrogen and Deuterium," Phys. Rev., 135, p. A603 (August 1964).

20. R. E. MacFarlane, New Thermal Neutron Scattering Files for ENDF/B-VI Release 2, LA-12639-MS, Los Alamos National Laboratory, Los Alamos, New Mexico, March 1994.

21. J. A. Bucholz, Initial Global 2-D Shielding Analysis For the Advanced Neutron Source Core and Reflector, ORNL/TM-12672, Martin Marietta Energy Systems, Inc., Oak Ridge Natl. Lab.,, August 1995.

22. Y. Farawila, U. Gohar, and C. Maynard, KAOS/LIB-V: A Library of Nuclear Response Functions Generated by KAOS-V Code from ENDF/B-V and Other Data Files, ANL/FPP/TM-241, Argonne National Laboratory, Argonne, Illinois, April 1989.

23. P. Ageron, "Neutronic Design of the ILL Cold Sources: An Historical Perspective," pps. 1-18, Proceedings International Workshop on Cold Neutron Sources, LA-12146-C, cosponsored by Los Alamos National Laboratory Manuel Lujan Jr. Neutron Scattering Center (LANSCE) and Oak Ridge National Laboratory Advanced Neutron Source (ANS), August 1991.

24. R. D. Cheverton and T. M. Sims, HFIR Core Nuclear Design, ORNL-4621, Oak Ridge National Laboratory, July 1971.

25. R. M. Harrington and C. T. Ramsey, Preliminary Probabilistic Design Basis Accident Evaluation of the Cold Source Facilities of the Advanced Neutron Source, ORNL/M-4606, Martin Marietta Energy Systems, Inc., Oak Ridge Natl. Lab., August 1995.

26. Oak Ridge National Laboratory Standard Practice Procedure X-GP-16, "Procurement of Critical Application/Safety-Class Items and Services at ORNL,” Revision 0, May 1994. 


\section{APPENDIX A}

\section{WBS FOR THE HFIR COLD SOURCE PROJECT}

A-1 


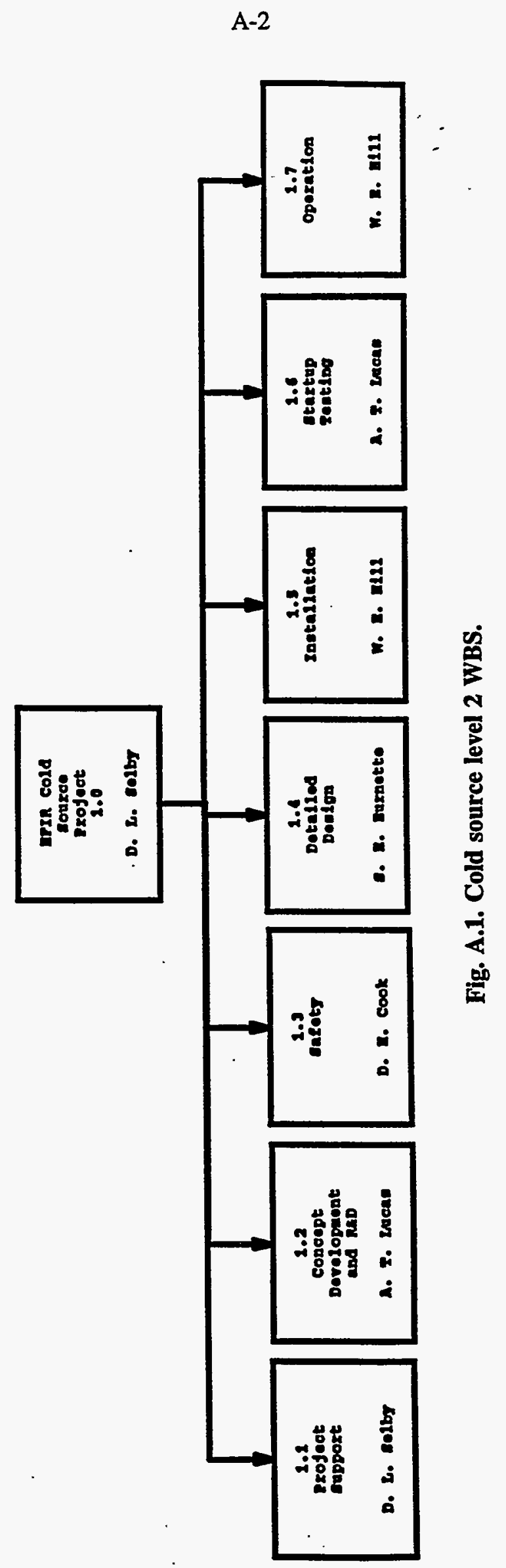


A-3

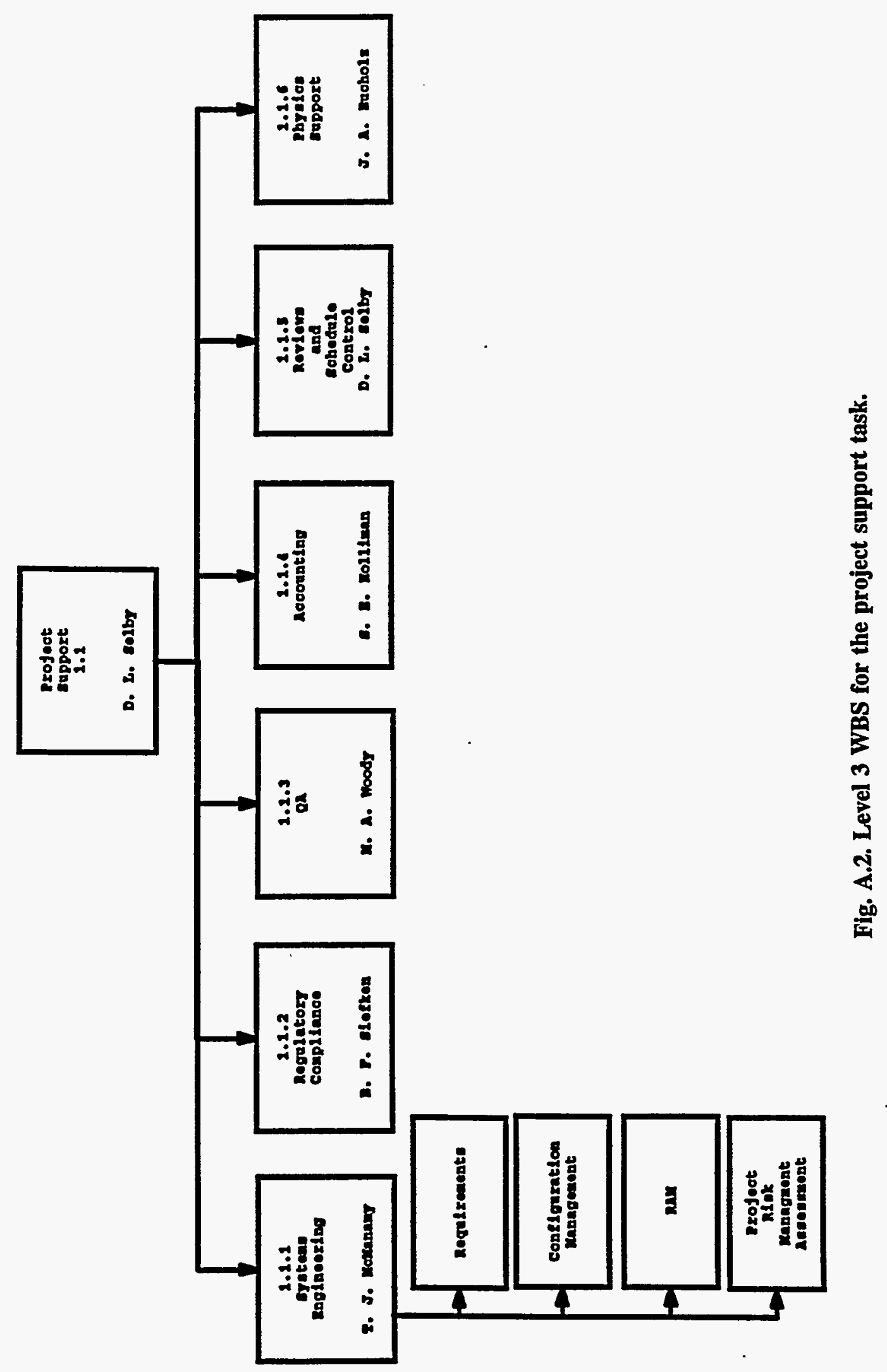




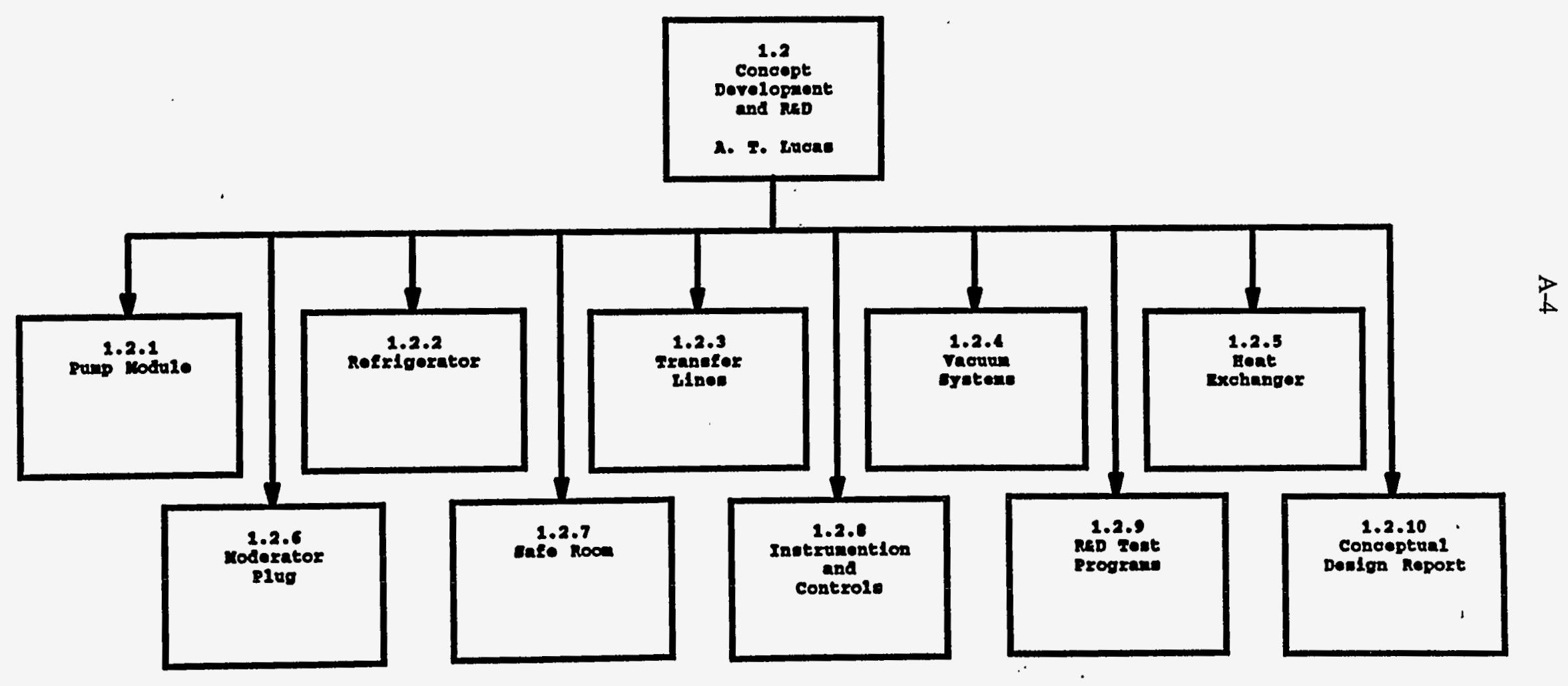

Fig. A.3. Level 3 WBS for the concept development and R\&D task. 


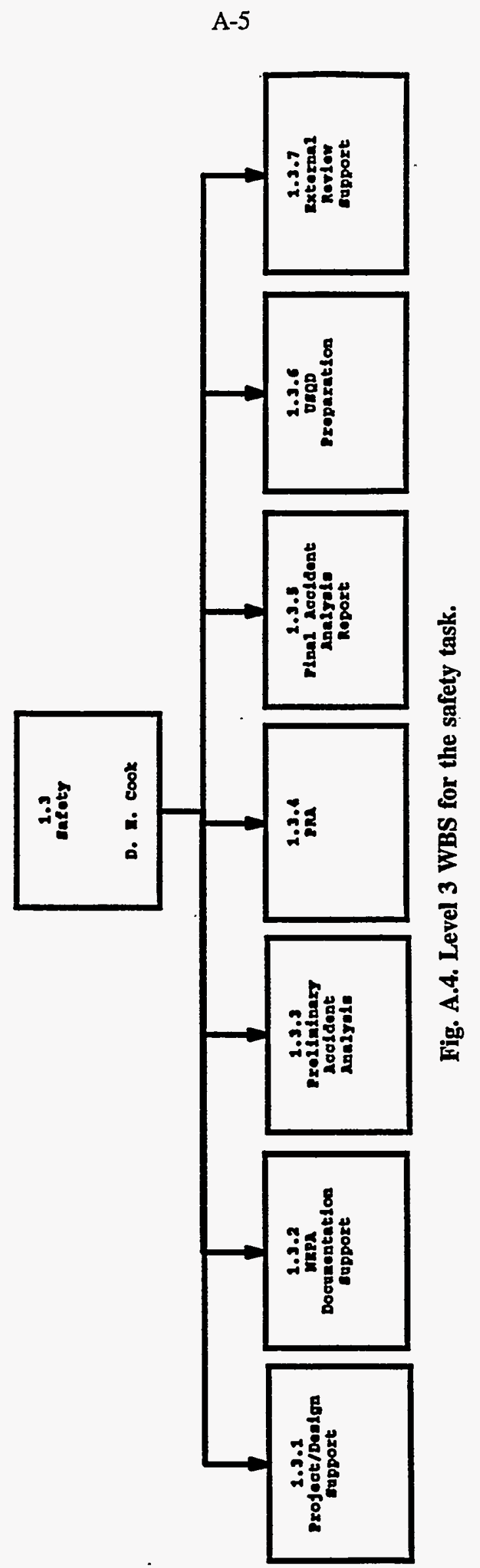




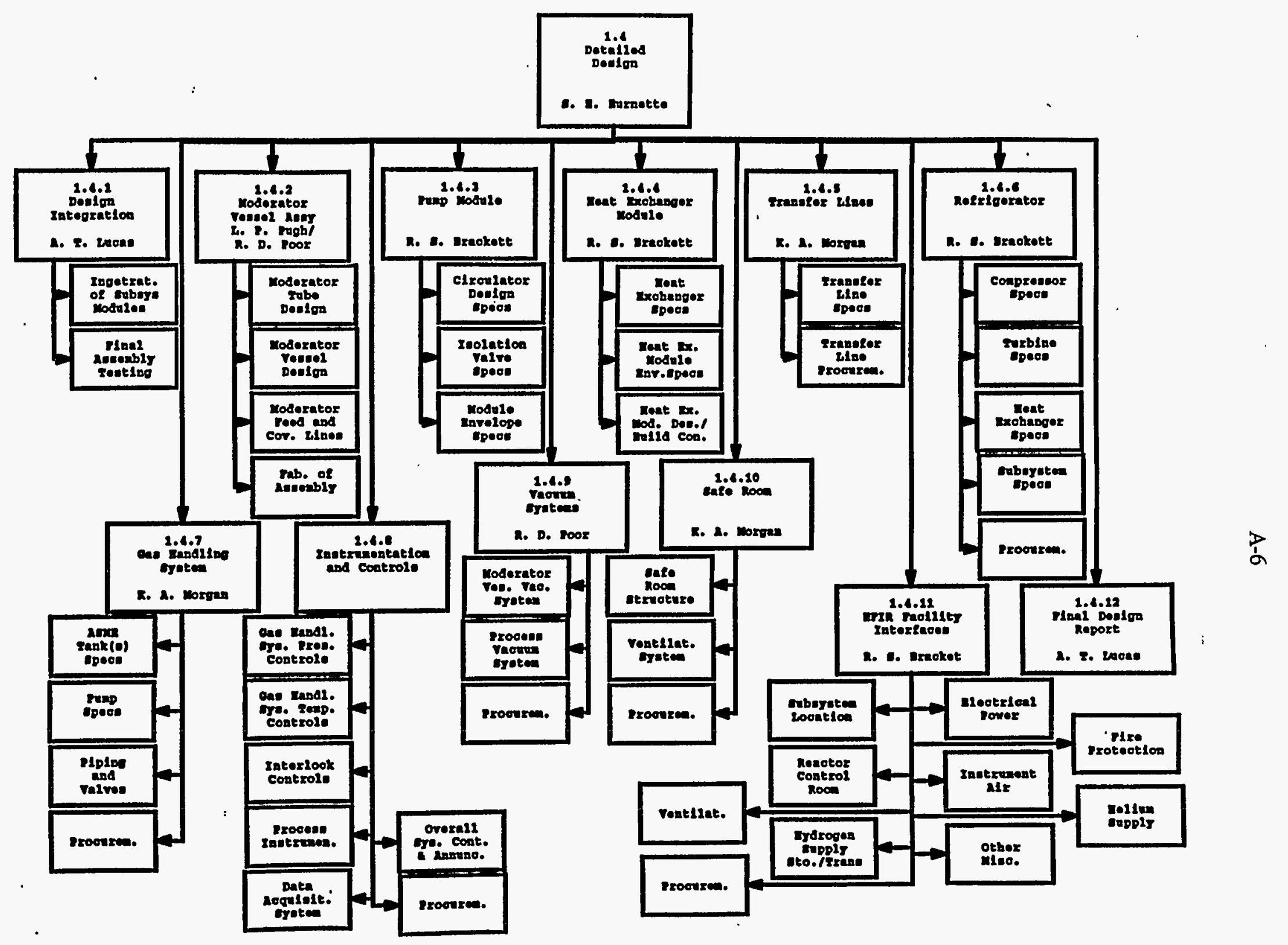

Fig. A.5. Level 3 WBS for the detailed-design task. 


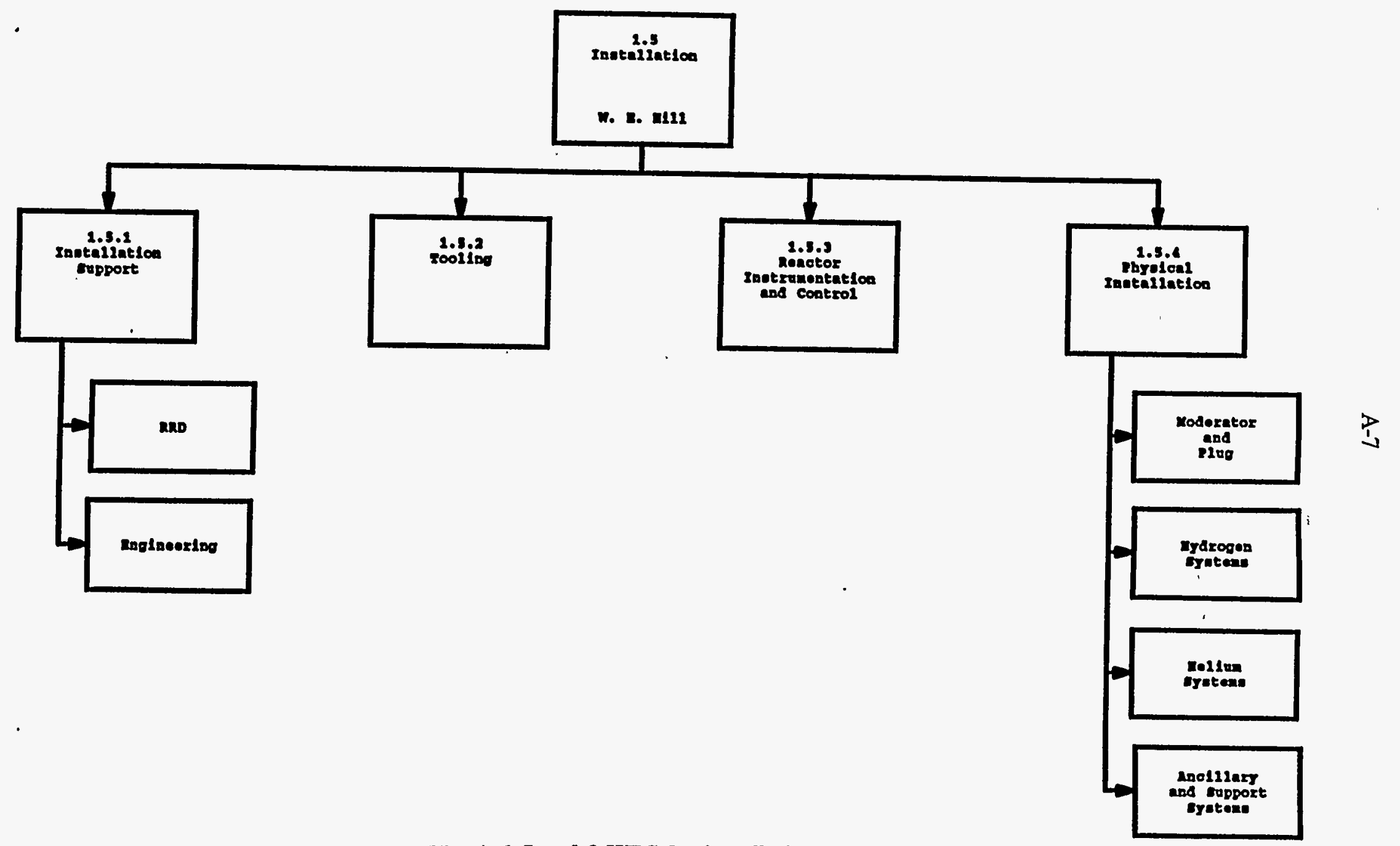

Fig. A.6. Level 3 WBS for installation task. 


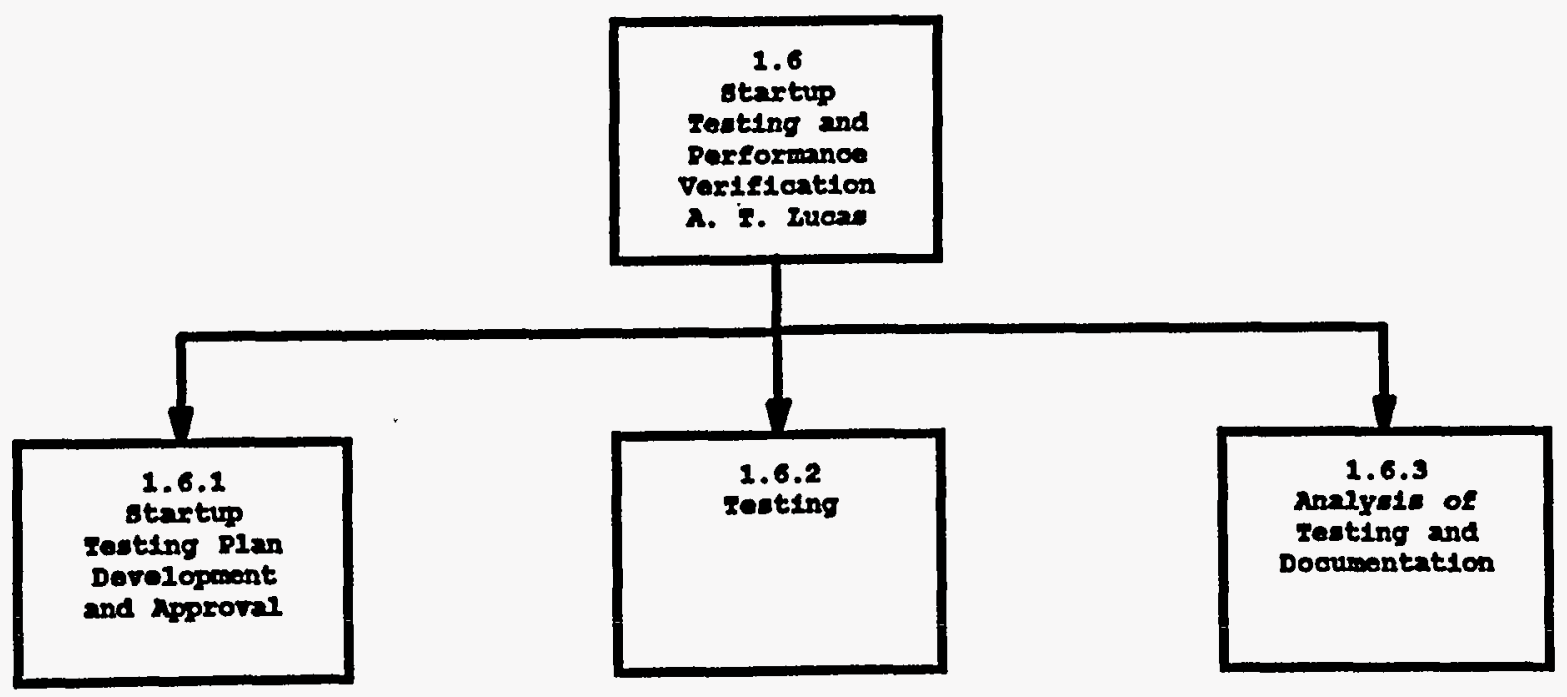

Fig. A.7. Level 3 WBS for the start-up testing and performance verification task. 


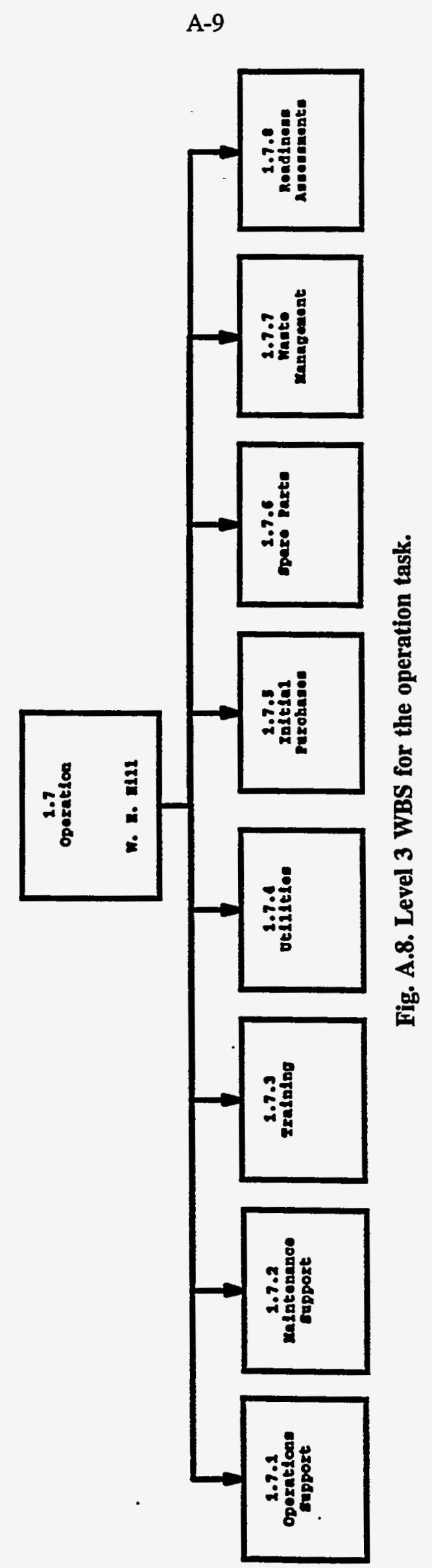



Appendix B

RISK MANAGEMENT ASSESSMENT FORMS

B-1 

B-3

RISK MANAGEMENT ASSESSMENT/PLAN

PROJECT TITLE HFIR Cold Source

PAGE 1 OF

DATE OF THIS ASSESSMENT

$9 / 28 / 95$

WBS/SYSTEM NUMBER $\quad 1.1$

RESPONSIBLE PERSON D.Selby

WBS/SYSTEM TITLE Project Support

ELEMENT DESCRIPTION

SIGNATURE

POTENTIAL PROBLEM OR FAILURE MODE Signifant Schedule Delay caused by reviews

EFFECTS (MARK AN "X" FOR ALL EFFECTS OF FAILURE)

\begin{tabular}{|l|c|c|c||}
\hline \multicolumn{1}{|c|}{ EFFECT } & KNOWN & PROBABLE & NO EFFECT \\
\hline SAFETY & & & \\
\hline ENVIRONMENTAL INSULT & & & $\times$ \\
\hline COST IMPACT & & & $\times$ \\
\hline FUCTIONAL PERFORMANCE & & $X$ & \\
\hline PROJECT SCHEDULE & & & $X$ \\
\hline OPERATIONAL IMPACT & $\times$ & & \\
\hline
\end{tabular}

RANKING OF CONSEQUENCE OF PROBLEM OR FAILURE:

SIGNIFICANT (X) OR INSIGNIFICANT () 
TABLE OF POSSIBLE CAUSES

\begin{tabular}{|c|c|c|c|}
\hline \multicolumn{2}{|r|}{ POSSIBLE CAUSES } & \multirow{2}{*}{$\begin{array}{l}\text { PROBABILITY } \\
\text { Low (L) } \\
\text { Unknown (U) } \\
\text { High (H) }\end{array}$} & \multirow{2}{*}{\begin{tabular}{l}
\multicolumn{1}{c}{ RISK } \\
Acceptable (A) \\
Unacceptable (U)
\end{tabular}} \\
\hline NUMBER & DESCRIPTION & & \\
\hline 1 & $\begin{array}{l}\text { Internal reviews identify new issues which } \\
\text { require additional unplanned work. }\end{array}$ & $\bar{U}$ & $\bar{U}$ \\
\hline 2 & $\begin{array}{l}\text { DOE reviews identify issues which require } \\
\text { additional unplanned work. }\end{array}$ & $\bar{U}$ & $\bar{U}$ \\
\hline & & & - \\
\hline & & & \\
\hline & . & & \\
\hline & & & \\
\hline & & & \\
\hline & & & \\
\hline & & & \\
\hline & & & \\
\hline & & & \\
\hline & & & \\
\hline & & & \\
\hline & & & \\
\hline & & & \\
\hline & & & \\
\hline & & & \\
\hline & - & & \\
\hline & & & \\
\hline
\end{tabular}




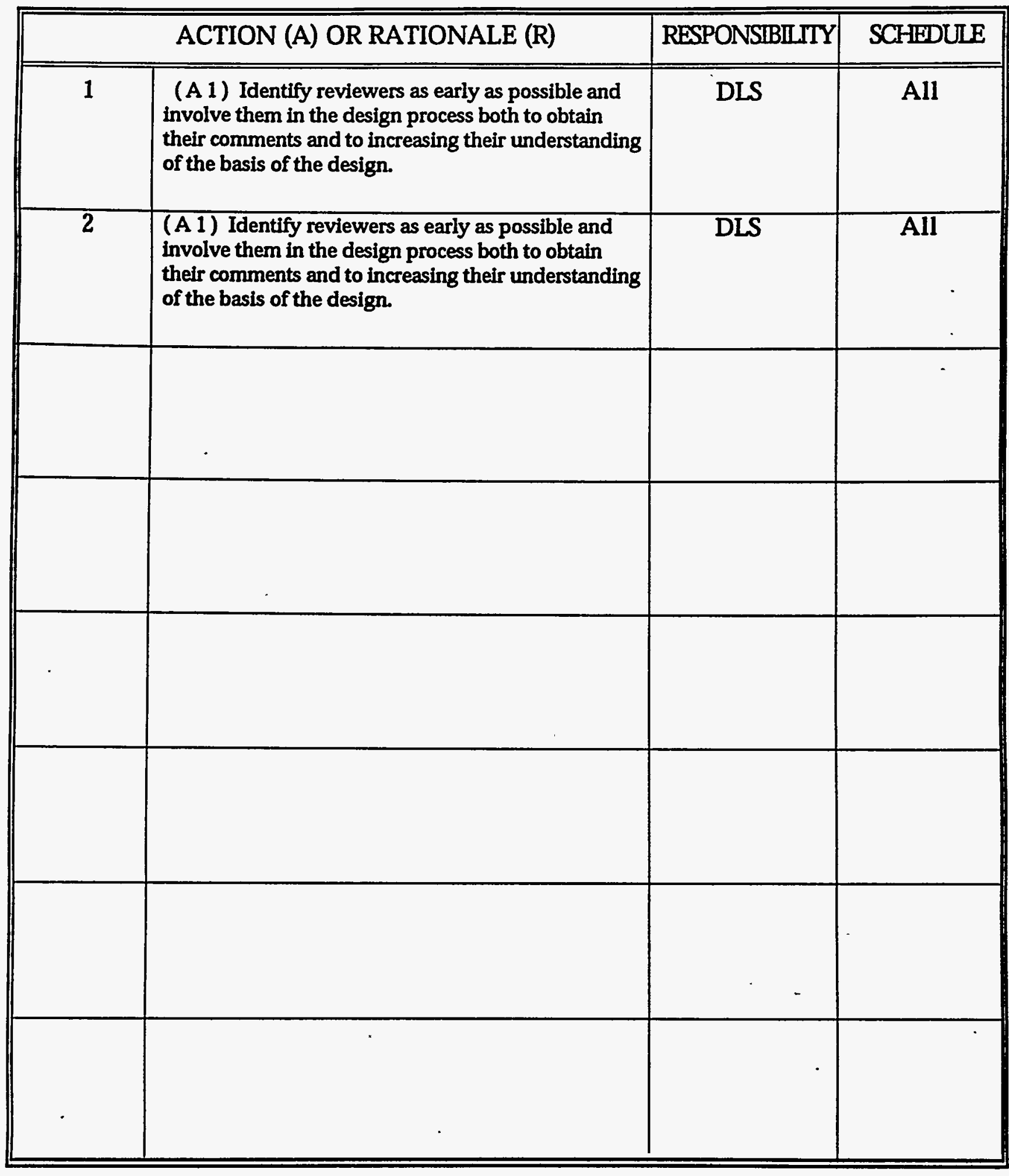


PROJECT TITLE HFIR Cold Source

PAGE 1 OF

DATE OF THIS ASSESSMENT

$9 / 28 / 95$

WBS/SYSTEM NUMBER 1.1

RESPONSIBLE PERSON D.LSelby WBS/SYSTEM TITLE Project Support

ELEMENT DESCRIPTION SIGNATURE

POTENTIAL PROBLEM OR FAILURE MODE Staff resource avallability less then planned

EFFECTS (MARK AN "X" FOR ALL EFFECTS OF FAILURE)

\begin{tabular}{|l|c|c|c||}
\hline \multicolumn{1}{|c|}{ EFFECT } & KNOWN & PROBABLE & NO EFFECT \\
\hline SAFETY & & & \\
\hline ENVIRONMENTAL INSULT & & & $X$ \\
\hline COST IMPACT & & & $X$ \\
\hline FUCTIONAL PERFORMANCE & & $X$ & \\
\hline PROJECT SCHEDULE & & & $X$ \\
\hline OPERATIONAL IMPACT & $\times$ & & \\
\hline
\end{tabular}

RANKING OF CONSEQUENCE OF PROBLEM OR FAILURE:

SIGNIFICANT (X) OR INSIGNIFICANT () 
B-7

TABLE OF POSSIBLE CAUSES

\begin{tabular}{|c|c|c|c|}
\hline \multicolumn{2}{|r|}{ POSSIBLE CAUSES } & \multirow{2}{*}{$\begin{array}{l}\text { PROBABILITY } \\
\text { Low (L) } \\
\text { Unknown (U) } \\
\text { High (H) }\end{array}$} & \multirow{2}{*}{\begin{tabular}{|c|}
\multicolumn{1}{c}{ RISK } \\
\\
Acceptable (A) \\
Unacceptable (U)
\end{tabular}} \\
\hline NUMBER & DESCRIPTION & & \\
\hline 1 & Other HFIR tasks given a higher priority & $\bar{H}$ & $\mathbf{U}$ \\
\hline & & & \\
\hline & & & \\
\hline & & & \\
\hline & & & \\
\hline & & & \\
\hline & & & \\
\hline & & & \\
\hline & & & \\
\hline & & & \\
\hline & & & \\
\hline & & & \\
\hline & & & \\
\hline & & & \\
\hline & & & \\
\hline & & & \\
\hline - & & & \\
\hline & & & \\
\hline & & & \\
\hline & & & \\
\hline
\end{tabular}




\begin{tabular}{|c|l|c|c|}
\hline \multicolumn{2}{|c|}{ ACTION (A) OR RATIONALE (R) } & RESPONSIBIITY & SCHEDULE \\
\hline 1 & $\begin{array}{l}\text { (A 1) Develop complete resource estimates for all } \\
\text { stages of the cold source work and incorporate into } \\
\text { the project planning base. }\end{array}$ & DLS . & $\begin{array}{c}\text { Conceptual } \\
\text { Design }\end{array}$ \\
\hline 1 & $\begin{array}{l}\text { (A2) Obtain commitments from the supervisors for } \\
\text { the staff time requirerments based on normal } \\
\text { operational requirements }\end{array}$ & DLS & $\begin{array}{c}\text { Detailed } \\
\text { Design }\end{array}$ \\
\hline 1 & $\begin{array}{l}\text { (A3) Obtain senior laboratory management } \\
\text { guidance for setting priorities between the cold } \\
\text { source work and other tasks. }\end{array}$ & DLS & $\begin{array}{c}\text { Detailed } \\
\text { Design }\end{array}$ \\
\hline & & & \\
\hline & & & \\
\hline & & & \\
\hline & & & \\
\hline & & & \\
\hline & & & \\
\hline
\end{tabular}


WBS/SYSTEM NUMBER $\quad 1.1$ WBS/SYSTEM TITLE Project Support

ELEMENT DESCRIPTION Requirements

POTENTIAL PROBLEM OR FAILURE MODE Project Requirements are not adequately identified and defined prior to design start.

EFFECTS (MARK AN "X" FOR ALL EFFECTS OF FAILURE)

\begin{tabular}{||l|c|c|c|}
\hline \multicolumn{1}{|c|}{ EFFECT } & KNOWN & PROBABLE & NO EFFECT \\
\hline SAFETY & & & \\
\hline ENVIRONMENTAL INSULT & & & $X$ \\
\hline COST IMPACT & & & $X$ \\
\hline FUCTIONAL PERFORMANCE & & $X$ & \\
\hline PROJECT SCHEDULE & & $X$ & \\
\hline OPERATIONAL IMPACT & & $X$ & \\
\hline
\end{tabular}

RANKING OF CONSEQUENCE OF PROBLEM OR FAILURE:

SIGNIFICANT $(X) \quad$ OR INSIGNIFICANT ()

Risk Assessment WBS1.1 
TABLE OF POSSIBLE CAUSES

\begin{tabular}{|c|c|c|c|}
\hline \multicolumn{2}{|r|}{ POSSIBLE CAUSES } & \multirow{2}{*}{$\begin{array}{l}\text { PROBABILITY } \\
\text { Low (L) } \\
\text { Unknown (U) } \\
\text { High (H) }\end{array}$} & \multirow{2}{*}{$\begin{array}{c}\text { RISK } \\
\text { Acceptable (A) } \\
\text { Unacceptable (U) }\end{array}$} \\
\hline NUMBER & DESCRIPTION & & \\
\hline 1 & $\begin{array}{l}\text { Cryogenic hydrogen requirements not } \\
\text { well defined in existing reactor guidance. }\end{array}$ & $\mathrm{H}$ & $U$ \\
\hline 2 & $\begin{array}{l}\text { Requirements not identified until external } \\
\text { review when difficult to incorporate }\end{array}$ & $U$ & $\mathbf{U}$ \\
\hline - & & & \\
\hline . & & & - \\
\hline & & & \\
\hline & . & & \\
\hline & & & \\
\hline & . & & \\
\hline & & & \\
\hline & & & \\
\hline & & & \\
\hline & & & \\
\hline & & & \\
\hline & & & \\
\hline & & & \\
\hline & & & \\
\hline & & & \\
\hline - & & & \\
\hline & & & \\
\hline & & & \\
\hline
\end{tabular}




\begin{tabular}{|c|l|c|c|}
\hline \multicolumn{2}{|c|}{ ACTION (A) OR RATIONALE (R) } & RESPONSIBITTY & SCHEDULE \\
\hline \hline 1 & $\begin{array}{l}\text { (A1) Review guidance used for existing facilities at } \\
\text { Brookhaven High Flux Beam Reactor and NIST cold } \\
\text { source facility. Review experience at other cold } \\
\text { sources in reactors (IIL, Julich, Saclay). }\end{array}$ & DLS & $\begin{array}{c}\text { Conceptual } \\
\text { Design }\end{array}$ \\
\hline 1 & $\begin{array}{l}\text { (A2) Ensure requirements are documented in a } \\
\text { Systems Requirement Document prior to initiation of } \\
\text { detailed design }\end{array}$ & TJM & $\begin{array}{c}\text { Conceptural } \\
\text { Design }\end{array}$ \\
\hline 2 & $\begin{array}{l}\text { (A1) Conduct an external review as soon as } \\
\text { practical in the design process }\end{array}$ & DLS & $\begin{array}{c}\text { Conceptural } \\
\text { Design }\end{array}$ \\
\hline 2 & $\begin{array}{l}\text { (A2) Attempt to have DOE representation at } \\
\text { working design meetings. }\end{array}$ & DLS & All \\
\hline & & & \\
\hline & & & \\
\hline & & & \\
\hline & & & \\
\hline & & & \\
\hline & & & \\
\hline & & & \\
\hline & & & \\
\hline
\end{tabular}


PROJECT TITLE HFIR Cold Source

PAGE 1 OF

DATE OF THIS ASSESSMENT

$9 / 25 / 95$

WBS/SYSTEM NUMBER $\quad 1.1$

RESPONSIBLE PERSON DI.Selby

WBS/SYSTEM TITLE Project Support

ELEMENT DESCRIPTION

SIGNATURE

POTENTIAL PROBLEM OR FAILURE MODE Significant project changes during design phase not fully assessed for overall impacts

EFFECTS (MARK AN "X" FOR ALL EFFECTS OF FAILURE)

\begin{tabular}{|l|c|c|c|}
\hline \multicolumn{1}{|c|}{ EFFECT } & KNOWN & PROBABLE & NO EFFECT \\
\hline & & & \\
\hline SAFETY & & & $\times$ \\
\hline ENVIRONMENTAL INSULT & & & $X$ \\
\hline COST IMPACT & & $X$ & \\
\hline FUCTIONAL PERFORMANCE & & $X$ & \\
\hline PROJECT SCHEDULE & & $X$ & \\
\hline OPERATIONAL IMPACT & & & $\times$ \\
\hline
\end{tabular}

RANKING OF CONSEQUENCE OF PROBLEM OR FAILURE:

SIGNIFICANT (X) OR INSIGNIFICANT () 


\section{B-13}

\section{TABLE OF POSSIBLE CAUSES}

\begin{tabular}{|c|c|c|c|}
\hline \multicolumn{2}{|r|}{ POSSIBLE CAUSES } & \multirow{2}{*}{$\begin{array}{l}\text { PROBABILITY } \\
\text { Low (L) } \\
\text { Unknown (U) } \\
\text { High }(H)\end{array}$} & \multirow{2}{*}{\begin{tabular}{|c|}
\multicolumn{1}{c}{ RISK } \\
Acceptable (A) \\
Unacceptable (U)
\end{tabular}} \\
\hline NUMBER & DESCRIPTION & & \\
\hline 1 & $\begin{array}{l}\text { Design responsibility split between } \\
\text { different organizations }\end{array}$ & $\mathrm{L}$ & $\bar{A}$ \\
\hline \multirow[t]{2}{*}{1} & $\begin{array}{l}\text { Scattering instrument users not actively } \\
\text { involved in design }\end{array}$ & $\bar{L}$ & $\bar{A}$ \\
\hline & & & - \\
\hline & & & \\
\hline & $\bar{T}$ & & \\
\hline & & & \\
\hline & & & \\
\hline & & & \\
\hline & & & \\
\hline & & & \\
\hline & & & \\
\hline & & & \\
\hline & & & \\
\hline & & & \\
\hline & & & \\
\hline & & & \\
\hline$\because$ & & & \\
\hline & & & \\
\hline & & & \\
\hline
\end{tabular}




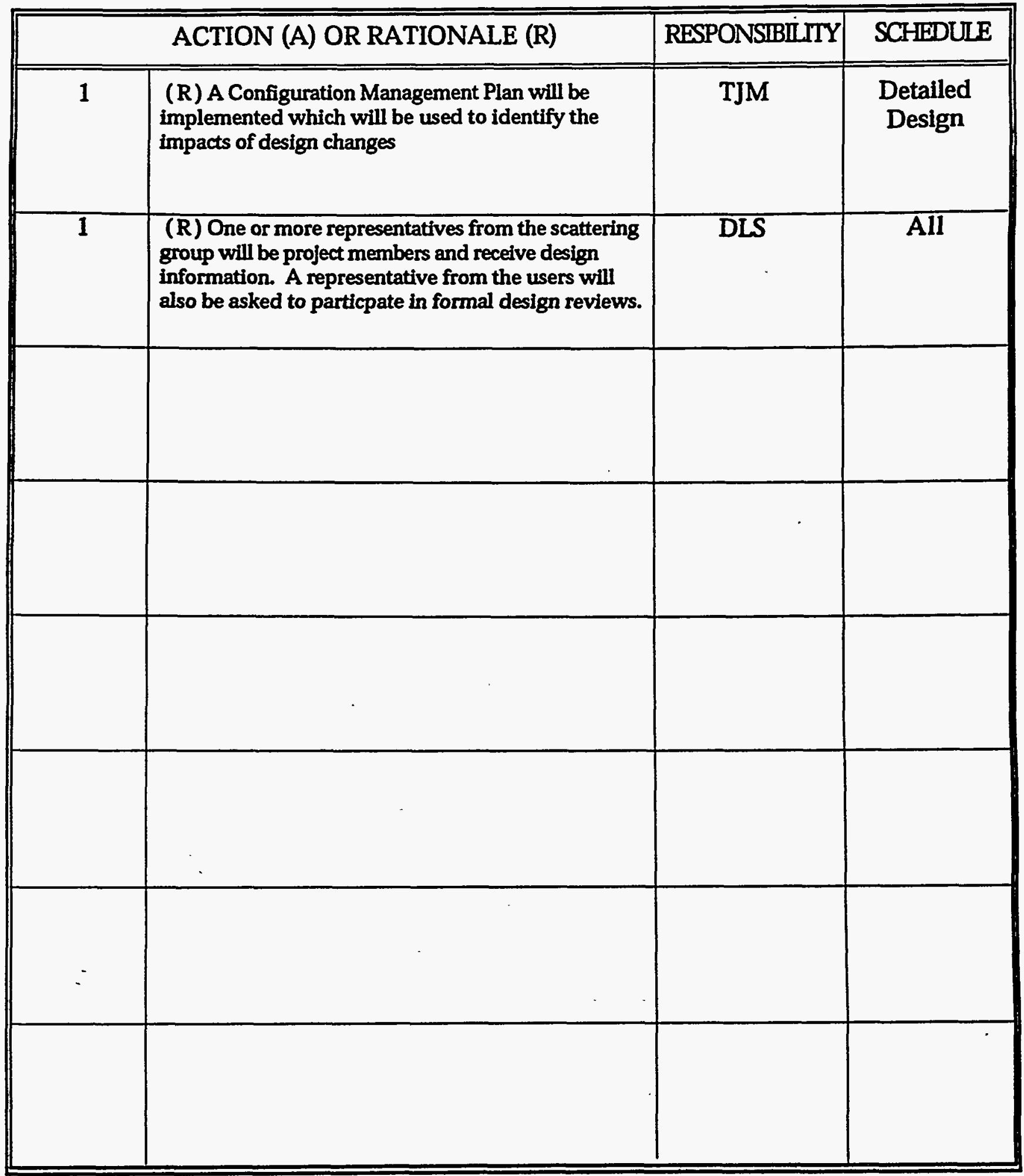


WBS/SYSTEM NUMBER $\quad 1.1$

RESPONSIBLE PERSON DLS

WBS/SYSTEM TITLE Project Support

ELEMENT DESCRIPTION SIGNATURE

POTENTIAL PROBLEM OR FAILURE MODE Interferences with other on-going or planned projects with major potential impacts

EFFECTS (MARK AN "X" FOR ALL EFFECTS OF FAILURE)

\begin{tabular}{||l|c|c|c||}
\hline \multicolumn{1}{|c|}{ EFFECT } & KNOWN & PROBABLE & NO EFFECT \\
\hline SAFETY & & & \\
\hline ENVIRONMENTAL INSULT & & & $\times$ \\
\hline COST IMPACT & & & $X$ \\
\hline FUCTIONAL PERFORMANCE & & $X$ & \\
\hline PROJECT SCHEDULE & & $X$ & \\
\hline OPERATIONAL IMPACT & & $X$ & \\
\hline
\end{tabular}

RANKING OF CONSEQUENCE OF PROBLEM OR FAILURE:

SIGNIFICANT (X) OR INSIGNIFICANT () 
TABLE OF POSSIBLE CAUSES

\begin{tabular}{|c|c|c|c|}
\hline \multicolumn{2}{|r|}{ POSSIBLE CAUSES } & \multirow{2}{*}{$\begin{array}{l}\text { PROBABILITY } \\
\text { Low (L) } \\
\text { Unknown (U) } \\
\text { High }(\mathrm{H})\end{array}$} & \multirow{2}{*}{$\begin{array}{l}\text { RISK } \\
\text { Acceptable (A) } \\
\text { Unacceptable (U) }\end{array}$} \\
\hline NUMBER & DESCRIPTION & & \\
\hline 1 & $\begin{array}{l}\text { Other upgrade projects started without } \\
\text { establihed interface control procedures. }\end{array}$ & $\bar{U}$ & $\bar{U}$ \\
\hline 2 & $\begin{array}{l}\text { Scattering instruments not available for } \\
\text { long periods due to installation /testing of } \\
\end{array}$ & $\bar{U}$ & $\bar{U}$ \\
\hline & & & \\
\hline & & & \\
\hline & & & \\
\hline & & & \\
\hline & & & \\
\hline & & & \\
\hline & & & \\
\hline & & & \\
\hline & & & \\
\hline & & & \\
\hline & & & \\
\hline & & & \\
\hline & & & \\
\hline & & & \\
\hline & & & \\
\hline & & & \\
\hline & & & $\because$ \\
\hline & & & \\
\hline
\end{tabular}


ACTION (A) AND RATIONALE (R) TABLE

\begin{tabular}{|c|c|c|c|}
\hline \multicolumn{2}{|c|}{ ACTION (A) OR RATIONALE (R) } & RESPONSIBLITY & SCHEDULE \\
\hline \hline 1 & $\begin{array}{l}\text { (A 1) Develop project management plan in } \\
\text { consulation with senior laboratory management to } \\
\text { either have a common project director for all upgrade } \\
\text { projects, or a well established interface control } \\
\text { system. }\end{array}$ & DLS & $\begin{array}{c}\text { Conceptual } \\
\text { Design }\end{array}$ \\
\hline 2 & $\begin{array}{l}\text { (A 1) Develop installation plan to minimize } \\
\text { instrument down time and coordinate with user group }\end{array}$ & WH & $\begin{array}{c}\text { Detailed } \\
\text { Design }\end{array}$ \\
\hline & & & \\
\hline & & & \\
\hline & & & \\
\hline & & & \\
\hline & & & \\
\hline & & & \\
\hline & & & \\
\hline & & & \\
\hline & & & \\
\hline & & & \\
\hline & & & \\
\hline & & & \\
\hline & & & \\
\hline & & & \\
\hline & & & \\
\hline & & & \\
\hline
\end{tabular}


WBS/SYSTEM NUMBER $\quad 1.2$ RESPONSIBLE PERSON A.T.Lucas WBS/SYSTEM TITLE Con cept Development and R\&D ELEMENT DESCRIPTION SIGNATURE

POTENTIAL PROBLEM OR FAILURE MODE

Configuration tested not representative of final design due to changes made during detailed design

EFFECTS (MARK AN "X" FOR ALL EFFECTS OF FAILURE)

\begin{tabular}{|l|c|c|c||}
\hline \multicolumn{1}{|c|}{ EFFECT } & KNOWN & PROBABLE & NO EFFECT \\
\hline SAFETY & & & \\
\hline ENVIRONMENTAL INSULT & & $X$ & \\
\hline COST IMPACT & & & $X$ \\
\hline FUCTIONAL PERFORMANCE & & $X$ & \\
\hline PROJECT SCHEDULE & & $X$ & \\
\hline OPERATIONAL IMPACT & & $X$ & \\
\hline
\end{tabular}

RANKING OF CONSEQUENCE OF PROBLEM OR FAILURE: SIGNIFICANT (X) OR INSIGNIFICANT () 
TABLE OF POSSIBLE CAUSES

\begin{tabular}{|c|c|c|c|}
\hline \multicolumn{2}{|r|}{ POSSIBLE CAUSES } & \multirow{2}{*}{$\begin{array}{l}\text { PROBABILITY } \\
\text { Low (L) } \\
\text { Unknown (U) } \\
\text { High (H) }\end{array}$} & \multirow{2}{*}{\begin{tabular}{l}
\multicolumn{1}{c}{ RISK } \\
\\
Acceptable (A) \\
Unacceptable (U)
\end{tabular}} \\
\hline NUMBER & DESCRIPTION & & \\
\hline$\overline{1}$ & $\begin{array}{l}\text { Identification of new or previously } \\
\text { unknown design requirement ( safety, etc ) }\end{array}$ & $U$ & $\bar{U}$ \\
\hline 2 & \begin{tabular}{l|} 
Design changes to incorporate \\
performance inporvements ( $\theta . g$. guides )
\end{tabular} & $U$ & $\bar{A}$ \\
\hline 3 & $\begin{array}{l}\text { Design reviews conducted after R\&D } \\
\text { testing require significant changes }\end{array}$ & $\bar{L}$ & $\bar{A}$ \\
\hline 4 & $\begin{array}{l}\text { ARD testing identifies the need for major } \\
\text { changes. }\end{array}$ & $\bar{U}$ & $\bar{U}$ \\
\hline . & & & \\
\hline & & & \\
\hline & & & \\
\hline & & & \\
\hline & & & \\
\hline & & & \\
\hline & & & \\
\hline & . & & \\
\hline & & & \\
\hline & & & \\
\hline & & & \\
\hline & & & \\
\hline & & & \\
\hline & & & 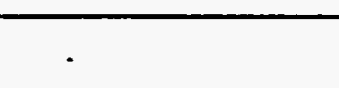 \\
\hline & & & \\
\hline
\end{tabular}




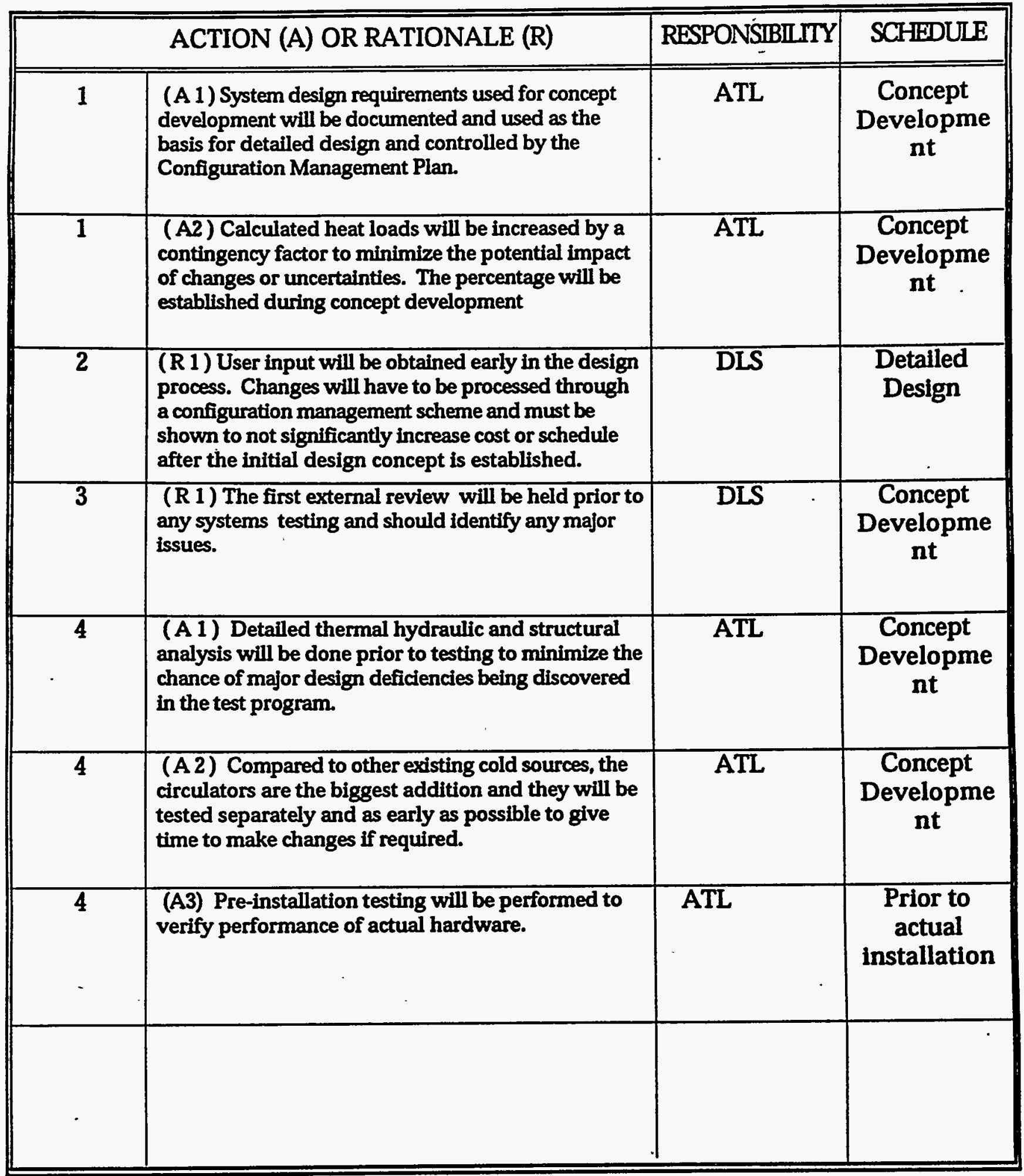




\section{RISK MANAGEMENT ASSESSMENT/PLAN}

PROJECT TITLE HFIR Cold Source

PAGE 1 OF

DATE OF THIS ASSESSMENT

$9 / 26 / 95$

WBS/SYSTEM NUMBER $\quad 1.2$

RESPONSIBLE PERSON A.T.Lucas

WBS/SYSTEM TITLE Concept Development and R\&D

ELEMENT DESCRIPTION

SIGNATURE

POTENTIAL PROBLEM OR FAILURE MODE Test results not available when needed for detailed desgin.

EFFECTS (MARK AN "X" FOR ALL EFFECTS OF FAILURE)

\begin{tabular}{|l|c|c|c||}
\hline \multicolumn{1}{|c|}{ EFFECT } & KNOWN & PROBABLE & NO EFFECT \\
\hline & & & \\
\hline SAFETY & & & $X$ \\
\hline ENVIRONMENTAL INSULT & & & $X$ \\
\hline COST IMPACT & & $X$ & \\
\hline FUCTIONAL PERFORMANCE & & $X$ & \\
\hline PROJECT SCHEDULE & $X$ & & \\
\hline OPERATIONAL IMPACT & & & $X$ \\
\hline
\end{tabular}

RANKING OF CONSEQUENCE OF PROBLEM OR FAILURE:

SIGNIFICANT (X) OR INSIGNIFICANT () 
TABLE OF POSSIBLE CAUSES

\begin{tabular}{|c|c|c|c|}
\hline \multicolumn{2}{|r|}{ POSSIBLE CAUSES } & \multirow{2}{*}{$\begin{array}{l}\text { PROBABILITY } \\
\text { Low (L) } \\
\text { Unknown (U) } \\
\text { High (H) }\end{array}$} & \multirow{2}{*}{$\begin{array}{l}\text { RISK } \\
\text { Acceptable (A) } \\
\text { Unacceptable (U) }\end{array}$} \\
\hline NUMBER & DESCRIPTION & & \\
\hline 1 & Late delivery of components from vendors & $\bar{L}$ & $\bar{A}$ \\
\hline 2 & $\begin{array}{l}\text { Test facility not available when needed } \\
\text { due to conflict with other programs. }\end{array}$ & $\mathbf{L}$ & $\bar{A}$ \\
\hline 3 & $\begin{array}{l}\text { Hardware fallure (s) (pump fallure, etc) } \\
\text { dely test completion. }\end{array}$ & $\mathbf{U}$ & $\bar{U}$ \\
\hline 4 & Project funding delays prevent timely start & $\mathbf{U}$ & $\mathbf{U}$ \\
\hline & & & \\
\hline & & & \\
\hline & & & \\
\hline & & & \\
\hline - & & & \\
\hline & & & \\
\hline & & & \\
\hline & & & \\
\hline & & & \\
\hline & & & \\
\hline & & & \\
\hline & & & \\
\hline & & & \\
\hline & & & \\
\hline & & & \\
\hline & 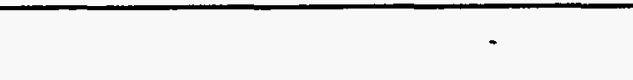 & & \\
\hline
\end{tabular}




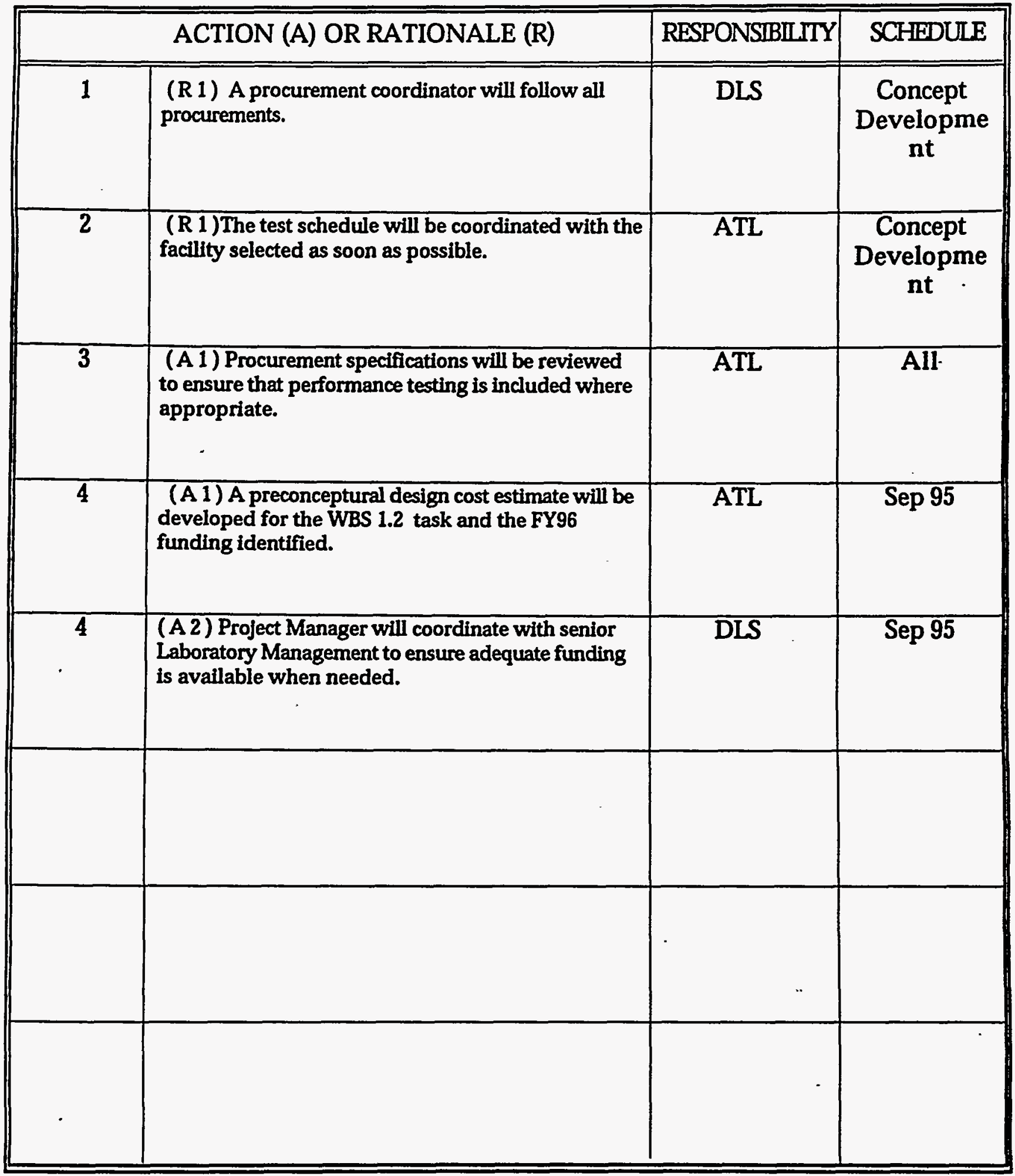


WBS/SYSTEM TITLE Safety

ELEMENT DESCRIPTION

SIGNATURE

POTENTIAL PROBLEM OR FAILURE MODE

HEIR Technical Specifications can not be revised and the cold source must be designed for $1000 \mathrm{psi}$ external pressure resulting in very high heat loads

EFFECTS (MARK AN "X" FOR ALL EFFECTS OF FAIIURE)

\begin{tabular}{||l|c|c|c||}
\hline \multicolumn{1}{|c|}{ EFFECT } & KNOWN & PROBABLE & NO EFFECT \\
\hline & & & \\
\hline SAFETY & & & $X$ \\
\hline ENVIRONMENTAL INSULT & & & $X$ \\
\hline COST IMPACT & & $X$ & \\
\hline FUCTIONAL PERFORMANCE & $X$ & & \\
\hline PROJECT SCHEDULE & & $X$ & \\
\hline OPERATIONAL IMPACT & $\times$ & & \\
\hline
\end{tabular}

RANKING OF CONSEQUENCE OF PROBLEM OR FAILURE:

SIGNIFICANT (X) OR INSIGNIFICANT () 
B-25

TABLE OF POSSIBLE CAUSES

\begin{tabular}{|c|c|c|c|}
\hline \multicolumn{2}{|r|}{ POSSIBLE CAUSES } & \multirow{2}{*}{$\begin{array}{l}\text { PROBABILITY } \\
\text { Low (L) } \\
\text { Unknown (U) } \\
\text { High (H) }\end{array}$} & \multirow{2}{*}{\begin{tabular}{l}
\multicolumn{1}{c}{ RISK } \\
Acceptable (A) \\
Unacceptable (U)
\end{tabular}} \\
\hline NUMBER & DESCRIPTION & & \\
\hline 1 & $\begin{array}{l}\text { Current cold source design assumes Tech. } \\
\text { Spec. can be modified to allow venting. }\end{array}$ & $\bar{H}$ & $\bar{U}$ \\
\hline & & & \\
\hline & & & \\
\hline & & & \\
\hline & & & \\
\hline & & & \\
\hline & & & \\
\hline & & & \\
\hline & & & \\
\hline 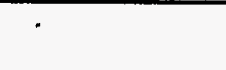 & & & \\
\hline & & & \\
\hline & & & \\
\hline & & & \\
\hline & & & \\
\hline & & & \\
\hline & & & \\
\hline & & & \\
\hline & & & \\
\hline & $\cdot$ & & \\
\hline
\end{tabular}




\begin{tabular}{|c|l|c|c|}
\hline \multicolumn{2}{|c|}{ ACTION (A) OR RATIONALE (R) } & RESPONSIBIITY & SCHEDULE \\
\hline \hline 1 & $\begin{array}{l}\text { (A 1) Develop a plan for obtaining a revision to the } \\
\text { tech. specs. }\end{array}$ & DHC & $\begin{array}{c}\text { Conceptual } \\
\text { Design }\end{array}$ \\
\hline 1 & $\begin{array}{l}\text { (A2) Evaluate consequence of not obtaining a } \\
\text { revision }\end{array}$ & ATL & $\begin{array}{c}\text { Conceptual } \\
\text { Design }\end{array}$ \\
\hline 1 & $\begin{array}{l}\text { (A 3) Develop a project schedule milestone for } \\
\text { submitting the revision, designing for the higher } \\
\text { pressure or deciding the project is not viable because } \\
\text { of the technical specification requirements. } \\
\end{array}$ & DLS & $\begin{array}{c}\text { Conceptual } \\
\text { Design }\end{array}$ \\
\hline & & & \\
\hline & & & \\
\hline & & & \\
\hline & & & \\
\hline & & & \\
\hline & & & \\
\hline & & & \\
\hline & & & \\
\hline
\end{tabular}




\section{RISK MANAGEMENT ASSESSMENT/PLAN}

PROJECT TITLE HFIR Cold Source

PAGE 1 OF

DATE OF THIS ASSESSMENT

$9 / 25 / 95$

WBS/SYSTEM NUMBER $\quad 1.4$

RESPONSIBLE PERSON S.E.Burnette

WBS/SYSTEM TITLE Detaied Design

ELEMENT DESCRIPTION

SIGNATURE

POTENTIAL PROBLEM OR FAILURE MODE

Refrigeration System does not have adequate capacity.

EFFECTS (MARK AN "X" FOR ALL EFFECTS OF FAILURE)

\begin{tabular}{|l|c|c|c||}
\hline \multicolumn{1}{|c|}{ EFFECT } & KNOWN & PROBABLE & NO EFFECT \\
\hline SAFETY & & & \\
\hline ENVIRONMENTAL INSULT & & & $X$ \\
\hline COST IMPACT & & & $X$ \\
\hline FUCTIONAL PERFORMANCE & & & $X$ \\
\hline PROJECT SCHEDULE & $X$ & & \\
\hline OPERATIONAL IMPACT & & & \\
\hline
\end{tabular}

RANKING OF CONSEQUENCE OF PROBLEM OR FAILURE:

SIGNIFICANT (X) OR INSIGNIFICANT () 
TABLE OF POSSIBLE CAUSES

\begin{tabular}{|c|c|c|c|}
\hline \multicolumn{2}{|r|}{ POSSIBLE CAUSES } & \multirow{2}{*}{$\begin{array}{l}\text { PROBABILITY } \\
\text { Low (L) } \\
\text { Unknown (U) } \\
\text { High (H) }\end{array}$} & \multirow{2}{*}{\begin{tabular}{l}
\multicolumn{1}{c}{ RISK } \\
Acceptable (A) \\
Unacceptable (U)
\end{tabular}} \\
\hline NUMBER & DESCRIPTION & & \\
\hline 1 & $\begin{array}{l}\text { Detailled design increases heat load after } \\
\text { refrigeration capacity is specified. }\end{array}$ & $\mathbf{L}$ & $\bar{A}$ \\
\hline & : & & \\
\hline & & & \\
\hline & & & \\
\hline & & & \\
\hline & & & \\
\hline & & & \\
\hline & & & \\
\hline & & & \\
\hline & & & \\
\hline & & & \\
\hline & & & \\
\hline & & & \\
\hline & & & \\
\hline & & & \\
\hline & & & \\
\hline- & & & \\
\hline & & & \\
\hline & & & \\
\hline
\end{tabular}




\begin{tabular}{|c|c|c|c|}
\hline \multicolumn{2}{|r|}{ ACTION (A) OR RATIONALE (R) } & RESPONSIBIITY & SCHEDULE \\
\hline 1 & $\begin{array}{l}\text { (R 1) R\&D program will develop required material } \\
\text { thicknesses and heat load. Contingency will be } \\
\text { added. }\end{array}$ & & \\
\hline & & & \\
\hline & & & \\
\hline & & & \\
\hline & & & \\
\hline & & & \\
\hline & & & \\
\hline & & & \\
\hline & & & \\
\hline & & & \\
\hline & . & & \\
\hline & & & \\
\hline & & & \\
\hline & & & \\
\hline & & & \\
\hline & 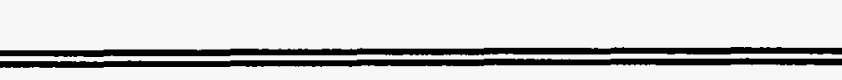 & & \\
\hline
\end{tabular}


PROJECT TITLE HFIR Cold Source

PAGE 1 OF

DATE OF THIS ASSESSMENT

WBS/SYSTEM NUMBER $\quad 1.7$

RESPONSIBLE PERSON W.E._Hill

WBS/SYSTEM TITLE Operations

ELEMENT DESCRIPTION

SIGNATURE

POTENTIAL PROBLEM OR FAILURE MODE

Material failure due to irradiation embrittlement at cryogenic temperature

EFFECTS (MARK AN "X" FOR ALL EFFECTS OF FAILURE)

\begin{tabular}{|l|c|c|c||}
\hline \multicolumn{1}{|c|}{ EFFECT } & KNOWN & PROBABLE & NO EFFECT \\
\hline SAFETY & & & \\
\hline ENVIRONMENTAL INSULT & & $\times$ & \\
\hline COST IMPACT & & & $\times$ \\
\hline FUCTIONAL PERFORMANCE & & & \\
\hline PROJECT SCHEDULE & $\times$ & & \\
\hline OPERATIONAL IMPACT & $\times$ & & \\
\hline
\end{tabular}

RANKING OF CONSEQUENCE OF PROBLEM OR FAILURE:

SIGNIFICANT (X) OR INSIGNIFICANT () 
B-31

TABLE OF POSSIBLE CAUSES

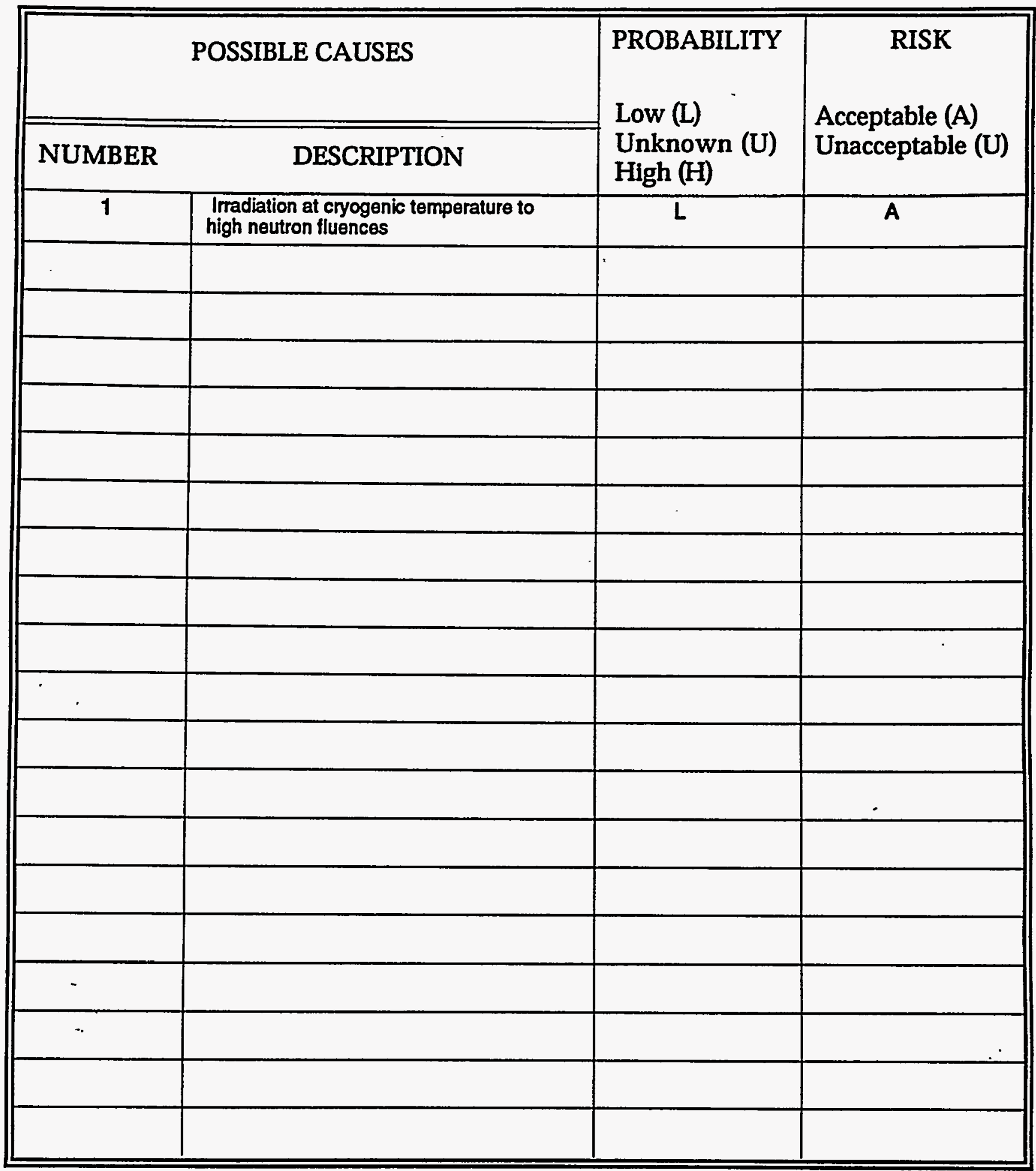




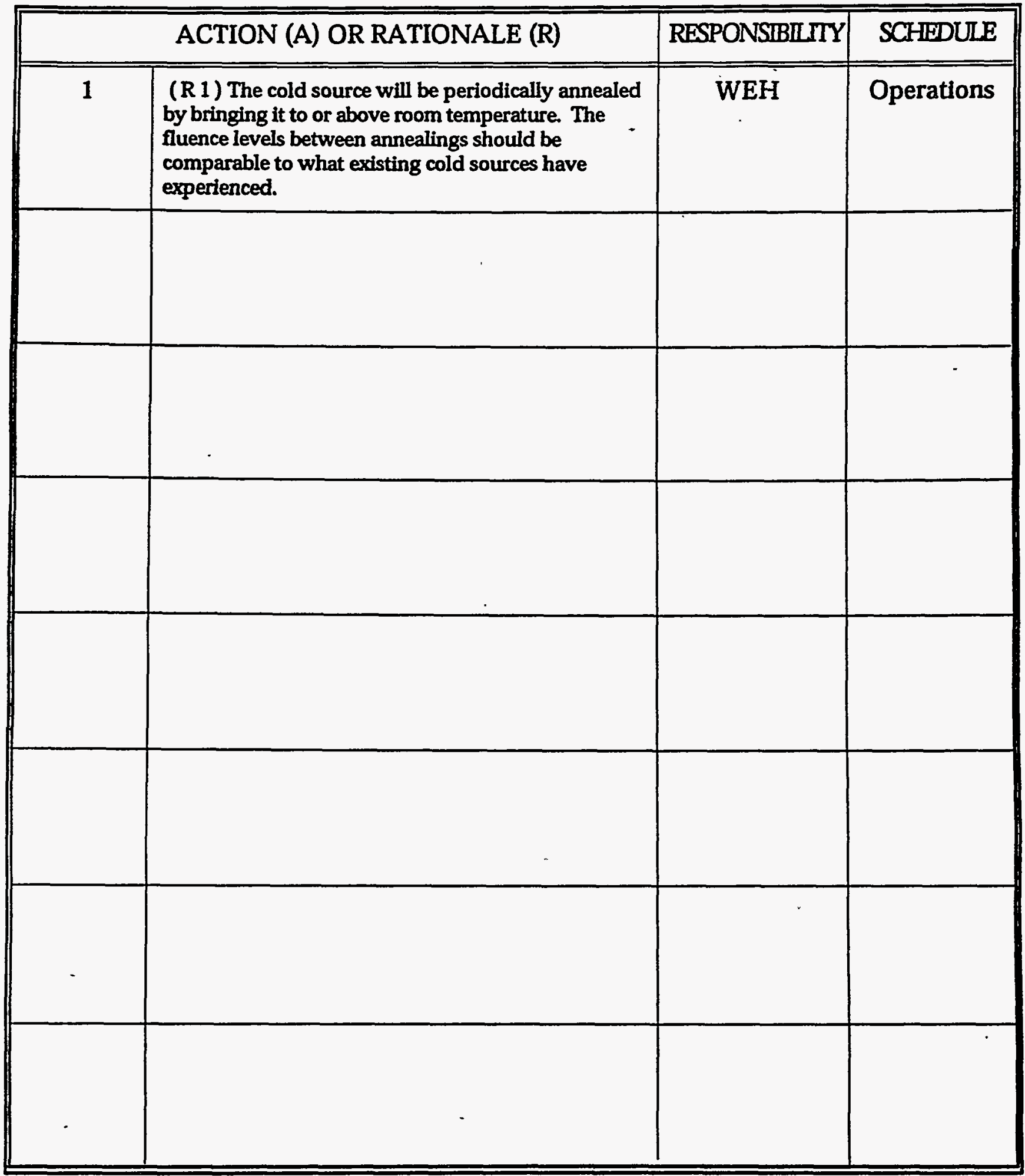




\section{INTERNAL DISTRIBUTION}

1. B. R. Appleton

2. J. B. Ball

3. L. W. Boyd

4. R. S. Brackett

5. J. A. Bucholz

6. S. E. Burnette

7-11. J. H. Campbell

12. R. D. Cheverton

13. J. E. Cleaves

14. D. H. Cook

15. M. B. Farrar

16. K. Farrell

17. G. F. Flanagan

18. J. D. Freels

19. J. C. Gehin

20. F. X. Gallmeier

21. H. A. Glovier

22. R. M. Harrington

23. J. B. Hayter

24. W. E. Hill

25. C. R. Hyman

26. R. L. Johnson

27. J. E. Lee

28. M. A. Linn
29-33. A. T. Lucas

34. T. J. McManamy

35. H. A. Mook

36. R. H. Nelson

37. L. D. Proctor

38. L. P. Pugh

39. C. T. Ramsey

40. J. B. Roberto

41. K. L. Rogers

42. R. B. Rothrock

43. J. A. Schmitz

44-48. D. L. Selby

49. B. F. Siefken

50. K. A. Smith

51. C. D. West

52. G. D. Wignall

53. P. T. Williams

54. M. A.Woody

55. ORNL Patent Office

56-57. Central Research Library

Document Reference Section

58. Y-12 Technical Library

59-60. Laboratory Records Department

61. Laboratory Records (RC)

\section{EXTERNAL DISTRIBUTION}

62. D. Royer, Deputy Division Manager, Brookhaven National Laboratory, Reactor Division, Building 120, Upton, NY 11973

63. W. F. Manning, U.S. Department of Energy, Oak Ridge Operations Office, FEDC, MS8218, P.O. Box 2009, Oak Ridge, TN 37831-8218

64. I. L. Thomas, Director, Materials Science Division, Office of Energy Research, U.S. Department of Energy, ER-13, Washington, DC 20585

65-66. Office of Scientific and Technical Information, P.O. Box 62, Oak Ridge, TN 37831 
